\title{
Design and Development of a Vacuum Chamber for Testing of an Advanced Plasma Ignition System
}

\author{
Zachary Tyler Eichelberger
}

Follow this and additional works at: https://researchrepository.wvu.edu/etd

\section{Recommended Citation}

Eichelberger, Zachary Tyler, "Design and Development of a Vacuum Chamber for Testing of an Advanced Plasma Ignition System" (2017). Graduate Theses, Dissertations, and Problem Reports. 5531.

https://researchrepository.wvu.edu/etd/5531

This Thesis is protected by copyright and/or related rights. It has been brought to you by the The Research Repository @ WVU with permission from the rights-holder(s). You are free to use this Thesis in any way that is permitted by the copyright and related rights legislation that applies to your use. For other uses you must obtain permission from the rights-holder(s) directly, unless additional rights are indicated by a Creative Commons license in the record and/ or on the work itself. This Thesis has been accepted for inclusion in WVU Graduate Theses, Dissertations, and Problem Reports collection by an authorized administrator of The Research Repository @ WVU. For more information, please contact researchrepository@mail.wvu.edu. 


\title{
Design and Development of a Vacuum Chamber for Testing of an Advanced Plasma Ignition System
}

\author{
Zachary Tyler Eichelberger
}

\author{
Thesis submitted \\ to the College of Engineering and Mineral Resources \\ At West Virginia University \\ in partial fulfillment of the requirements for the degree of \\ Master of Science in \\ Mechanical Engineering
}

\author{
James E. Smith, Ph.D., Chair \\ Andrew Lowery, Ph.D. \\ V'yacheslav Akkerman, Ph.D. \\ Department of Mechanical and Aerospace Engineering
}

\author{
Morgantown, West Virginia \\ 2017
}

Keywords: Vacuum Chamber, Plasma, Finite Element Analysis, Strain Gauge Copyright 2017 Zachary Tyler Eichelberger 


\title{
ABSTRACT \\ Design and Development of a Vacuum Chamber for Testing of an Advanced Plasma Ignition System
}

\author{
Zachary Tyler Eichelberger
}

\begin{abstract}
Recent advancements in plasma igniter technology has led to further investigation of plasma igniter applications. Previous research conducted with this technology has shown the effects of plasma under pressure. The research completed was focused on the design and development of a vacuum chamber required for testing plasma applications at pressures below atmospheric conditions and near absolute vacuum. Further research was to develop an apparatus for testing the plasma igniter inside a vacuum chamber to evaluate the effects of Resonance Frequency (RF) plugs and the ability to manipulate the plasma corona electromagnetically. This design analysis was performed using a Finite Element Analysis (FEA) program. The Computer Aided Design (CAD) program known as Solidworks was employed to model the stresses in the design for the limited selection of appropriate materials available for construction of the vacuum chamber. A model of the proposed vacuum chamber was created to run simulations for these conditions. The design of the vacuum chamber required the materials used in the construction to be nonconductive which restricted the material selection. Other parameters were established so that sensors and recording equipment could be used for data acquisition. The ability to record the internal conditions of the vacuum chamber and visual data in the ultraviolet (UV) and infrared (IR) spectrums were a primary concern. Longitudinal and hoop stresses were analyzed for the vacuum chamber design to determine the validity of the simulated results. These results also provided supplementary information on the mechanics of the vacuum chamber assembly. The results from the FEA simulation and experimental validation of that simulation provided a reliable modelling tool for this design effort. The vacuum chamber material was able to withstand the stresses produced by the external atmospheric pressure and successful experiments were conducted using an active plasma source.
\end{abstract}




\section{Table of Contents}

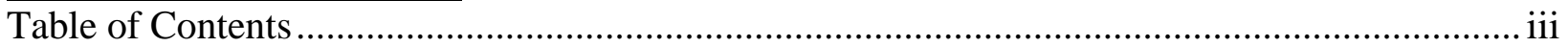

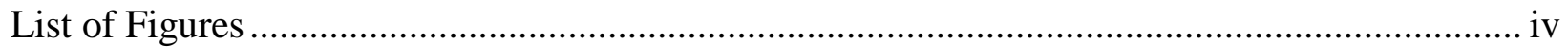

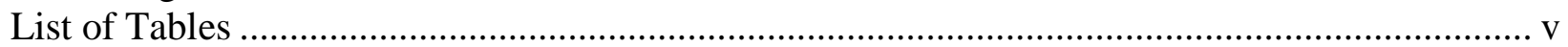

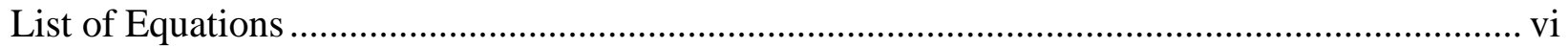

Nomenclature ................................................................................................................ vii

Acknowledgments................................................................................................................. viii

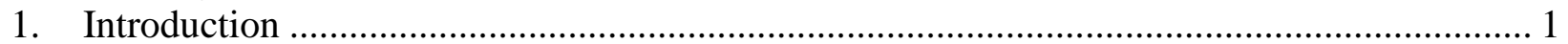

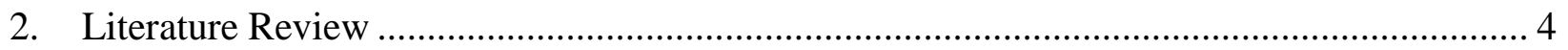

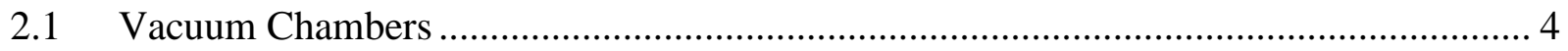

2.2 Strain Gauges for Experimentation ......................................................................... 7

2.3 The Fourth State of Matter: Plasma ……………..................................................... 10

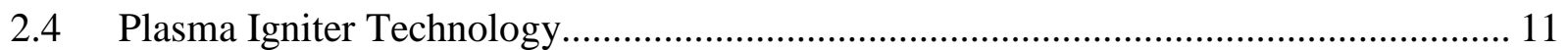

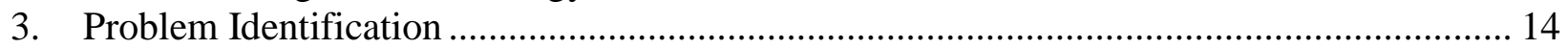

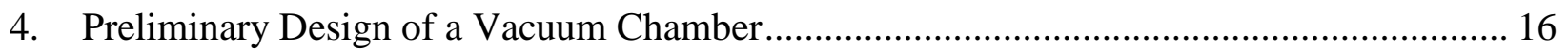

$4.1 \quad$ Preliminary Design Approach ................................................................................ 16

4.2 Specifications for the Preliminary Design .................................................................... 17

4.3 Finite Element Analysis Simulation for the Preliminary Design ................................... 21

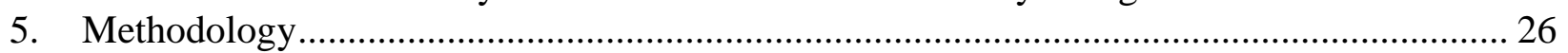

5.1 Methodology of Experiments................................................................................... 26

5.2 Experimental Hypothesis .................................................................................... 28

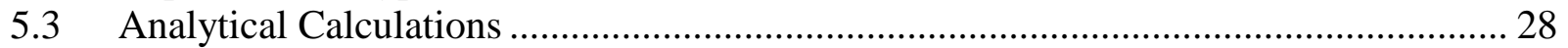

5.4 Procedure of Experiments ......................................................................................... 31

5.4.1 Procedure for pulling a Vacuum .............................................................................. 31

5.4.2 Procedure for Testing the Plasma Igniter inside the Vacuum Chamber.................. 35

5.4.3 Procedure for Generating Plasma Arcs with High Voltage... Error! Bookmark not defined.

5.4.4 Procedure for Strain Gauge Experiments ………................................................... 38

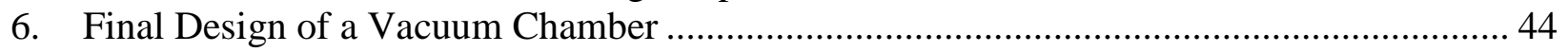

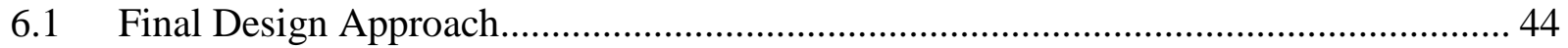

6.2 Finite Element Analysis of the Final Design ................................................................ 46

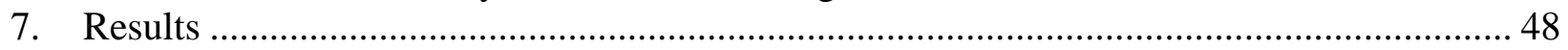

7.1 Functionality of the Preliminary Vacuum Chamber .................................................... 48

7.2 Comparison of the FEA Simulation and Strain Gauge Results ...................................... 50

7.3 Plasma Igniter Application at Low Pressure and Vacuum Conditions ............................ 53

7.4 Parallel Plates and Plasma Arc Applications ………...................................................... 55

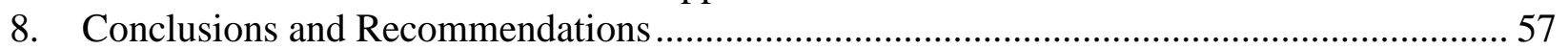

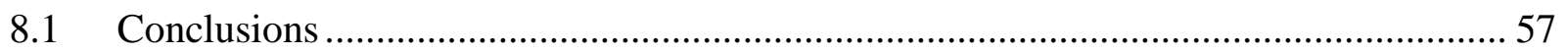

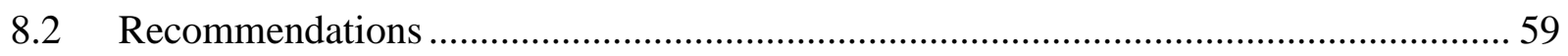

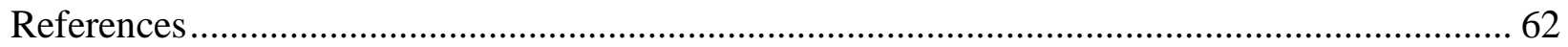

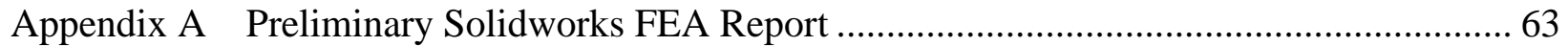

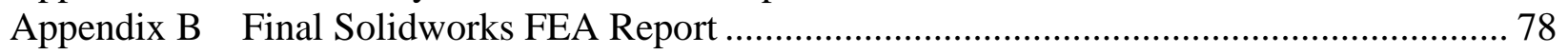

Appendix C Strain Gauge Experiment Data ............................................................................. 91

Appendix D Parallel Plates Experiment Data .............................................................................. 94 


\section{List of Figures}

Figure 1. Axial Stress Developed in a Pressure Vessel ....................................................... 52

Figure 2. Minimum Plasma Corona.................................................................................... 53

Figure 3. Maximum Plasma Corona ........................................................................... 54 


\section{$\underline{\text { List of Tables }}$}

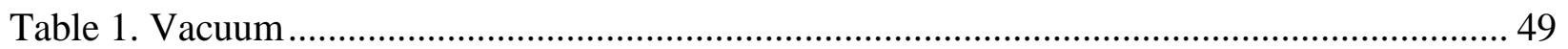




\section{List of Equations}

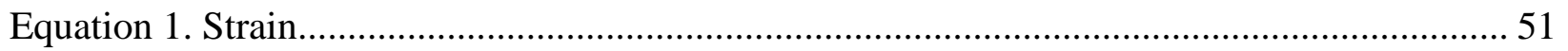

Equation 2. Hooke's Law ............................................................................................... 51

Equation 3. Calculation for Spherical Hoop Stress ............................................................... 52 
Nomenclature

$\begin{array}{ll}\text { CAD } & \text { Computer Aided Design } \\ \text { FEA } & \text { Finite Element Analysis } \\ \text { UV } & \text { Ultraviolet } \\ \text { IR } & \text { Infrared } \\ \text { RF } & \text { Resonance Frequency } \\ \text { FOS } & \text { Factor of Safety } \\ \text { CFM } & \text { Cubic Feet per Minute } \\ \text { ICE } & \text { Internal Combustion Engine } \\ \boldsymbol{\sigma}_{\boldsymbol{\theta} \text { cylinder }} & \text { Cylindrical Hoop Stress } \\ \boldsymbol{\sigma}_{\boldsymbol{\theta} \text { sphere }} & \text { Spherical Hoop Stress } \\ \boldsymbol{\sigma}_{\boldsymbol{L}} & \text { Longitudinal Stress } \\ \mathrm{P} & \text { Pressure } \\ \mathrm{R} & \text { Outer Radius } \\ \mathrm{r} & \text { Inner Radius } \\ \mathrm{t} & \text { Thickness } \\ \mathrm{E} & \text { Young's Modulus } \\ \boldsymbol{l} & \text { Length } \\ \sigma & \text { Stress } \\ \Delta \boldsymbol{l} & \text { Elongation } \\ \boldsymbol{\varepsilon} & \text { Strain }\end{array}$




\section{Acknowledgments}

I would like to thank Dr. James E. Smith for providing me the mentorship and tools to succeed in graduate school and life, along with Dr. Andrew Lowery for guidance and insight on my research, and my peers; Lucas Ware, Alex Hatch, Michelle Jamshidi, Jack Bennett, and James Hunsucker III for support in my endeavors. 


\section{Introduction}

The focus of this research was to investigate the applications of the plasma igniter technology in different environments of low pressure and near vacuum conditions. This research would allow a greater understanding of the plasma igniter technology and provide a methodology to better manipulate the plasma for multiple applications for academic and commercial applications. The plasma igniter technology has shown in previous experiments and research that under pressure the corona of plasma that is generated from the plasma igniter shrinks and compresses to a much smaller size [1]. The assumption is that by reducing the ambient pressure in an experiment, the plasma corona will expand significantly and increase in diameter. This will allow the plasma igniter to perform more efficiently by having more contact with the fuel mixture leading to a more complete burn providing higher fuel efficiency and the reduction of regulated emissions [2].

By testing the plasma igniter technology under pressure and at a near vacuum, the behavior of the plasma corona can be modeled, and the expansion of the corona can be measured. From these experiments, further progress can be made for deciding how to manipulate the plasma generated and improve upon the plasma igniter technology along with the multiple applications that can come out of this same technology.

Possible test scenarios include applications consisting of pulsing the plasma corona along the length of the vacuum chamber with electromagnets for possible use in high altitude aircrafts such as Scramjets. To recreate these conditions for the experiments, a vacuum chamber needed to be designed that complied with all the necessary parameters for safety, data acquisition, and any type of testing that would later be used for the plasma igniter technology.

The design of the vacuum chamber had to be unique from the commercially available vacuum chambers due to the nature of the plasma applications and testing. Most vacuum chambers are 
designed using aluminum or other metals and conductive materials. The plasma igniter power supply has over 40,000 volts directed to the plasma igniter plug and any conductive materials in contact with the plug would lead to significant safety hazard. For this reason, the materials chosen for constructing the vacuum chamber had to be nonconductive materials such as plastics, glass, and composites.

The materials selection was restricted even further to materials that would be inexpensive so that multiple units of varying shapes and sizes could be developed to accommodate differing test conditions. The materials selected were acrylic and Garolite. Further safety guidelines for the design were established for the structural integrity of the vacuum chamber. Since the list of available materials was reduced to types of brittle materials and not ductile, the design was simulated in Solidworks Computer Aided Design (CAD) software and tested for the loading conditions required for the experiments that would be run inside the chamber.

Once the results of this initial simulation showed that the vacuum chamber was suitable for use under the required test conditions, the simulation result would need to be validated by applying strain gauges to the vacuum chamber. These results could then be compared to the results from the Finite Element Analysis (FEA) report produced in the Solidworks CAD software.

With a secure vacuum chamber, the design also needed to include the ability to add data acquisition sensors that later might be required for testing other applications for the plasma igniter. Several types of sensors would include pressure gauges, vacuum gages, and thermocouples along with recording equipment that can capture the full range of the spectrum of the events occurring inside the vacuum chamber. The equipment would need to capture the visual spectrum as well as Ultraviolet (UV) and Infrared (IR) to gain a better understanding of how the plasma igniter technology behaved at low pressure and near perfect vacuum conditions. 
Once the design of the vacuum chamber included these specifications, the remaining requirements consisted of the future experiments that would be tested inside the vacuum chamber. These experiments would have the vacuum chamber purged with other gases such as Nitrogen. Other experiments would use electromagnets inside and outside the vacuum chamber to manipulate the plasma. This would have external electromagnets move the plasma around inside the chamber as well as having internal electromagnets pulsing the plasma corona inside the vacuum chamber.

By having a customized vacuum chamber to test these applications, the plasma igniter technology can grow in these areas and improve upon each application. This is the needed relationship between the research being conducted and the plasma igniter technology. By focusing on the special conditions inside a vacuum and generating a plasma corona, this technology can progress forward.

The purpose for the custom-built vacuum chamber comes down to the nature of generating and sustaining the plasma corona. This requires that the chamber is made almost entirely of nonconductive materials and that the chamber needs to have all the required equipment for all future projects without rebuilding a new vacuum chamber. Additional sensors must be easily added to the vacuum chamber without harming the structural integrity. 


\section{Literature Review}

\subsection{Vacuum Chambers}

A vacuum is defined as "the space in which there is no matter or in which the pressure is so low that any particles in the space do not affect any processes being performed in the volume. It is a condition well below normal atmospheric pressure and is measured in units of pressure (the pascal). A vacuum can be created by removing air from a space using a vacuum pump or by reducing the pressure using a fast flow of fluid, as in Bernoulli's principle” [3]. Vacuum chambers are pressure vessels that use pumps to extract air and other gases filling the chamber to lower the pressure of the container as it approaches a near absolute vacuum. The majority of commercially available vacuum chambers are constructed from aluminum as seen in the figure below.

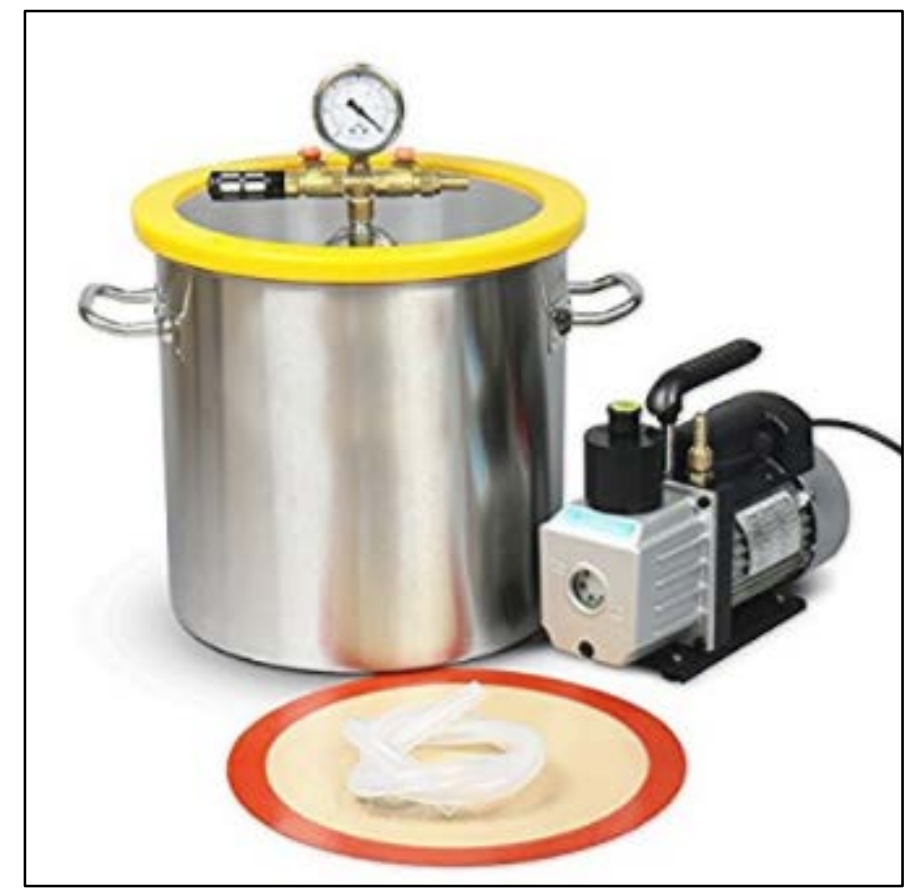

Figure 1. A Common Vacuum Chamber Model [4]

Since the research being performed will be using high voltage, using aluminum for the housing of the vacuum chamber was not suitable. 
The stresses induced on a vacuum chamber is proportional to the surface area of the chamber itself [5]. As the volume of a vacuum chamber increase, so does the surface area and in turn, the stresses increase from the external pressure of the atmosphere acting on the surface area of the vacuum chamber. This is the primary concern for designing a vacuum chamber so that it can handle the atmospheric pressure creating stresses on the chamber's walls.

The applications of vacuum chambers are critical to the validation of research for low pressure and vacuum environments. This allows experimentation in conditions that would otherwise be vastly more expensive and inconvenient for experimentation, such as sending equipment high into the atmosphere or low earth orbit. The expenses for sending a small payload of test equipment can reach upwards of $\$ 500,000$ or more for only 10 pounds of test and data acquisition equipment [6].

After incurring these expenses, there is also the inconvenience or the inability to modify the experiments when performing them at high altitudes. For these reasons, a vacuum chamber is suitable for carrying out these experiments with the convenience of operating in a laboratory. To simulate the atmospheric pressure of low earth orbit, the pressure inside the vacuum chamber would need to reach as low as $10^{\wedge}-8$ Pascals [7]. The following table shows the percentage of absolute vacuum compared to multiple units of pressure. This will be an important reference for comparing the vacuum gage pressure inside the vacuum chamber and identifying the percentage of an absolute vacuum reached while conducting future experiments. 
Table 1. Vacuum Gage Pressure Scale [8]

\begin{tabular}{|c|c|c|c|c|c|c|}
\hline $\begin{array}{c}\% \\
\text { Vacuum }\end{array}$ & $\begin{array}{c}\text { Torr } \\
\text { ( } \mathrm{mm} \text { Mercury) }\end{array}$ & Micron & $\begin{array}{l}\text { psia, } \\
\text { (lb/in } 2 \\
\text { abs) }\end{array}$ & $\begin{array}{l}\text { Inches } \\
\text { Mercury } \\
\text { Absolute }\end{array}$ & $\begin{array}{c}\text { Inches } \\
\text { Mercury } \\
\text { Gauge }\end{array}$ & $\begin{array}{c}k P a \\
a b s\end{array}$ \\
\hline 0.0 & 760.0 & 760,000 & 14.7 & 29.92 & 0.00 & 101.4 \\
\hline 1.3 & 750.0 & 750,000 & 14.5 & 29.5 & 0.42 & 99.9 \\
\hline 1.9 & 735.6 & 735,600 & 14.2 & 28.9 & 1.02 & 97.7 \\
\hline 7.9 & 700.0 & 700,000 & 13.5 & 27.6 & 2.32 & 93.5 \\
\hline 21.0 & 600.0 & 600,000 & 11.6 & 23.6 & 6.32 & 79.9 \\
\hline 34.0 & 500.0 & 500,000 & 9.7 & 19.7 & 10.22 & 66.7 \\
\hline 47.0 & 400.0 & 400,000 & 7.7 & 15.7 & 14.22 & 53.2 \\
\hline 50.0 & 380.0 & 380,000 & 7.3 & 15.0 & 14.92 & 50.8 \\
\hline 61.0 & 300.0 & 300,000 & 5.8 & 11.8 & 18.12 & 40 \\
\hline 74.0 & 200.0 & 200,000 & 3.9 & 7.85 & 22.07 & 26.6 \\
\hline 87.0 & 100.0 & 100,000 & 1.93 & 3.94 & 25.98 & 13.3 \\
\hline 88.0 & 90.0 & 90,000 & 1.74 & 3.54 & 26.38 & 12 \\
\hline 89.5 & 80.0 & 80,000 & 1.55 & 3.15 & 26.77 & 10.7 \\
\hline 90.8 & 70.0 & 70,000 & 1.35 & 2.76 & 27.16 & 9.3 \\
\hline 92.1 & 60.0 & 60,000 & 1.16 & 2.36 & 27.56 & 8 \\
\hline 93.0 & 51.7 & 51,700 & 1.00 & 2.03 & 27.89 & 6.9 \\
\hline 93.5 & 50.0 & 50,000 & 0.97 & 1.97 & 27.95 & 6.7 \\
\hline 94.8 & 40.0 & 40,000 & 0.77 & 1.57 & 28.35 & 5.3 \\
\hline 96.1 & 30.0 & 30,000 & 0.58 & 1.18 & 28.74 & 4 \\
\hline 96.6 & 25.4 & 25,400 & 0.49 & 1.00 & 28.92 & 3.4 \\
\hline 97.4 & 20.0 & 20,000 & 0.39 & 0.785 & 29.14 & 2.7 \\
\hline 98.7 & 10.0 & 10,000 & 0.193 & 0.394 & 29.53 & 1.3 \\
\hline 99.0 & 7.6 & 7,600 & 0.147 & 0.299 & 29.62 & 1.0 \\
\hline 99.87 & 1.0 & 1,000 & 0.01934 & 0.03937 & 29.88 & 0.13 \\
\hline 99.90 & 0.75 & 750 & 0.0145 & 0.0295 & 29.89 & 0.1 \\
\hline 99.99 & 0.10 & 100 & 0.00193 & 0.00394 & 29.916 & 0.013 \\
\hline 99.999 & 0.01 & 10 & 0.000193 & 0.000394 & 29.9196 & 0.0013 \\
\hline 100 & 0.00 & 0 & 0 & 0 & 29.92 & 0 \\
\hline
\end{tabular}

Vacuum chambers not only reduce the expense of completing experiments, they also increase the ability to have a safe environment to complete tests. At high altitudes and low earth orbit, irregularities can occur that could impact the test equipment, disqualify the results from tests, and impact the study in unforeseen ways. While validated trials in real world conditions is a necessity before being applied to a final design, it is equally important to have preliminary testing completed in controlled environments.

By using a vacuum chamber, the system can be controlled by adjusting the pressure inside the chamber to mimic the pressure of high altitudes and approaching an absolute vacuum for simulated low earth orbit situations. By using a vacuum chamber to carry out these experiments; time, money, and effort are saved while limiting the dangers to the equipment and having a safe environment 
for personnel conducting the experiments. They also allow the personnel to easily change sensors and fixtures on the chambers and conduct a multitude of different experiments in a timely manner, adding to the benefits of vacuum chambers for experimentation.

\subsection{Strain Gauges for Experimentation}

Stain gauges are devices used to measure the strain in a material which are comprised of metallic foil that is flexible and changes electrical resistance as it deforms [9]. The use of strain gauges is valuable in the validation of Finite Element Analysis (FEA) reports from CAD software packages. With the results from the strain gauges, the FEA reports can be confirmed so that the loads applied to the CAD models and other physical parameters such as materials properties area correctly simulated. The readings from strain gauges can then be compared with the FEA results to see if the difference between these values fall within an acceptable range so that the results can be considered accurate, which will allow for verification of alternate chamber designs in the future.

Strain gauges allow the personnel conducting experimentation on the materials to confirm that the stain in a specimen does not exceed the limit on a stress-strain curve. This ensures that the specimen under load does not reach the yield stress and therefore lead to a material failure. The plot in the figure below shows how certain materials can use a $0.2 \%$ offset method to find the yield strength of the material for a given Young's Modulus. 


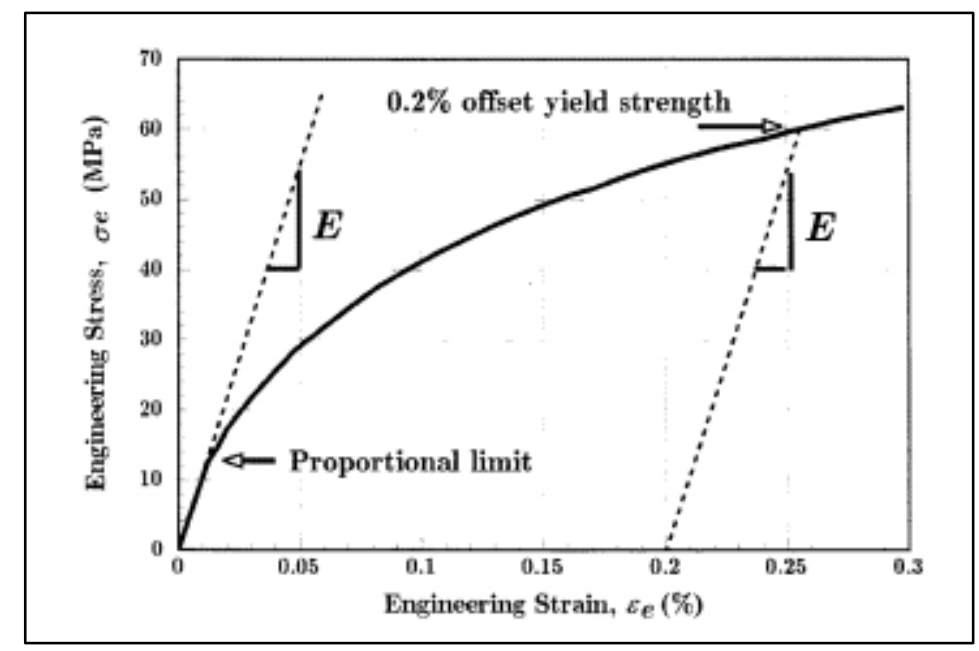

Figure 2. Stress Strain Curve [10]

Strain gauges work by using basic principles of mechanics of materials, by allowing the conductive material to elongate or compress while the strain gauge itself is applied to a member subjected to tension or compression [11]. The elongation or compression of the strain gauge creates changes in the electrical properties that can be measured and computed to display the micro strain of the examined specimen.

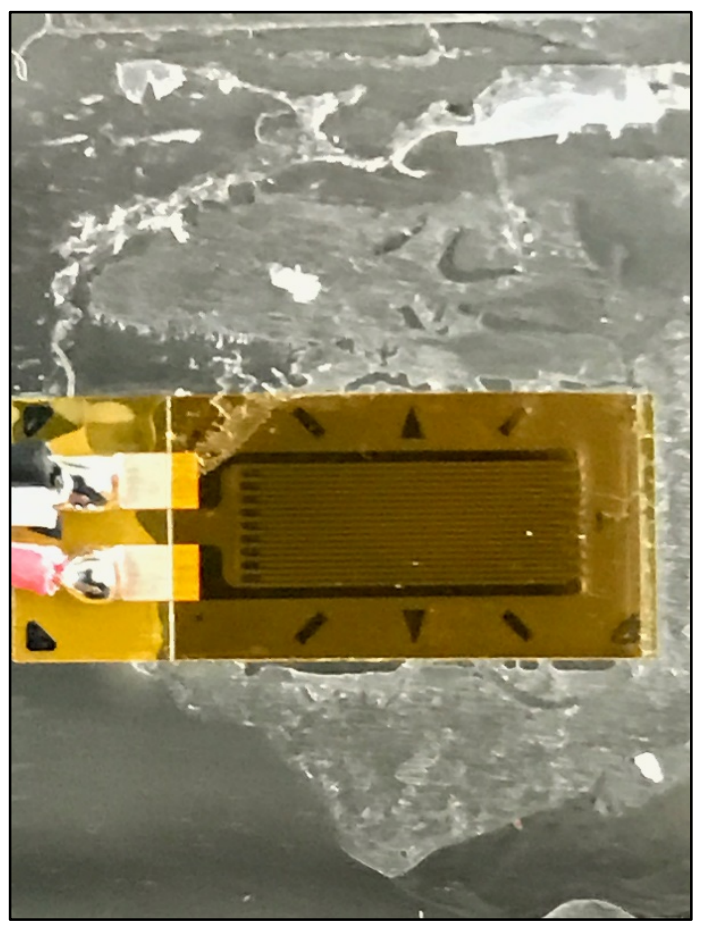


Figure 3. Layout of a Strain Gauge

The layout of the design of a strain gauge can be seen in the figure above. The pattern is designed so that even minimal elongation or compression of the strain gauge can generate enough electrical resistance to display an accurate value to measurement equipment [12].

To ensure that the stain gauges applied to the specimen expanded and contracted so that appropriate values are recorded and displayed, there are special adhesives for attaching strain gauges to the surface of a material. There are a range of special adhesives for strain gauges depending on the conditions, such as high temperature environments, that the material might be tested in. For the conditions that the vacuum chamber will be tested in, it is acceptable to use the standard strain gauge adhesive know as M bond 200.

Strain gauges are an essential component in the validation of the research conducted for the design of a vacuum chamber that can accommodate plasma applications. With the results from the strain gauges, the FEA reports from the CAD software package used for simulations can be compared against the findings of the strain gauges while the chamber has a vacuum pulled and is under the external load of the ambient pressure from the atmosphere. The comparison of values from simulations and experiments will show if the simulation was correctly created with the proper assumptions, fixtures, loading, and material properties used in the simulation.

Testing a specimen with strain gauges will help the experimenter understand the research being completed by seeing the strain developed underload and seeing if the result is comparable to the simulated results from the FEA reports. If the results of both cases are within the acceptable range, then the CAD model can be validated, and more tests can be simulated prior to experimentation with the physical model. Otherwise, mismatched results would lead to the 
conclusion that the factors in the simulation were either missing or incorrect and will need to be performed again to provide a more realistic approximation.

There are downsides to using stain gauges where some errors in results may occur. Strain gauges must be properly applied to the surface with the correct adhesives. If inappropriate adhesives are used, then the results will be skewed. Another error can arise with the application of the strain gauges on the surface of the material. Even by using the correct adhesive, if the strain gauge isn’t flush with the material surface, then the results can have a significant error [13]. Improper application to the surface can leave air pockets underneath the strain gauge and distorts how the gauge will expand and contract under loading. With quick curing times for the M bond 200 used to attach the strain gauge to the material surface, it is important to apply quickly and ensue the gauge pressed smoothly against the surface.

\subsection{The Fourth State of Matter: Plasma}

There are three states of matter that are commonly examined which are solids, liquids, and gases. The fourth state of matter is plasma. Plasma is a state of matter in which an ionized gaseous substance becomes highly electrically conductive to the point that long-range electric and magnetic fields dominate the behavior of the matter [14]. Below is a figure demonstrating plasma arcing to a glass sphere as a frame of reference to see what plasma looks like.

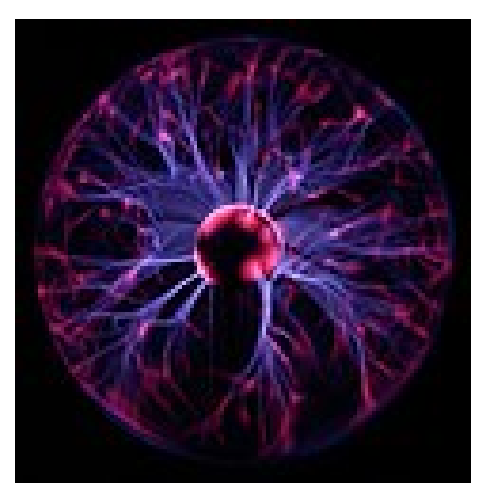

Figure 4. Plasma Orb [15] 
Ionized gas refers to how the electrons and ions are separated and free from one another [16]. Plasma is generated from having energy ionize the atoms in a gas which means that they will lose or gain electrons [17].

This occurs when the temperature is high enough to ionize the ambient gas or if the electrical fields are strong enough to cause ionization. [18]. For plasma, this state of matter is highly susceptible to the presence of magnetic and electric fields. The use of magnetic fields to manipulate the plasma generated inside the vacuum chamber will be discussed.

Benefits and applications of plasma can be used in the fields of electronic manufacturing using methods such as plasma etching [19]. Plasma can also be used in the transportation sector and can be used to replace spark plugs for improved combustion in vehicles.

\subsection{Plasma Igniter Technology}

The Plasma Igniter technology is a replacement for spark plugs that has substantial benefits in all aspects of conventional combustion applications. With the technology inside the plasma igniter, it has the ability to significantly improve combustion for Internal Combustion Engine (ICE) powered vehicles. The following figure shows the plasma igniter attached to the power supply and signal generator. From the figure, it can be seen that the plasma igniter is the size of a typical spark plug found in most ICE vehicles. 


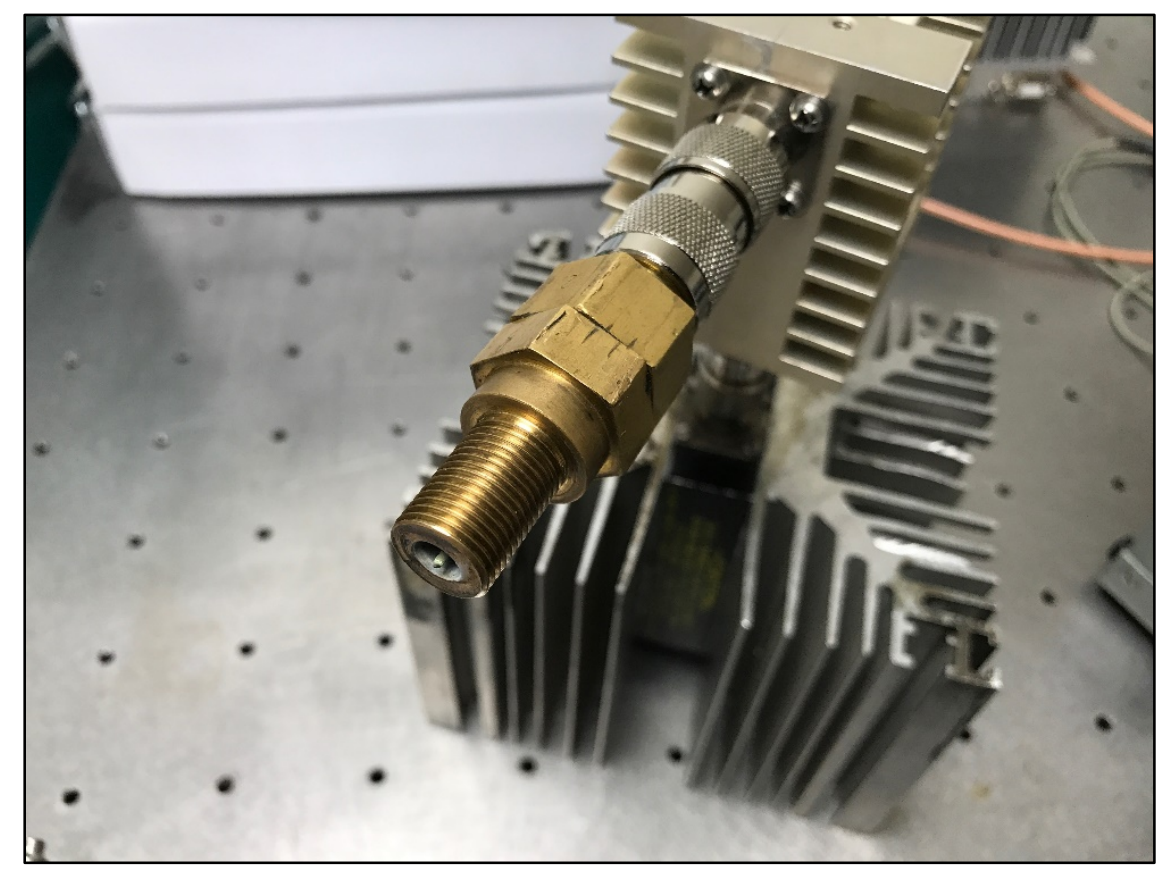

Figure 5. Plasma Igniter

The plasma igniter technology works by supplying the right frequency to the plasma igniter plug from the signal generator, as seen in the following figure, in such a way that it matches the resonance frequency (RF) of the plasma igniter plug. When this frequency and sufficient power is reached at the tip of the plasma igniter plug, the ambient gas is ionized and plasma is created. The figure below shows the setup for generating plasma with the plasma igniter. The far-right side of the figure shows the signal generator and power supply with the left side of the figure containing the plasma igniter 


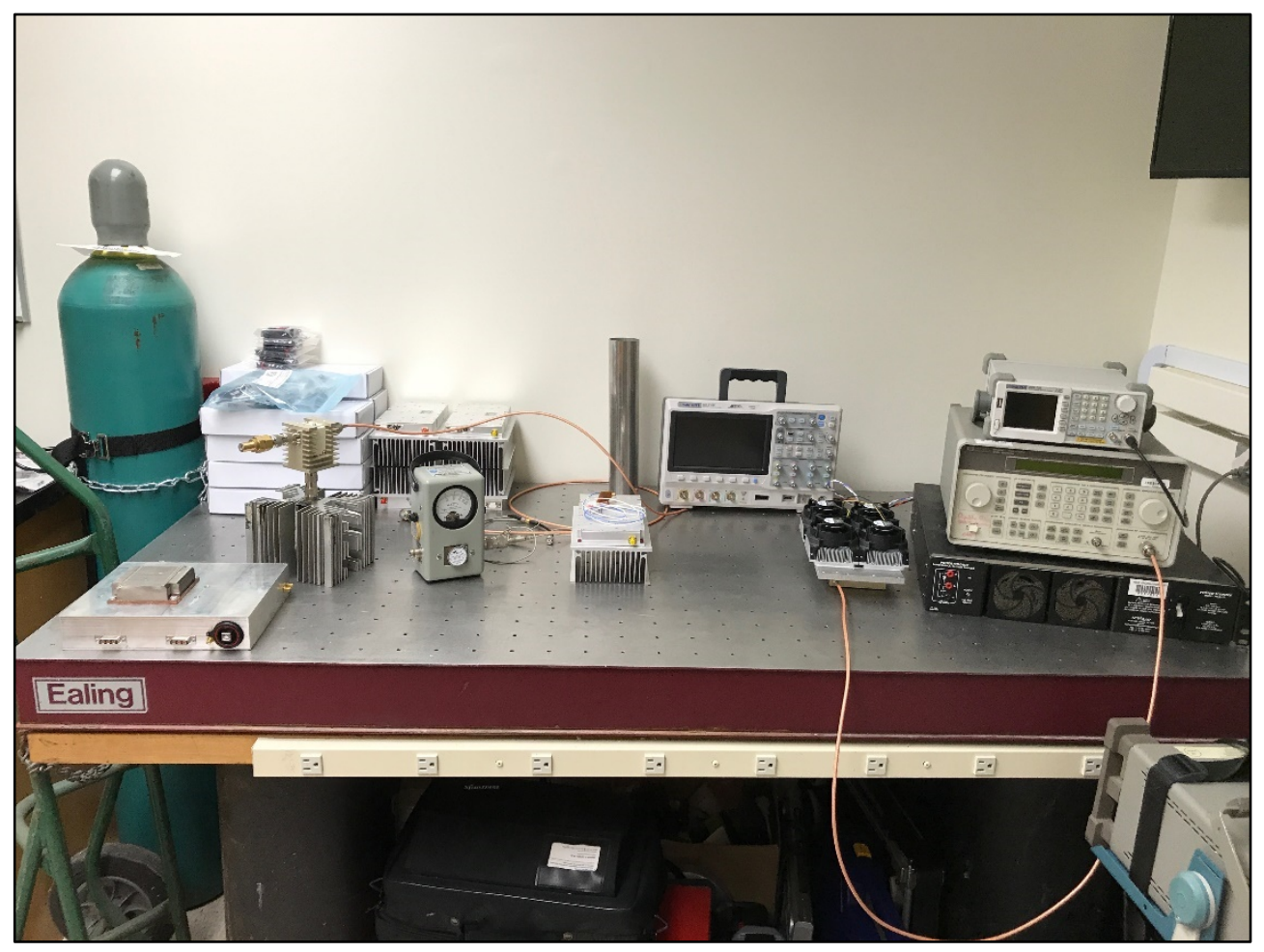

Figure 6. Signal Generator

The resonance frequency must match that of the quarter wave coaxial plug so that plasma is formed in the right location at the tip of the plug. [20]

There are two benefits that come from the use of the plasma igniter as a replacement to a typical spark plug. The major advantage that the plasma igniter has over spark plugs is that by creating a plasma, the corona is larger than a spark plug's discharge arc, it also creates a more complete burn inside the combustion cylinder [21]. A more complete burn leads to the two significant improvements in the combustion process. The first improvement is higher fuel economy per unit of power produced and in turn, the ability to combust with a leaner fuel to air mixture than with a spark plug [22]. 


\section{Problem Identification}

For the plasma igniter technology to progress further with testing and validation of experiments in low pressure and near perfect vacuum conditions, a customized vacuum chamber was required that meets the safety standards and experimental procedure criteria so that all current and future experiments could take place inside the chamber without the need to redesign for later tests. There are multiple applications where the plasma igniter technology can be used and to progress with each application, the proper environment to conduct these experiments is required.

The ideal vacuum chamber would be designed to withstand the external atmospheric pressure while at a full vacuum and have the structural integrity to withstand pressurized purging of the vacuum chamber, up to 1 atmosphere of gage pressure. The ideal vacuum chamber would also have the ability to reach a near perfect vacuum, which will use the atmospheric pressure at low earth orbit as a standard.

The structure of the vacuum chamber would consist of non-conductive materials. The materials would also allow personnel to view the inside of the chamber from all perspectives and to allow the UV and IR spectrums to come through the material so that viewing the impact that the plasma has on those spectrums can be recorded by data acquisition equipment. The support and auxiliary equipment would have the ability to flush the vacuum chamber with other gases, such as Nitrogen, so that the plasma can be tested, and provide sensor data collect capabilities for these different conditions. The final components of the design would include the ability to modify the structure so that any future experiments for plasma applications could be conducted. The purpose for the custom built vacuum chamber comes down to having the ability to generate and sustain the plasma corona. This requires that the chamber is made almost entirely of 
nonconductive materials and that the chamber needs to have all the required equipment for all future projects without rebuilding a new vacuum chamber. The additional equipment added in the future must be easily added to the vacuum chamber without harming the structural integrity to the point in which material failure would occur. The problem statement for the research could be summarized as creating a functional design for a vacuum chamber with the limitations on material selection and volume of the chamber along with the requirements for the environment in which the plasma igniter needed to be tested. 


\section{Preliminary Design of a Vacuum Chamber}

\subsection{Preliminary Design Approach}

The preliminary design for the vacuum chamber was to create a working model that met the requirements for testing plasma applications. The restrictions on the design of the vacuum chambers where given an inexpensive cost and having at least 0.5 cubic feet of volume to work with in the event that the plasma corona grew to a size of 2 orders of magnitude or larger from its original atmospheric pressure size. The design was meant to require the least amount of materials for construction so that the factor of safety was above five while a vacuum was pulled for the experiments with the plasma igniter technology.

The final design of the vacuum chamber would consist of more design features, but would be an evolved design of this preliminary design of the vacuum chamber. The creation of the chamber needed to be inexpensive, whereas pre-made acrylic chambers were overly expensive and could not be customized to the standards for the experimental procedure needed for this application [23].

The most important feature this design required was to pull a near perfect vacuum. As stated by NASA, an appropriate pressure for a perfect vacuum is $10^{\wedge}-8 \mathrm{~Pa}$ [24]. The vacuum chamber’s minimum pressure reached would be compared to the value for a perfect vacuum to validate whether or not the vacuum chamber's design was up to the standards for a vacuum chamber designed by NASA.

The second most important requirement was the structure needed to have a factor of safety equivalent to or greater than five to be considered safe enough to withstand the ambient atmospheric pressure compressing the external cylinder of acrylic. Since the chamber was pulling a vacuum and not pressurized, it was safe enough since the failure of the chamber would 
lead to an implosion and not an explosion. For safety, shields on each side of the vacuum chamber were installed to protect personnel conducting experiments in the event of catastrophic failure.

The final primary requirement is that the vacuum chamber needed to be modular so that it could be used for various experiments with minimal effort in exchanging the required parts to run the experiment. Some examples of parts for other experiments would be a sapphire viewing port to connect at the base of the chamber to recorded video and images of the effects of plasma on the UV and IR spectrums. Other equipment that needs to be modular would be sensors like thermocouples. Once a working model of the preliminary design was completed, then the FEA report could be simulated, generated, and then validated with strain gauge experiments to make sure the chamber was safe to use at an absolute vacuum and changes could be made to improve upon the design for a recommended final design for the vacuum chamber.

\subsection{Specifications for the Preliminary Design}

The requirements for the design consisted of a working chamber volume of 0.5 cubic feet or larger. This volume was selected so that the chamber could have a height of 1 foot which gave ample room to view the plasma generated from the plasma igniter. The diameter was selected to be less than 1 foot since sourcing parts for an acrylic cylinder that had a diameter larger than 8 inches was difficult to find or too expensive for the scope of this research.

The top and bottom of the chamber was selected to be made of a wood composite called G10 or better known as Garolite. The properties were stronger than traditional woods and was also a non-conductive material which was a primary factor in its selection. The connections holding the plate and acrylic cylinder together were four steel rods. Since they were independent of each 
other with no conductive connections to the rods themselves, using metal for the connection between the top and bottom plates of Garolite was acceptable.

The top and bottom plate were then threaded so that the 14-mm plasma plug connection could be inserted into the chamber as seen in the figure below.

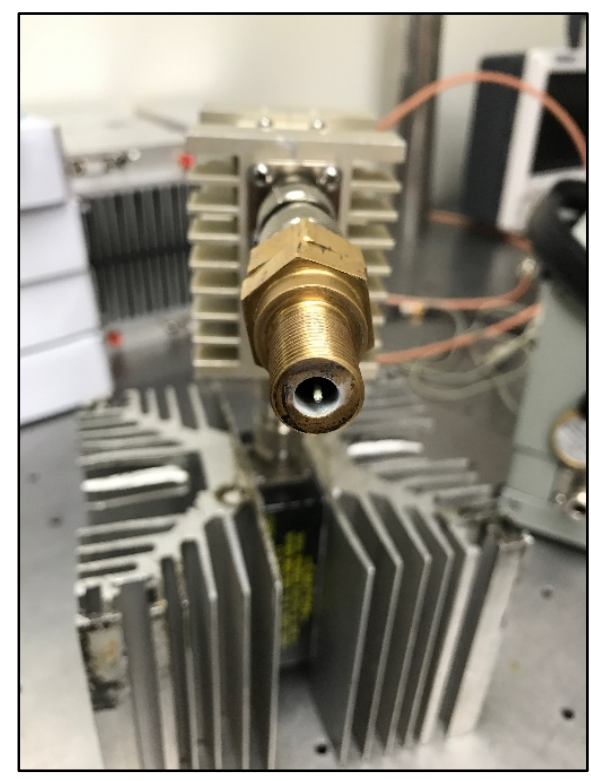

Figure 8. 14-mm Plasma Igniter Plug

The other connections that were threaded into the Garolite were 1/4 NPC threads for connection with the vacuum gage and the shutoff / bleed out valve.

There were multiple advantages originating from the preliminary design of the vacuum chamber. The first design feature was that the volume was 0.534 cubic feet, which was slightly over the required volume. This allowed parts to be added to the chamber without having to meticulously plan how attachments would be made. The structural properties of Garolite were significantly greater than those of acyclic by orders of magnitude. This allowed the reduction of stress concentrations for the threaded hole on the top and bottom plates of Garolite [25].

The other material benefits are that acrylic allows IR and UV spectrums to pass through the material unlike typical glass [26]. The following figure shows how the UV and IR spectrum are 
immediately outside the range of the visible spectrum and is important to know which materials allow these spectrums to pass through and which materials block these wavelengths.

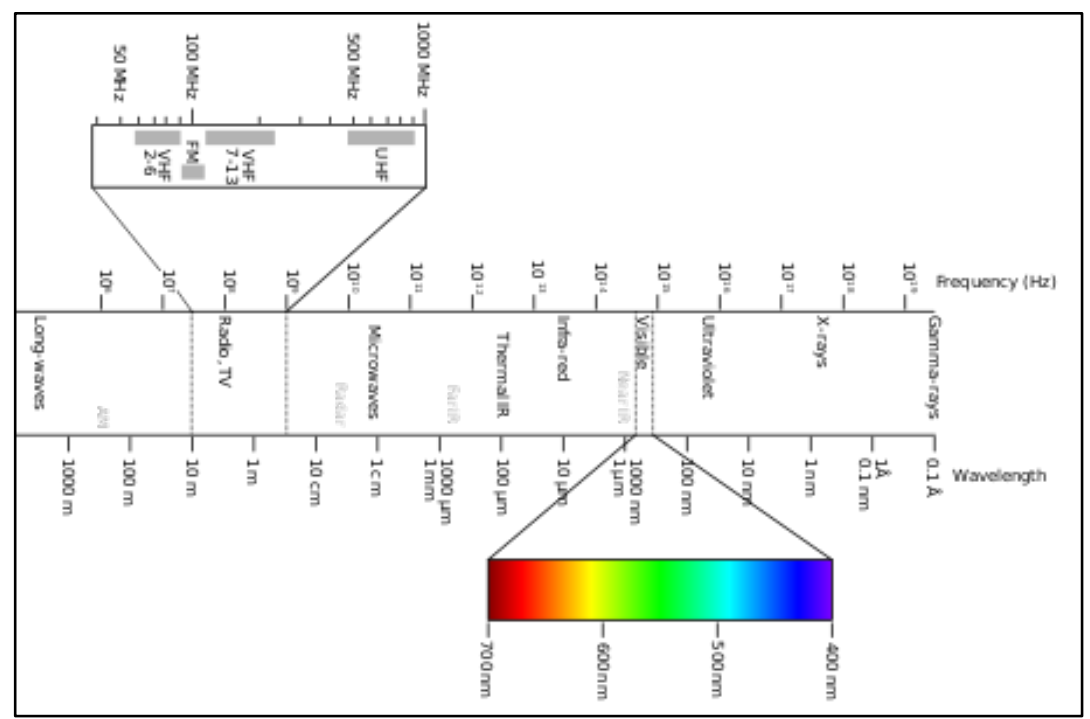

Figure 9. Wavelength Spectrum [27]

The other material benefits were that the materials were non-conductive materials and appropriate to be used with high voltage in experiments.

Of course, the preliminary design of the vacuum chamber was not perfect and contained some disadvantages in the design. The first disadvantage was the number of connections increasing the possibility of leaks preventing the vacuum chamber from reaching a full vacuum. To prevent leaking, the threaded connections needed Teflon tape to ensure the connections were protected from minuscule leaks.

This requires a lot of Teflon tape and re-taping for each connection exchange which lead to a very time-consuming process. Outside of the threaded connections, other connections had to be monitored for leaks such as the pressure rated hose that went from the vacuum pump to the vacuum chamber.

Another disadvantage in the design was that the volume still might need to increase for future experiments to 1 cubic feet in which a larger acrylic cylinder would need to be purchased. The 
FEA report will be compared with the strain gauge readings for safety since the chamber is mostly acrylic and acrylic is a brittle material. By increasing the volume significantly, the stress will also increase since the ambient pressure is the only load applied to the chamber and more stress will occur when there is more surface area. The chamber needs to reach a minimal pressure that is acceptable as previously stated. Ideally the vacuum chamber will reach that ultimate vacuum rating for the vacuum pump in use as seen in the figure below.

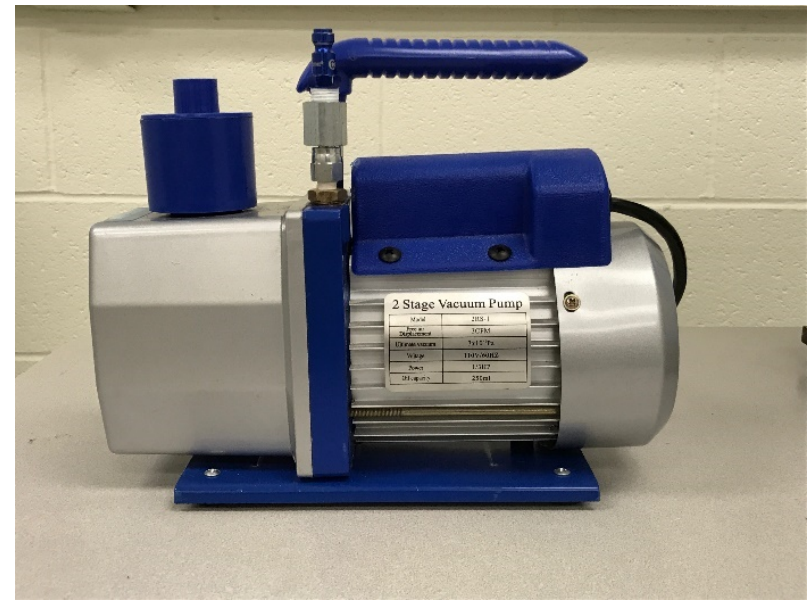

Figure 10. 2 Stage 3 CFM Vacuum Pump

If the vacuum chamber did not reach the ultimate vacuum listed on the pump rating seen in the following figure, then the difference of the ultimate vacuum rating on the vacuum pump and the pressure achieved would be compared to one another and determined if the value was acceptable to NASA standards for a full vacuum. 


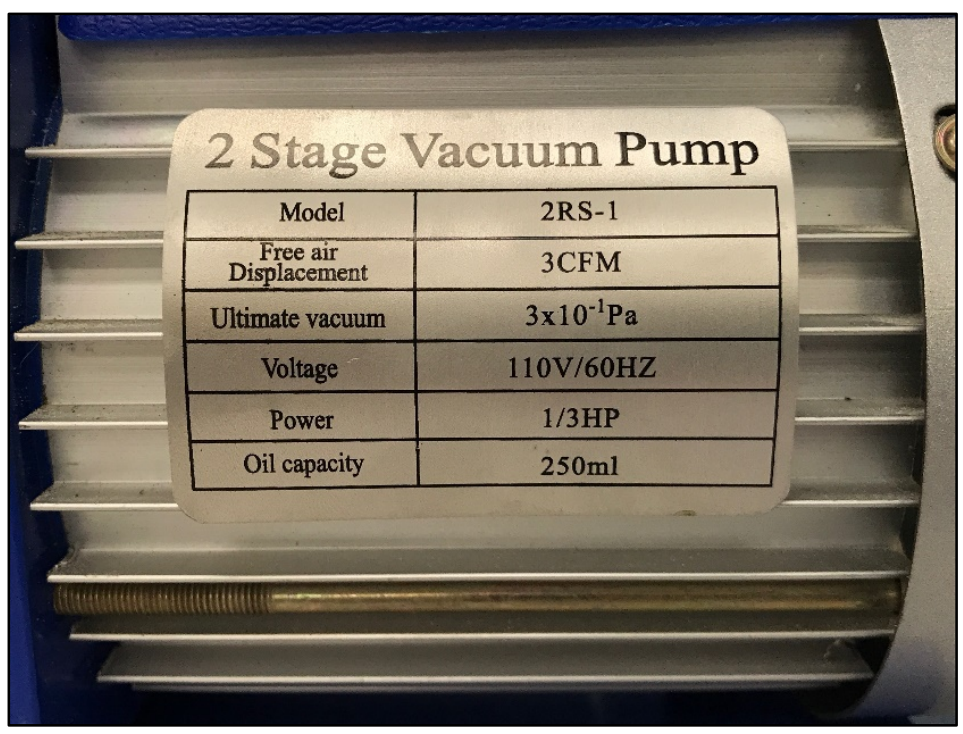

Figure 11. Vacuum Pump Rating

Once the vacuum was pulled and the chamber was ready, the strain gauge test would need to be completed to ensure the safety of the users conducting experiments with the vacuum chamber. With the strain recorded and calculating the stress in the material, the allowable stress could be compared to the yield stress and a Factor of Safety (FOS) could be determined. An extremely critical FOS would be considering 1.1 to 1.5 whereas a more moderate FOS would be considered to be within the range of 5 to 10 [28]. The higher the FOS, the more likely that the vacuum chamber could withstand a deviation in loading that might have been unseen from previous calculations and would protect personnel from these incidents.

Once the strain gauge data is collected, the allowable stress would be calculated by multiplying Young's Modulus to the strain to determine the stress in the material in that orientation. From there, the results could be compared to the FEA report and simulation from the model created in Solidworks.

\subsection{Finite Element Analysis Simulation for the Preliminary Design}


The initial simulation was set up with the selected materials, Garolite and medium impact acrylic. Medium impact acrylic was selected due to the non-conductive nature of acrylic along with the ability of have the IR and UV spectrums pass through for later recording equipment to monitor activity in these spectrums with the plasma igniter. Acrylic was selected over glass for multiple reasons, but the primary concern was that for future UV and IR experiments, glass would not allow the spectrums to pass though. [26]

Garolite, or also known as G-10, is a wood composite that has high strength for being comprised of wood and is a fraction of the price per unit weight when in comparison with other composite materials. Garolite was chosen to be a strong composite over conductive materials types that couldn’t be used with high voltage experiments.

Shown in the next two following tables are the material property tables for medium impact acrylic and Garolite.

Table 2. Material Properties for Medium Impact Acrylic [29]

\begin{tabular}{|l|l|l|}
\hline Property & Value & Units \\
\hline Elastic Modulus & 3200001536 & $\mathrm{~N} / \mathrm{m}^{\wedge} 2$ \\
\hline Poisson's Ratio & 0.349999994 & $\mathrm{~N} / \mathrm{A}$ \\
\hline Shear Modulus & 890000000 & $\mathrm{~N} / \mathrm{m}^{\wedge} 2$ \\
\hline Mass Density & 1200 & $\mathrm{~kg} / \mathrm{m}^{\wedge} 3$ \\
\hline Tensile Strength & 75842328 & $\mathrm{~N} / \mathrm{m}^{\wedge} 2$ \\
\hline Compressive Strength & & $\mathrm{N} / \mathrm{m}^{\wedge} 2$ \\
\hline Yield Strength & 41368544 & $\mathrm{~N} / \mathrm{m}^{\wedge} 2$ \\
\hline Thermal Expansion Coefficient & $5.199999941 \mathrm{e}-005$ & $/ \mathrm{K}$ \\
\hline Thermal Conductivity & 0.21 & $\mathrm{~W} /(\mathrm{m} \cdot \mathrm{K})$ \\
\hline
\end{tabular}

Table 3. Material Properties for Garolite [30] 


\begin{tabular}{|l|l|l|}
\hline Property & Value & Units \\
\hline Elastic Modulus & 435113.213 & psi \\
\hline Poisson's Ratio & 0.35 & N/A \\
\hline Shear Modulus & 129083.5865 & psi \\
\hline Mass Density & 0.0433527 & $\mathrm{lb} / \mathrm{in}^{\wedge} 3$ \\
\hline Tensile Strength & 10587.75485 & $\mathrm{psi}$ \\
\hline Compressive Strength & & psi \\
\hline Yield Strength & 6526.698195 & psi \\
\hline
\end{tabular}

There were a few assumptions that were made to simplify the model for the FEA simulation. The first assumption was that the only loads acting on the model would be gravity and ambient atmospheric pressure acting on the external surfaces of the model. This was assumed since other loading conditions like external forces or vibrations were not involved.

The effect of buckling of the cylinder was eliminate from the study since the height to base ratio was significantly less than 10:1 which is the common ratio for when it is appropriate to start viewing the effects of buckling in a column [31].

The next assumption was that threads are not a structural concern since they are solid steel and are orders of magnitude stronger than the other two materials. There were three types of parts that comprised the preliminary model. First where the 1/4 NPC threaded steel rods that were 12 inches long and one connecting each corner of the top and bottom pieces of Garolite. The top and bottom plates of Garolite were 12 inches long and 12 inches wide with a height of $1 / 2$ inch.

The cylinder was comprised of medium impact acrylic and was 12 inches in height with a 10inch inner diameter and 1/4-inch thickness. The final assembly in Solidworks is shown in the figure below with all the parts mated together and ready to be simulated. 


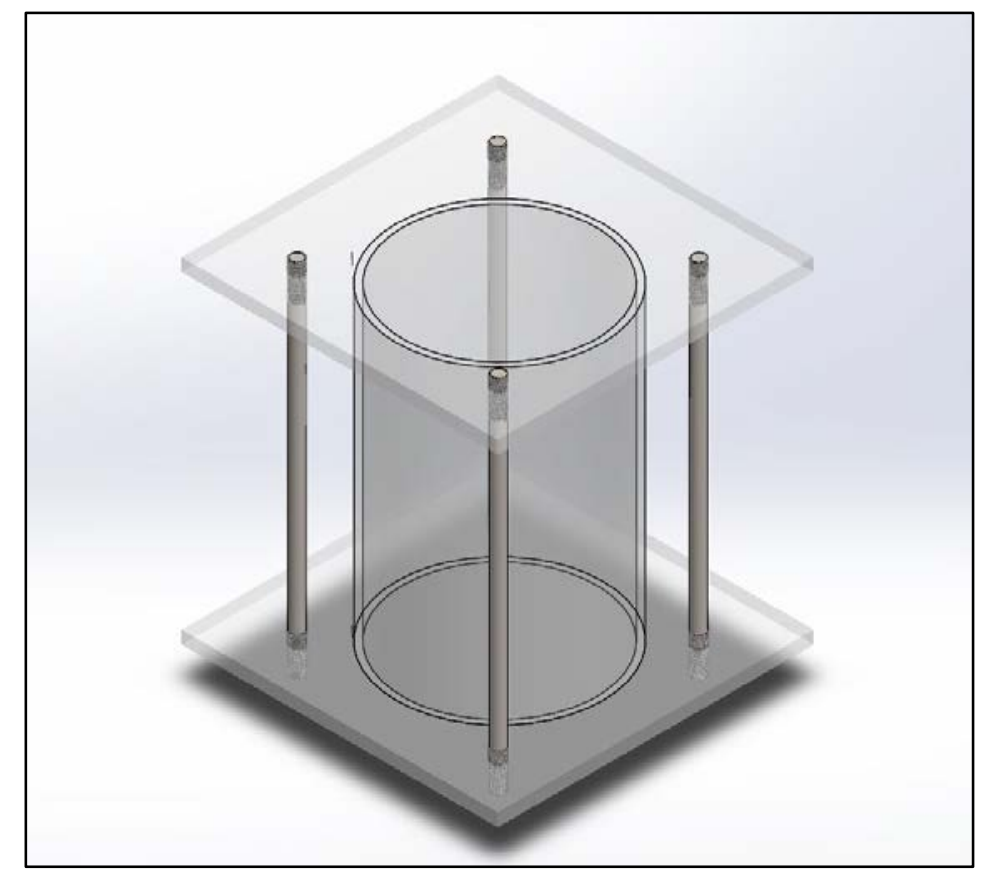

Figure 13. Preliminary CAD Model

The first step the FEA study was to set the fixtures of the model so that model could be planted as if it were bolted to a table or structure. The bottom plate was the selected fixture since that is where the vacuum chamber rested on top of the workbench.

This made sure the bottom plate was not allowed to deform and was required for the simulation to proceed. The loading was stated previously the gravity and the ambient atmospheric pressure would be the only loads applied to the model. The pressure used was atmospheric pressure at sea level which is $101.3 \mathrm{KPa}$ of $14.7 \mathrm{psi}$.

The atmospheric pressure was applied to external surface of cylinder and top and bottom plates so that the entire structure was impacted by this loading. The loading for the CAD model can be seen in the figure below. 


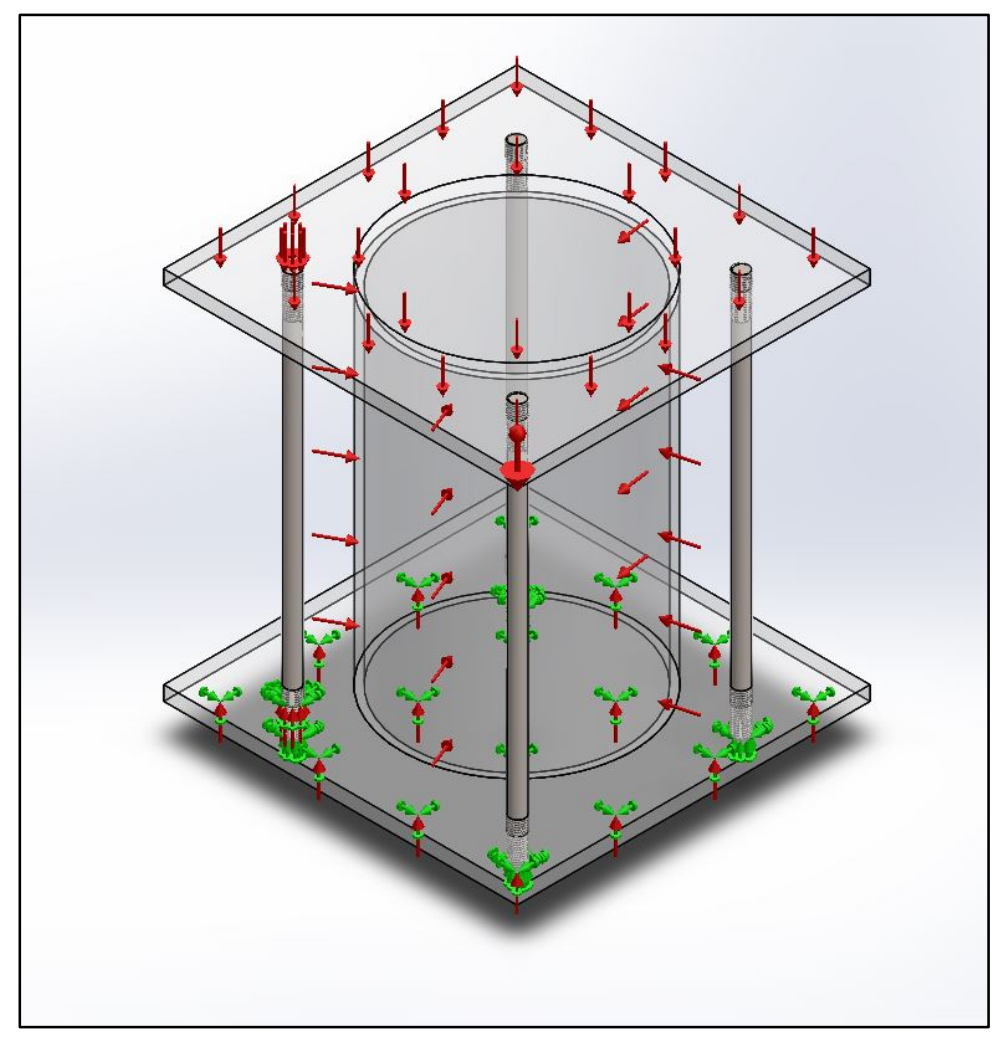

Figure 14. Preliminary FEA Loading

After this the simulation proceeded and results of the FEA report were collected such as stress, strain, displacement, and factor of safety. 


\section{Methodology}

\subsection{Methodology of Experiments}

The methodology of running the plasma igniter experiments with the vacuum chamber began with vacuum setup making it the most important procedure. The figure below shows what the setup of the vacuum chamber and equipment is required to perform the procedure.

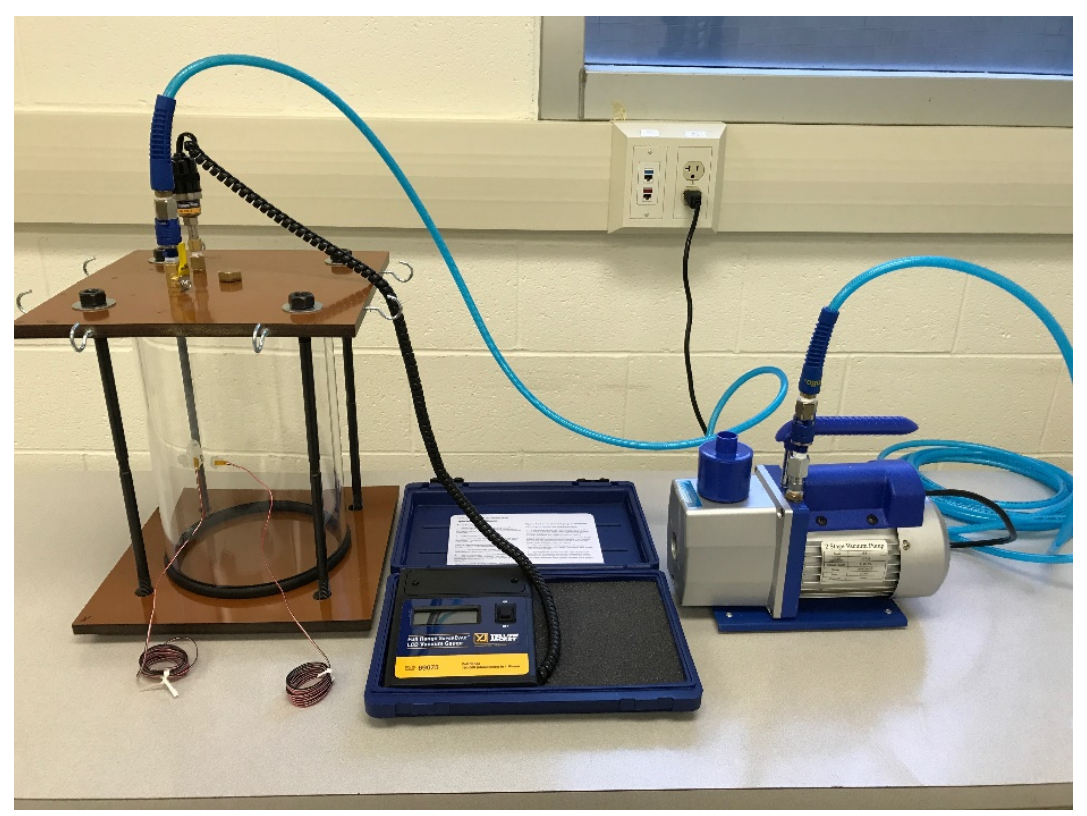

Figure 15. Vacuum Chamber Setup

It was vital to establish a secure and leak proof connection from the vacuum pump through the pressure rated hose to the vacuum chamber. The primary focus of this design was to reach the closest possible pressure to an absolute vacuum that the pump would be able to reach. By checking the ultimate vacuum rating on the side of the vacuum pump, the comparison of the that rating and the pressure level inside the chamber could be compared and see how close the vacuum chamber was from an absolute vacuum. 
Reaching the ultimate vacuum rating on the vacuum pump would lead to best results for plasma igniter by allowing it to expand without resistance from the pressure surrounding the plasma corona.

Once the vacuum was setup, then plasma can be tested for the first application which is seen in the figure below.

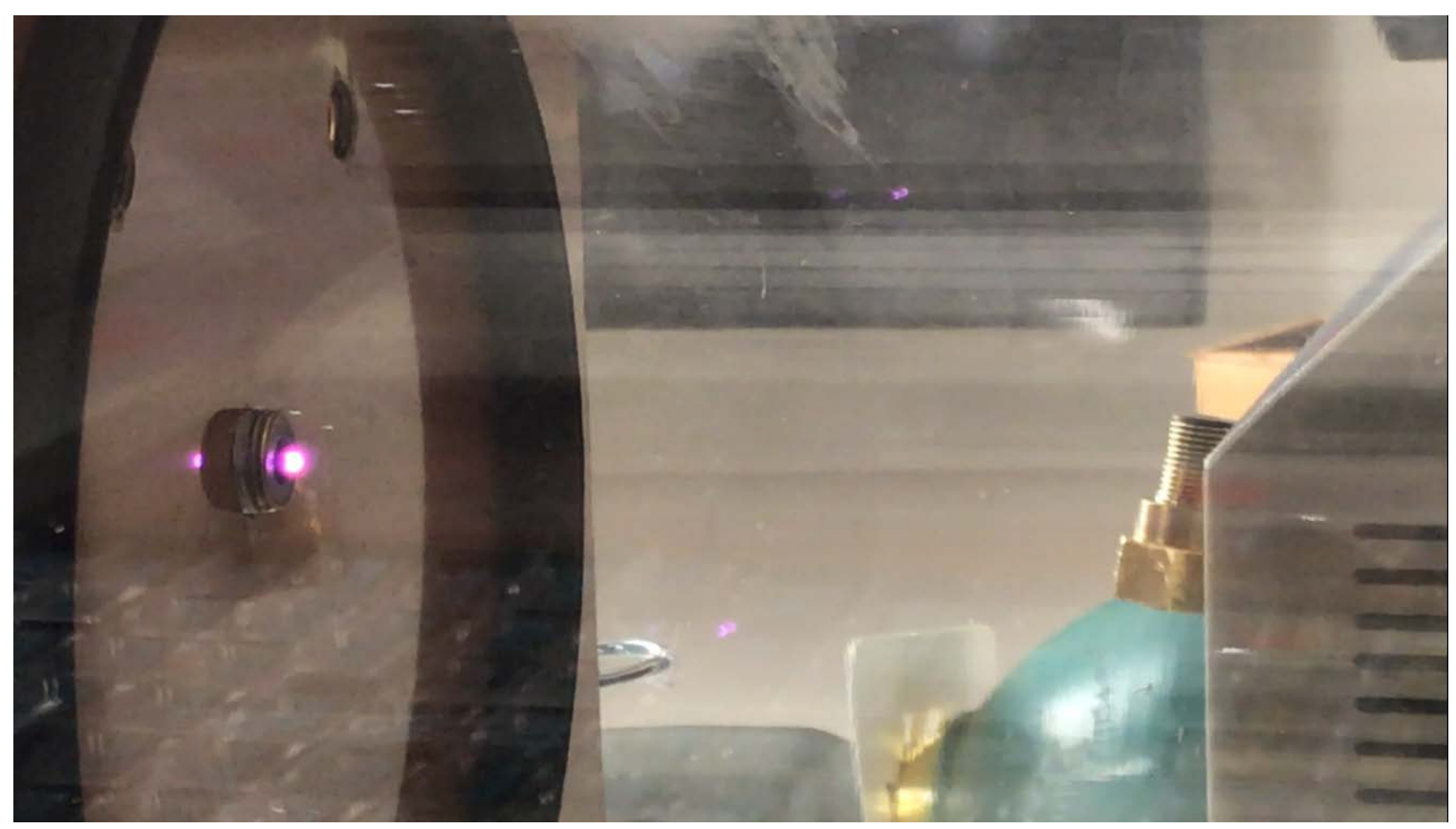

Figure 16. Plasma at a 98\% Vacuum

The results would be recorded and later examined to see the growth in the diameter and volume of the plasma corona. Once these results are recorded, then high voltage scenarios can take place to see how the plasma reacts at high voltage under a vacuum. In a further experiment, high voltage leads will be applied to parallel aluminum plates and then results will be recorded and later examined as to the effects that creating a voltage potential will have on the plasma. 


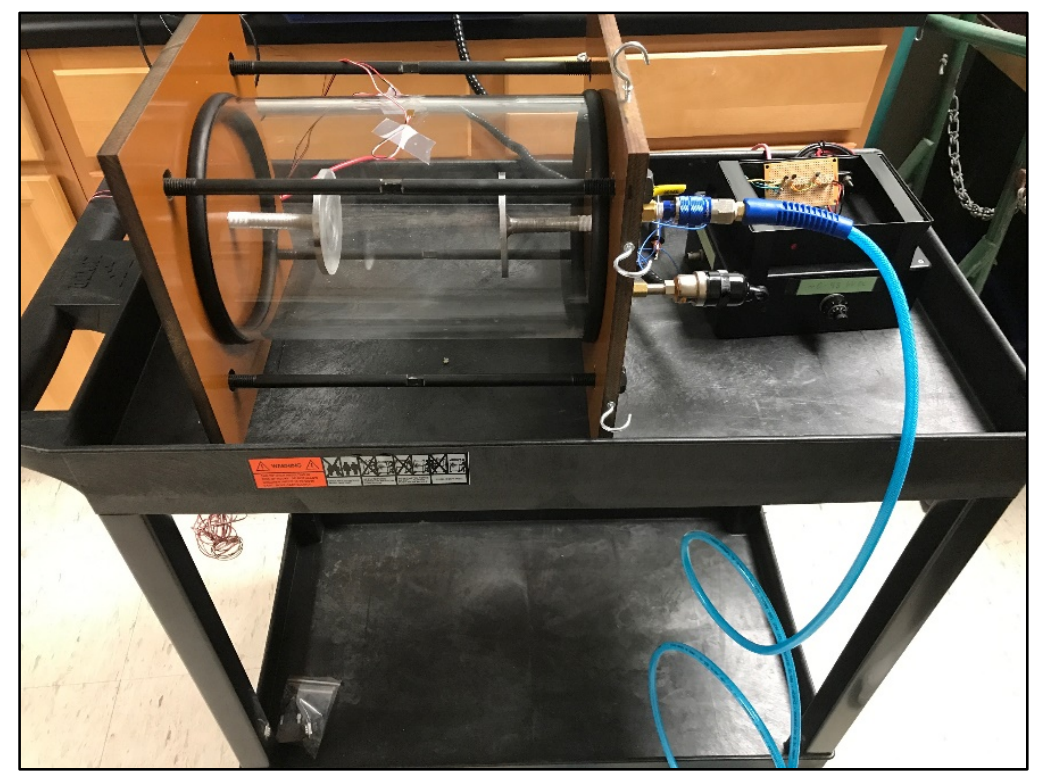

Figure 17. Parallel Plate Setup

Future experiments can then be conducted inside the vacuum chamber. Examples of future testing would include magnetic manipulation externally and internally with permanent magnets and electromagnets. This would indicate how the plasma can be manipulated to the point where it can internally pulse the plasma down the chamber length.

\subsection{Experimental Hypothesis}

Once the preliminary vacuum chamber was designed and manufactured, it could be tested to validate the functionality as a working vacuum chamber and test applications for the plasma igniter technology. To properly test the vacuum chamber and ensure that experiments with the plasma igniter technology could be conducted inside of the vessel, a test was run at below atmospheric pressure and near absolute vacuum conditions.

\subsection{Analytical Calculations}

The thoughts on how the vacuum chamber design would fail would be in the acrylic, since it has the lowest yield strength when compared to Garolite. The hoop stress can be calculated for a cylindrical pressure vessel as the following equation: 


$$
\sigma_{\theta \text { cylinder }}=P \cdot \frac{r}{t}
$$

The hoop stress for a spherical pressure vessel has an almost identical formula as hoop stress, just divided by 2 which will be discussed later:

$$
\sigma_{\theta \text { sphere }}=P \cdot \frac{r}{2 t}
$$

The longitudinal stress has as formula based off the axial loading of the system that is described below along with a figure describing the loading condition.

$$
\begin{aligned}
\sigma_{L} & =\frac{P \cdot \pi \cdot r^{2}}{\pi \cdot\left(R^{2}-r^{2}\right)}=\frac{P \cdot r^{2}}{(r+t)^{2}-r^{2}}=\frac{P \cdot r^{2}}{t^{2}+2 r t} \\
& =\left(P \cdot \frac{r}{t}\right)\left(\frac{r}{t+2 r}\right)
\end{aligned}
$$

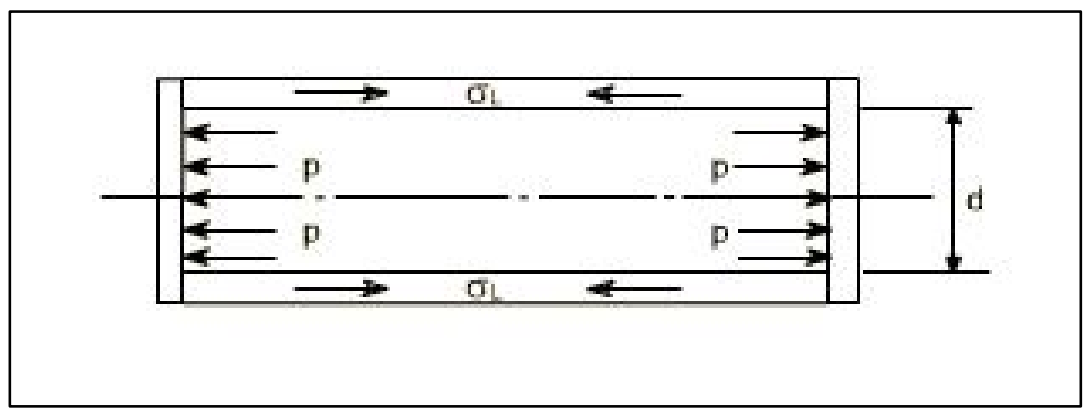

Figure 18. Loading Condition for Longitudinal Stress [33]

By observing these three equations, it can be seen how the hoop stress will always be larger for a cylinder than a sphere which will be important when discussing the final design of the vacuum chamber. It is important to observe that the hoop stress will be larger than the 
longitudinal stress. This can be seen in the previous equation for the longitudinal stress. The formula for hoop stress can be factored out. The remaining fraction cannot be less than 1 resulting in a lower value then the hoop stress equation. For this experiment, there is no combined loading, so we can observe that this calculation will be significant enough to understand the stress in the vacuum chamber when a vacuum it pulled.

It would seem that the vacuum chamber will be able to pull a vacuum significant enough to affect the plasma generated, but the biggest design concern is the potential for leakage from the chamber. There are many locations where leaks may occur, some of the locations are unlikely such as the rubber seal the connects the Garolite plates to the acrylic cylinder since the rubber can form to the Garolite when a load is applied creating an airtight seal.

The most likely locations are at the threaded connections on the Garolite plate or the threaded external connections to the vacuum gage or pressure rated hose to the vacuum pump.

It is also a possibility that the vacuum pump would stall since it is only a 1/3 horsepower pump and might not be powerful enough to pump enough air from the chamber while battling the ambient air located at the vacuum pumps vent.

From observations on plasma under pressure, it would be logical to assume that under a vacuum the plasma corona will grow since the previous experimentation of the plasma igniter under high pressure had shown the plasma corona shrank in sized significantly [1].

It should be noted that the size of the plasma corona should be relative to the power supplied since the power supplied creates the ability to ionize the air around the plasma igniter, but outside of that it is hard to predict the scale of the plasma's growth without experimentation.

The final hypothesis is when using the parallel plates attached to the top and bottom of the vacuum chamber, the plasma will arc from one plate to the other plate. Since air has a high 
electrical resistance, it has difficulty making a connection without thousands of volts to overcome the resistance [34]. Inside a vacuum, the resistance drops exponentially and allows the plasma to arc and make a connection. The distance that the plates are away from each other is still important, but it will just require less voltage to make the connection.

It is also believed that the plate finish may also be important to the path of least resistance and so the plates will have a polished finish.

\subsection{Procedure of Experiments}

\subsubsection{Procedure for pulling a Vacuum}

The first procedure for experimentation is creating a vacuum inside the vacuum chamber. Since the other experiments that will later use the chamber, it must reach an acceptable percentage of an absolute vacuum, it is of the utmost importance that it can operate effectively and repeatedly. To achieve this, a proper procedure for operating the vacuum chamber is important.

The first step for properly pulling a vacuum begins with understanding the ultimate vacuum rating on the vacuum pump in use. The vacuum pump currently in use is a 2 stage 3 CFM 1/3 Horsepower vacuum pump. On the side of the vacuum pump are the specifications including the ultimate vacuum rating shown in the figure below. 


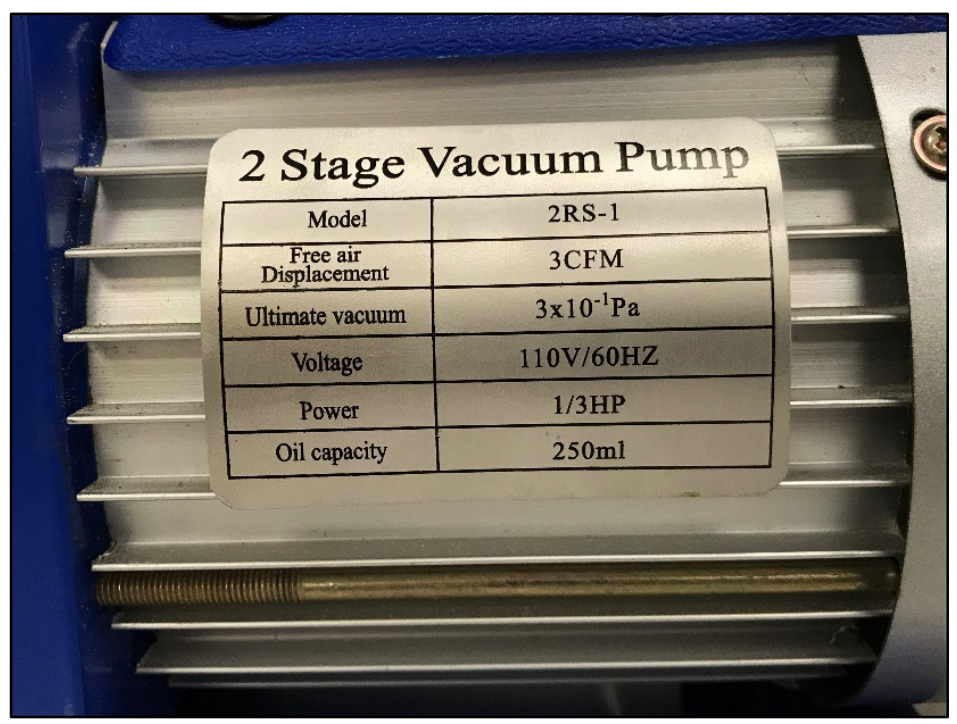

Figure 19. Vacuum Pump Rating

To see if the vacuum pump can reach an appropriate pressure level to consider the chamber to be at an absolute vacuum, the pump needs to be tested directly with the vacuum gauge. The value measured needs to be compared to what the pump states as the ultimate vacuum. This is critical to record because there may be a significant difference in the ultimate vacuum rating on a vacuum pump compared to what the vacuum gauge displays, even if there are no loose connections between the pump and gage. The vacuum gage connected directly to the vacuum pump didn’t reach an absolute vacuum. The vacuum gage reading was 4450 microns to 4500 microns when connected directly to the vacuum pump. This will be compared to the vacuum gage reading of the chamber since there is a higher probability of leakage occurring in the chamber.

This pressure value will be kept as a reference for when the vacuum chamber reaches its minimal pressure level to compare the minimal gage recording rather than the ultimate vacuum rating. Below is a figure showing the lowest photographed reading on the digital vacuum gage at 9920 microns. The actual lowest recorded pressure inside the chamber was 9600 microns. 


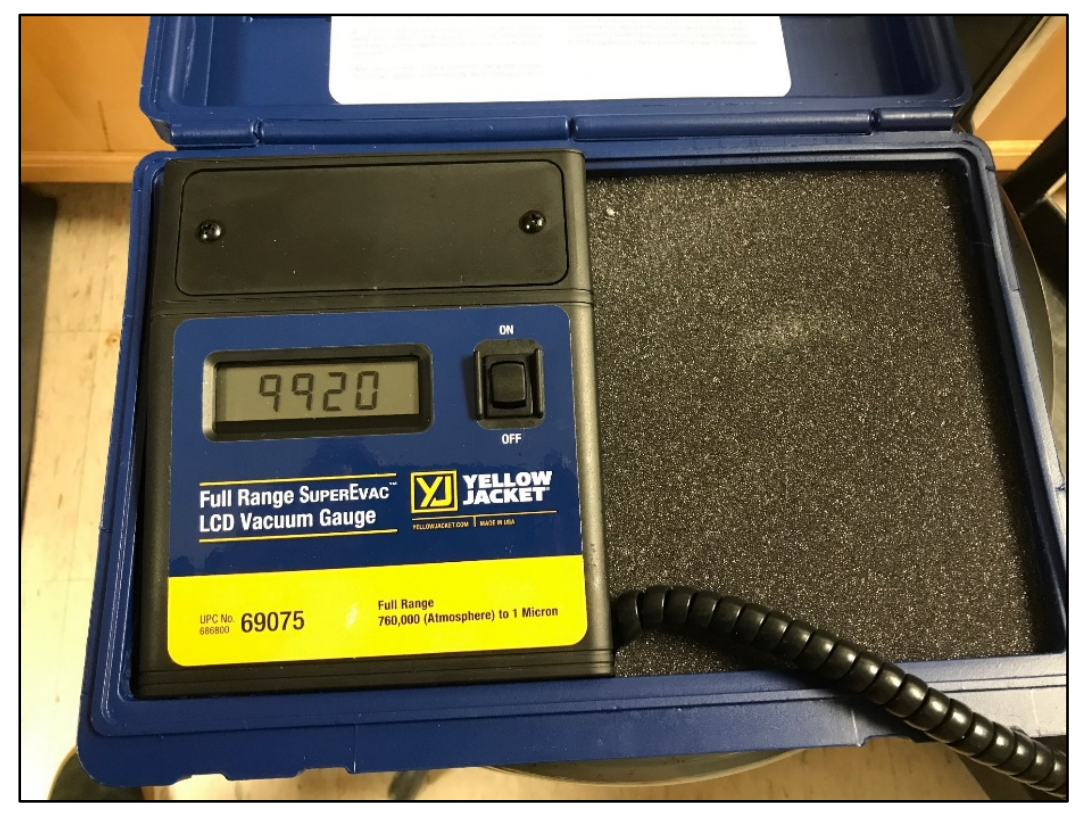

Figure 21. Minimal Vacuum Gauge Reading with 3 CFM Vacuum Pump

The following step is to tighten all the connections on the steel bars that hold the Garolite plates firmly against rubber gasket seal that is attached to the acrylic cylinder. It is extremely important to make sure the acrylic cylinder is flush with plates and the plates are parallel so that there is a proper seal around the gasket seals.

Once the Garolite plates are in place, all threaded connections can be wrapped in Teflon tape to secure an air tight connection and prevent leaking. The Teflon tape must be wrapped around the connection in a certain manner so that the it does not come undone when threading the connection. To do this, the Teflon tape must wrap around the threaded connector in the opposite direction of threading the connector into position.

After the connections are all wrapped, then the plasma igniter plug can be inserted into the 14-mm threaded connection in the Garolite. 


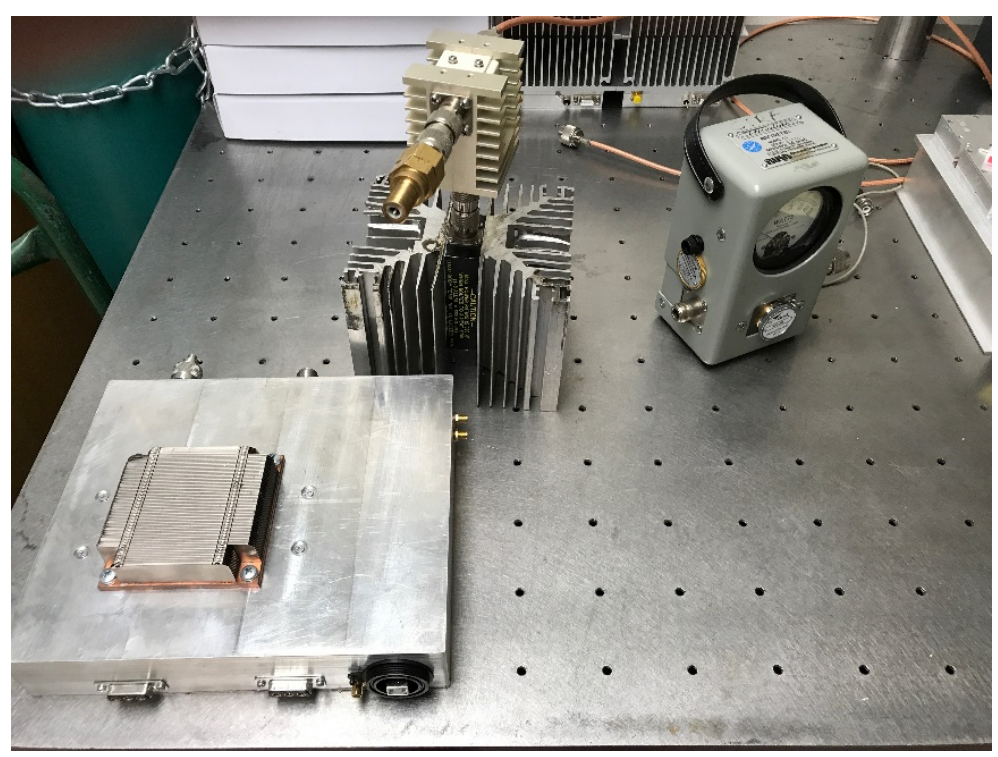

Figure 22. Plasma Igniter

The plasma igniter will then be connected to the power supply as seen in the figure above and then the vacuum chamber is prepared to be operated and start pulling a vacuum.

Make sure shutoff valve is open prior to turning on the vacuum pump so that air can be removed from the vacuum chamber. Once this is checked, the vacuum pump can be turned on. The average time to reach different pressure levels was collected from recorded data while experimenting.

Table 4. Recorded Pressure Values over Time

\begin{tabular}{|cc|}
\hline Time (Seconds) & Pressure (KPa) \\
\hline 0 & 101.3 \\
1.8 & 91.3 \\
2.6 & 81.3 \\
4.5 & 71.3 \\
7.7 & 61.3 \\
9.8 & 51.3 \\
13.1 & 41.3 \\
18.0 & 31.3 \\
\hline
\end{tabular}




\begin{tabular}{|cc|}
\hline 27.3 & 21.3 \\
36.7 & 11.3 \\
56.5 & 1.3 \\
65.9 & $\sim 0$ \\
\hline
\end{tabular}

These values were compared with the estimated time to pull a complete vacuum if the flow rate would remain linear until a perfect vacuum is reached. The basic equation below shows of the time to reach a perfect vacuum with a linear flow rate calculated in seconds.

$$
\frac{\forall}{\dot{\forall}}=\boldsymbol{t}
$$

\section{$\frac{12 \mathrm{in} \cdot \pi \cdot 4 \mathrm{in}^{2}}{\frac{3 \mathrm{ft}^{3}}{m \mathrm{~m}^{2}}} \cdot \frac{1 \mathrm{ft}^{3}}{(12)^{3} \mathrm{in}^{3}} \cdot \frac{60 \mathrm{~seconds}}{1 \text { minute }}=t=6.9813 \mathrm{~seconds}$ minute}

Comparing the time for a linear flow rate to pull an absolute vacuum to the actual recorded data shows the flow rate is not a linear rate and that it becomes exponentially harder to pull a vacuum as the pressure drops inside the chamber.

Once the vacuum chamber reaches the minimal pressure achievable, then the shutoff valve can be closed, and the vacuum pump turned off. The hose connecting the vacuum pump to the chamber can then be disconnected. Every two minutes, check the vacuum gage to make sure that there is less than a $5 \%$ change in pressure and that all the seals are air tight.

\subsubsection{Procedure for Testing the Plasma Igniter and Plasma Arcs Inside the Vacuum Chamber}


With the proper procedure completed for pulling a vacuum, the next procedure deals with the experiments for testing the plasma igniter in the vacuum chamber. Once the vacuum chamber has an acceptable vacuum, the plasma igniter can be turned on. By having the power supply connected to the plasma igniter, the signal generator can be used to tune the frequency so that plasma is generated.

The next experiment was attempting to create a plasma arc connecting parallel plates. The procedure for testing with parallel plates starts with opening the vacuum chamber to thread plates from the inside out into the Garolite. The following figure shows the aluminum parallel plates that would be attached to the Garolite plates.

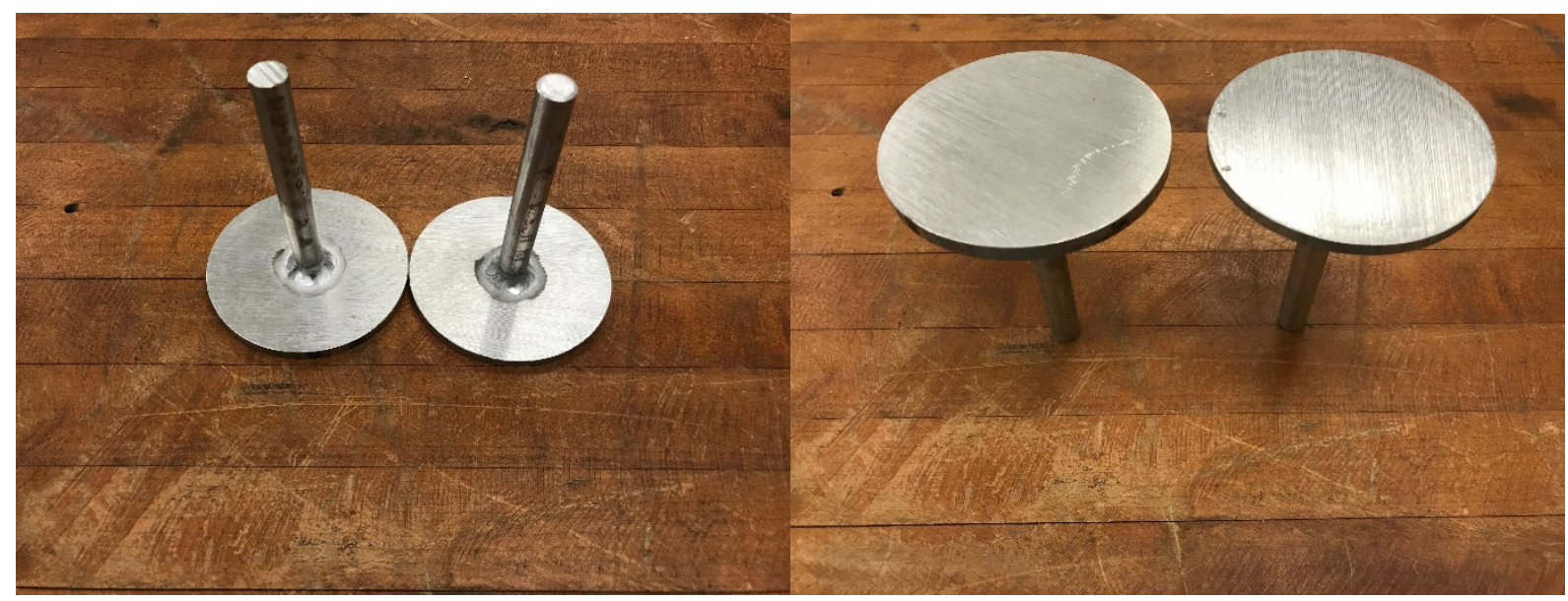

Figure 23. Parallel Plates

Once the plates have been threaded into the Garolite enough to hold them firmly, the threads must be wrapped with Teflon tape similar to the vacuum chamber procedure. Once the tape is on the pole connected to the aluminum plates, then the plates can be screwed into Garolite completely. The figure below shows the parallel plates threaded into the Garolite and prepared for the experiment 


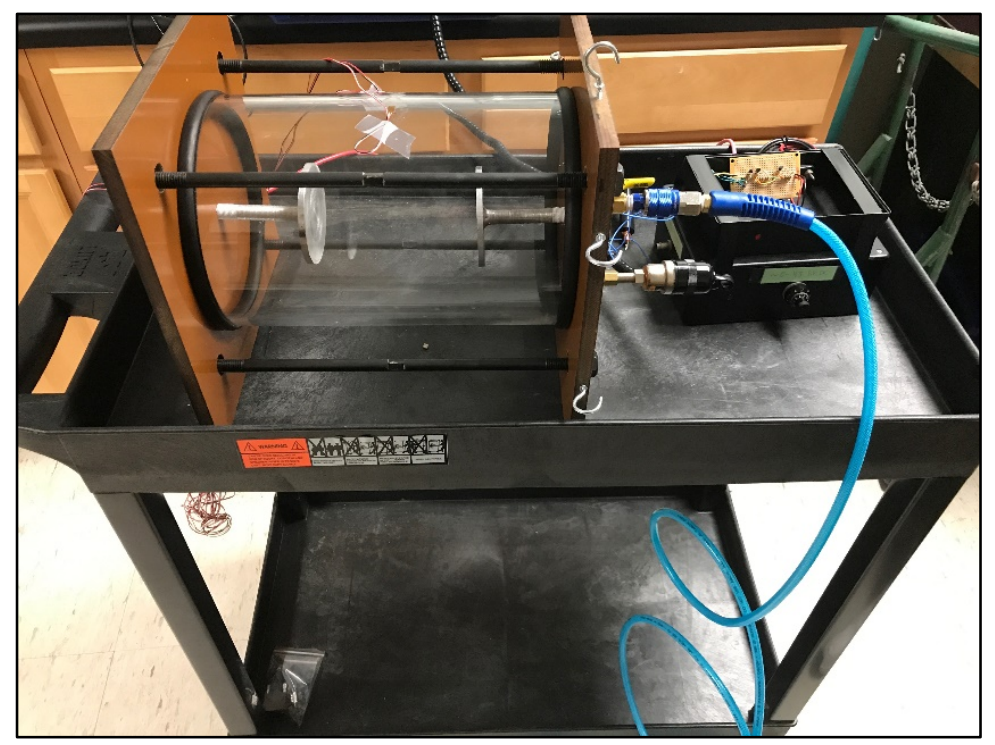

Figure 24. Parallel Plate Setup

With the parallel plates in place, the high voltage connections from the high voltage power supply can be attached to the respective sides of the vacuum chamber and the corresponding aluminum plates. From there, the high voltage power supply can be turned on. The next figure shows the high voltage power supply used in these experiments.

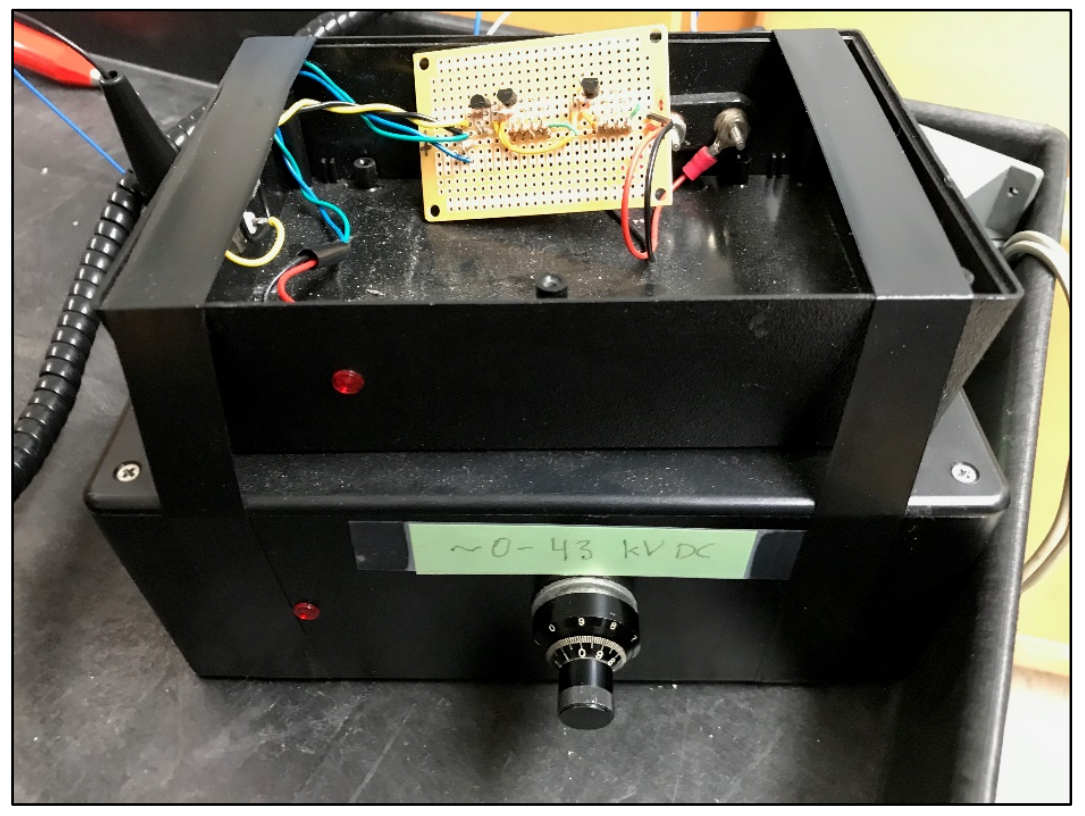

Figure 25. High Voltage Power Supply 
Once the high voltage power supply is turned on, the voltage can be dialed in and set prior to pulling the vacuum. The high voltage setting on the power supply goes up to 20,000 volts currently and with another power supply has the capability to reach 40,000 volts. The next step is to turn off the light and black out the room because any light will make it difficult to see the plasma when it makes the jump across plates. Once everything is setup then the vacuum pump can be turned on to begin to pull a vacuum.

It is better to pull the vacuum after the voltage is set so the progress can be seen at what pressure the plasma makes the jump across the plates and generates an arc. Once the vacuum pump is turned on, it is important to watch the pressure reading on the vacuum gauge to notice when the plasma begins to arc from the aluminum plates. The pressure at which the plasma arc made the connection was recorder to be 14,900 microns.

\subsubsection{Procedure for Strain Gauge Experiments}

After the experiments with the plasma igniter were completed, the strain gauge experiment was required to compare against the FEA report produced from the CAD model and simulation conducted in Solidworks. The procedure for setting up strain gauge experiment consisted of applying the strain gauges to the specimen's surface, preparing the recording equipment, and finding the strain for each orientation. The first step to applying strain gauges to the vacuum chamber is to properly set up the orientation seen in the figure below. 


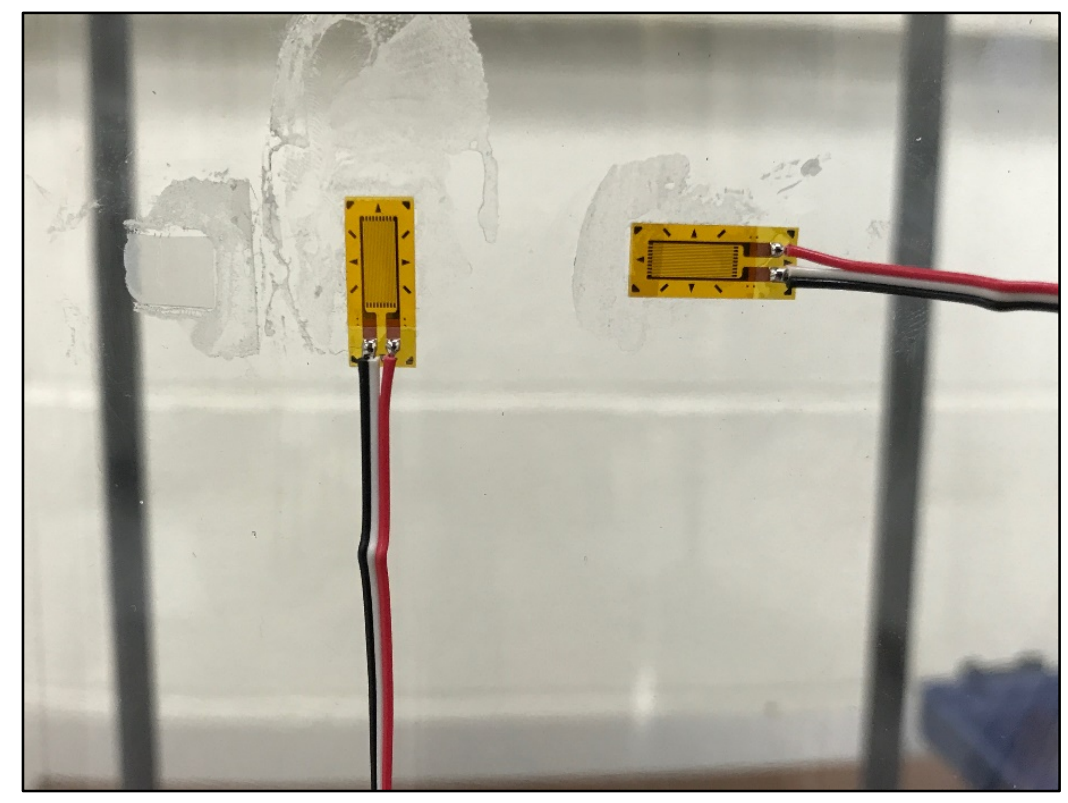

Figure 27. Strain Gauge Orientation

These experiments consisted of apply two strain gauges to the vacuum chamber. One for longitudinal strain and one for hoop strain. Once the strain gauge is setup in the correct positioning and orientation, the delicately apply $\mathrm{M}$ bond 200 adhesive to the material surface and roll the strain gauge on to the material surface so that all air bubbles are eliminated, and the entire strain gauge is flush with the material surface. Let the bond cure for up to 30 minutes and then the procedure can continue.

Once the strain gauges have been applied and the adhesive has cured, the specimen is ready for testing. The first step is to perform the vacuum chamber procedure so that a vacuum is performed prior to calibration. This provides the best results as the strain gauges aren’t recording a transient loading condition and instead is measuring a static compression condition. The following step is to match the three wire leads to their ports, connect to correct diagram for the strain gauge model being used, and check the stain gauge resistance from the documentation. The following step is to turn on strain gauge equipment by power it is with a USB power supply. 
Once the equipment is turned on, the first step is to make sure the gauge factor is correctly adjusted as seen in the following figure.

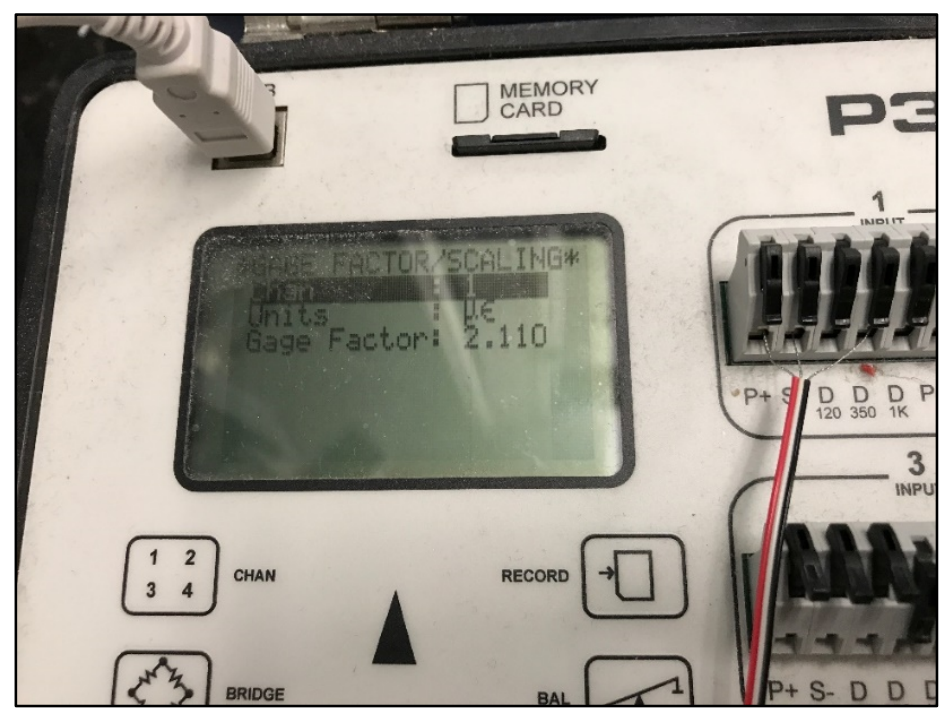

Figure 29. Gauge Factor Input

The gauge factor is adjusted to match the number on the stain gauge documentation and paperwork listed in the next figure.

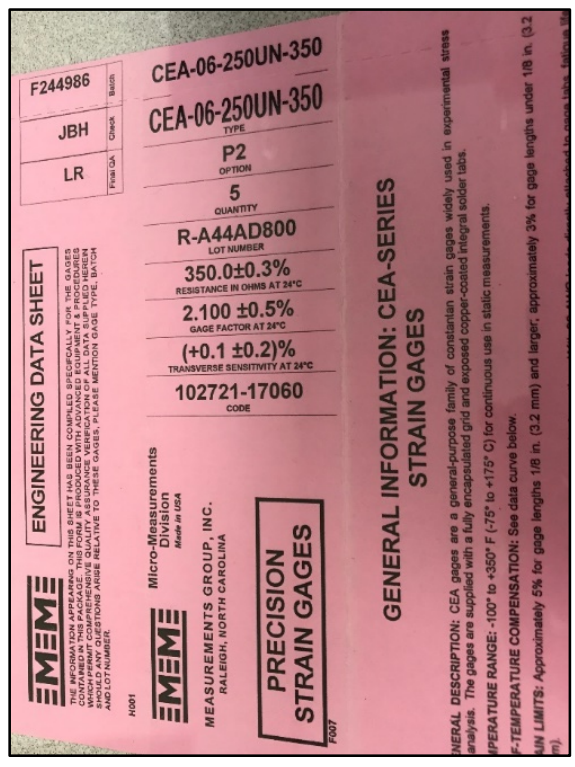

Figure 30. Strain Gauge Documentation 
From there, the correct diagram must be selected for the appropriate Wheatstone bridge setup. Without the correct Wheatstone bridged setup, the recorded values may be distorted. The left Wheatstone bridge diagram in the figure below was used for the strain gauge experiment.

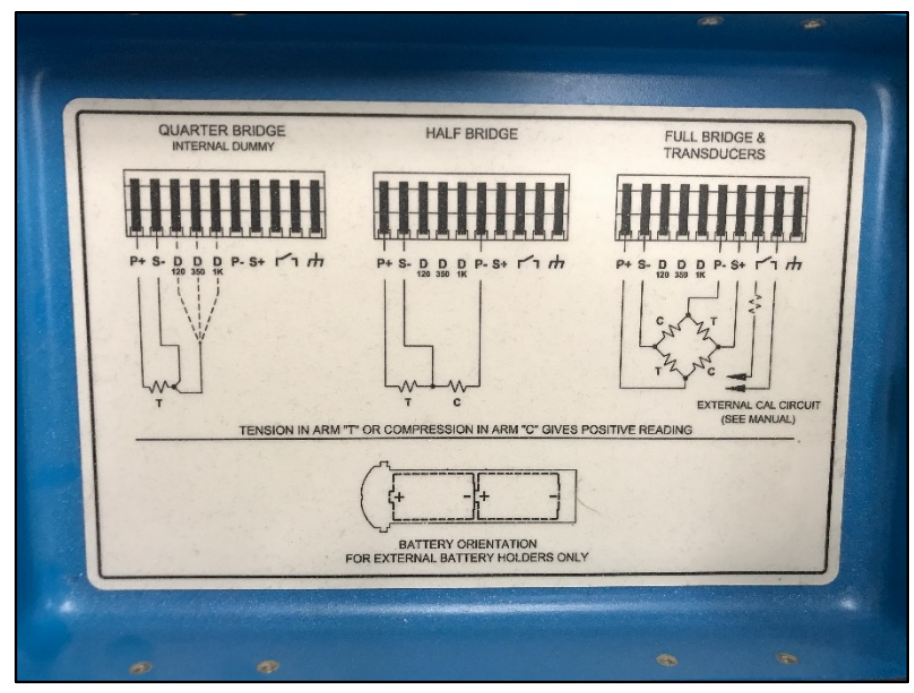

Figure 31. Wheatstone Bridge Diagram

The Quarter Bridge setting is selected for all channels, even the inactive channels 3 and 4. The other options are Half Bridge and Full Bridge. These other options are available when the strain gauges in use have more electrical leads.

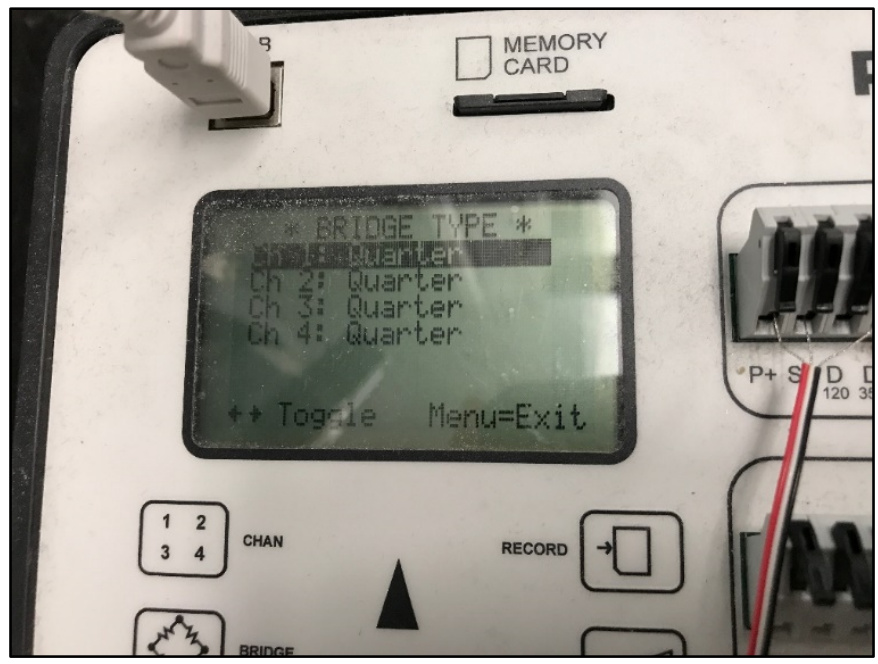

Figure 32. Bridge Type for All Channels 
Then the active channels were turned on and the channels 3 and 4 were deactivated since channel 1 was the hoop strain orientation and channel 2 was the longitudinal strain orientation.

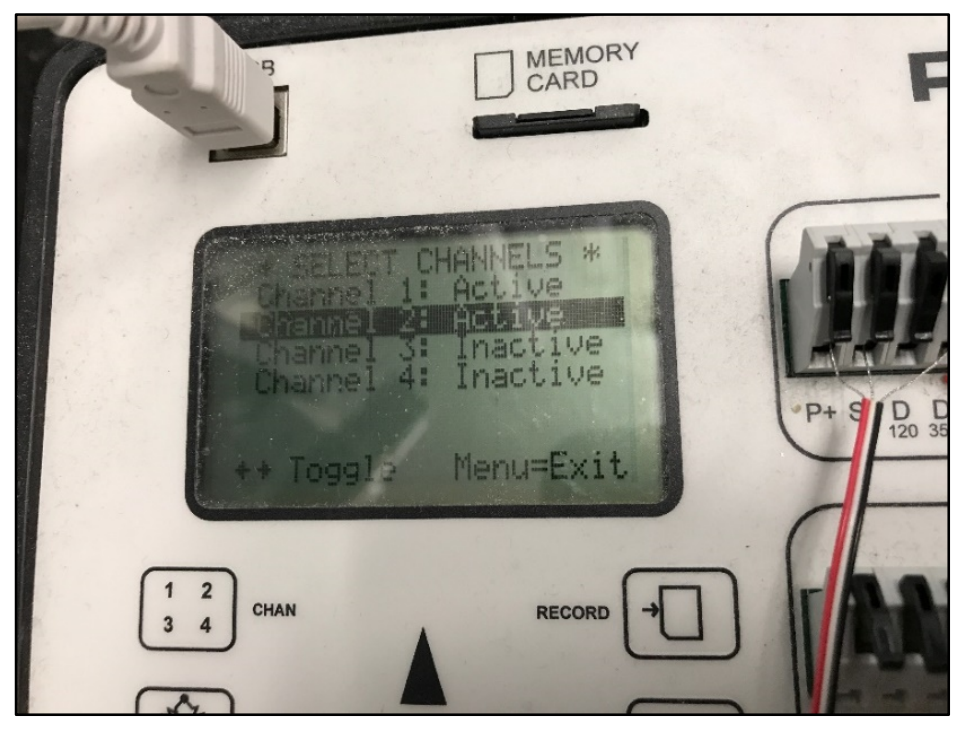

Figure 33. Active Channels 1 and 2

Only channel 1 and channel 2 display strain in micro strain. The next step is to balance the equipment and save the settings. Then the calibration process can start and then it will display a calibration number required to properly calculate the strain as seen in the following figure.

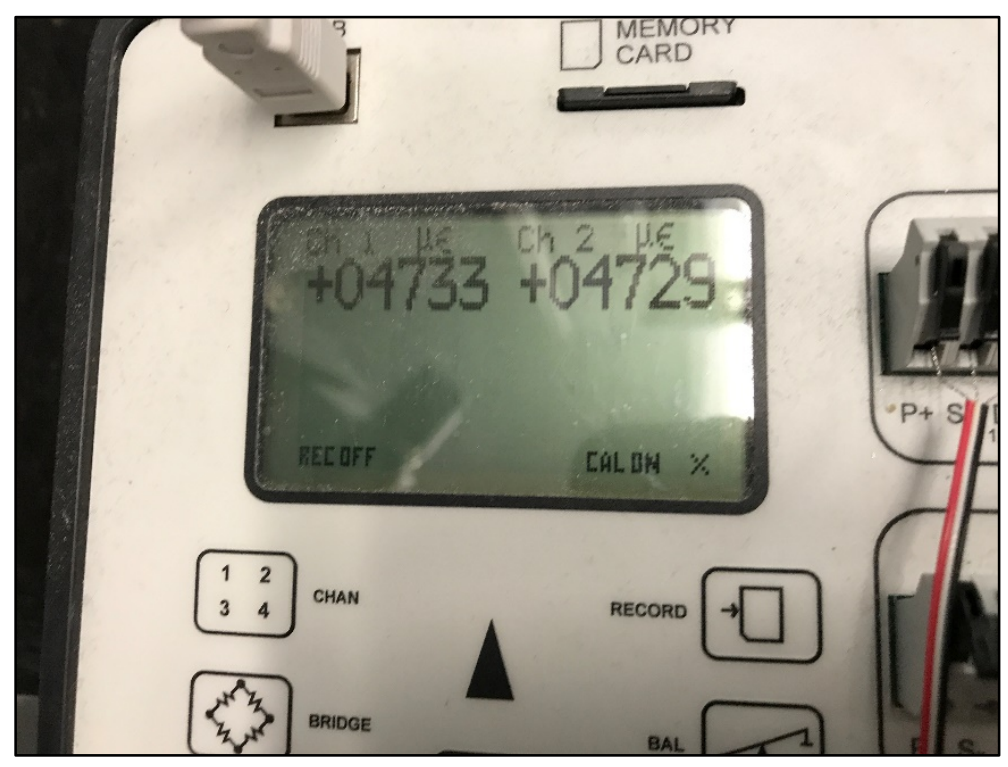

Figure 34. Calibration Data 
These two numbers will be used in a later calculation to find the exact strain that each gauge is measuring. After the calibration data is recorded, then the equipment should be balanced again to use a double check method so that the strain reading is the most accurate value possible. The strain recorded in the figure below can then be compared to the FEA report and simulation

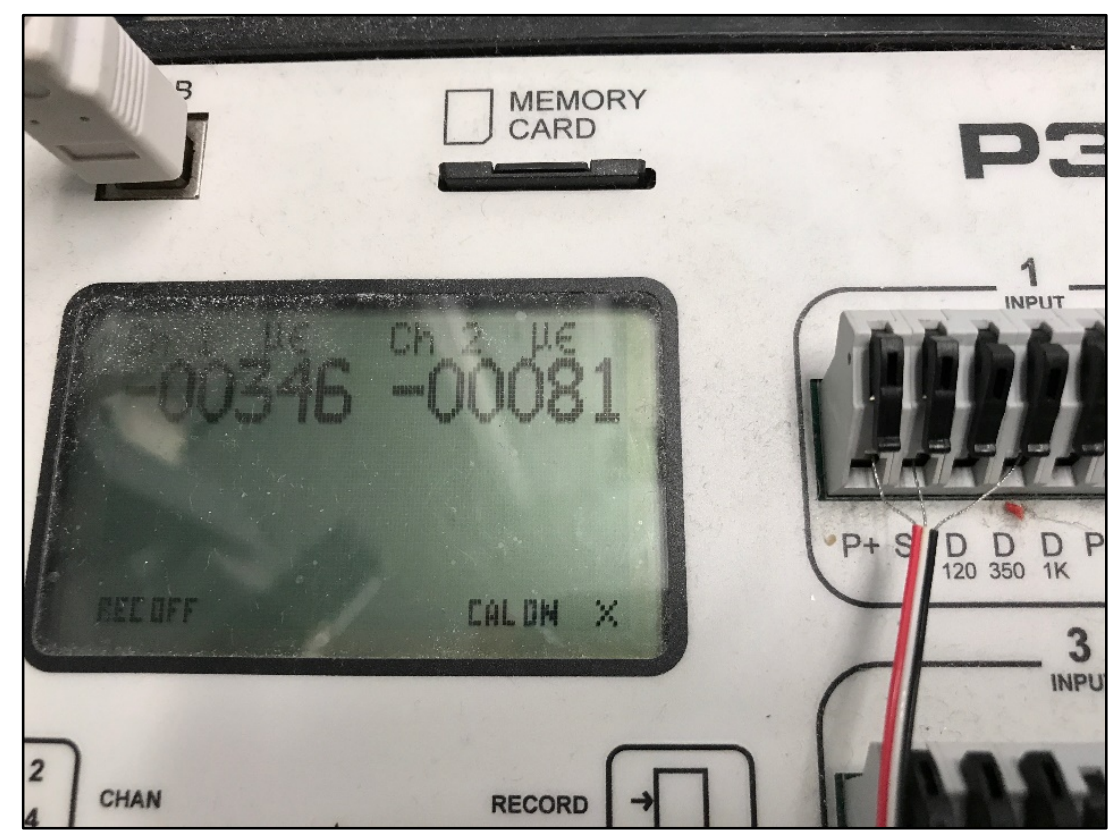

Figure 35. Recorded Strain 


\section{Final Design of a Vacuum Chamber}

\subsection{Final Design Approach}

When creating the final design for the vacuum chamber, there were three final variations to the design as suggestions. The first option was designed so that the acrylic cylinder would curve at the top to reduce the stress concentration at the edge of the cylinder similar to the vacuum chamber shown in the following figure.

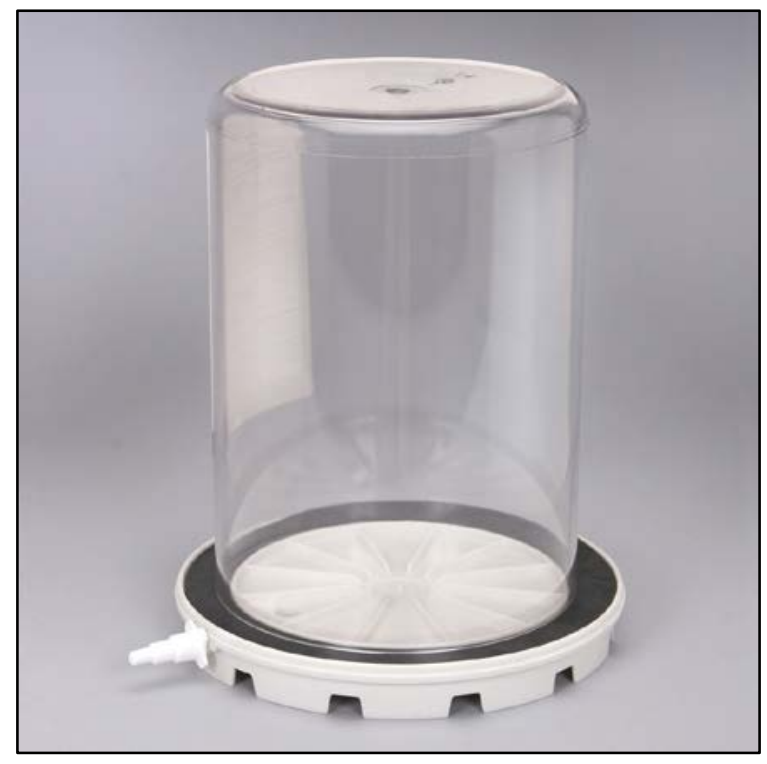

Figure 36. Final Design Option 1 [35]

The next option would be building a miniature vacuum chamber approximately 1:4 scale of the original vacuum chamber, shown in the figure below. 


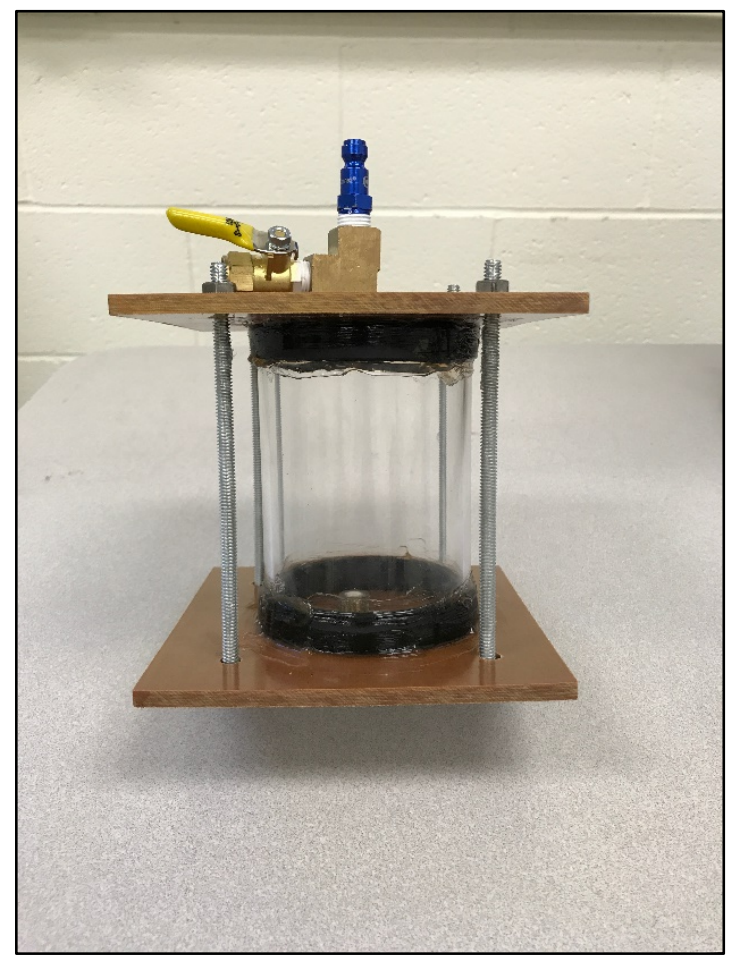

Figure 37. Final Design Option 2

The third option consisted on creating an extremely modular design that had the capability to have exchangeable acrylic cylinders with a lead screw connection that could adjust the distance between the top and bottom Garolite plates. Each option had their own benefits and contributions to future experiments and their disadvantages as well.

Option 1, the dome style acrylic vacuum chamber, had the advantage of the curvature at the top which reduced the stress concentration and increased its ability to withstand more stressful loading conditions. The downside is that the complex geometry would be a custom part would need to be manufactured and the manufacturing cost could go over budget for this design iteration.

Option 2, the micro vacuum chamber, had the properties of the preliminary design and was scaled down to an appropriate sized generating plasma. The disadvantage of this option is that smaller leaks have a larger impact on this design seeing that it is a 1:4 scale sized of the original 
model. This would mean the mass flow rate of a leak on the original model would be proportional to filling the Option 2 design four time faster. This would be done with the same vacuum pump and therefore the pump wouldn't be able to overcome the mass flow rate of the leak in the smaller chamber.

Option 3 had the benefits of easily exchanging acrylic cylinders to meet the requirements of the experiment at hand. This would allow multiple volumes to be used for experiments depending on the volume required. This design feature came from the lead screw that could adjust the gap between both Garolite plates from being flush with one another to as far apart as the length of the lead screw.

The decision for the design of a final FEA report was decided on by examining the geometry of each option. Since Option 1 would have different geometry compared to the original design unlike Options 2 and 3, then the final FEA report and simulation would be completed for Option 1 and compared with the results from the preliminary design. The analysis and simulation of the micro vacuum chamber would have been useful due to the scale of the chamber, but the surface area was reduced substantially and therefore the stress associated with the design was reduced as well. Option 3 would have multiple volume iterations to test and the basis of the design comes from the ability to exchange the acrylic cylinder of the vacuum chamber allowing the use of different volumes for experiments.

\subsection{Finite Element Analysis of the Final Design}

For the FEA report and simulation, the fixture on the model created for the study would be the same as the preliminary model by placing the bottom Garolite plate fixed and unable to deform. The next step was to apply the loading conditions which consist of gravity acting on all parts and an external pressure equal in magnitude to ambient atmospheric conditions at sea level 
to be placed on the entire surface of the dome and cylindrical chamber as seen in the figure below.

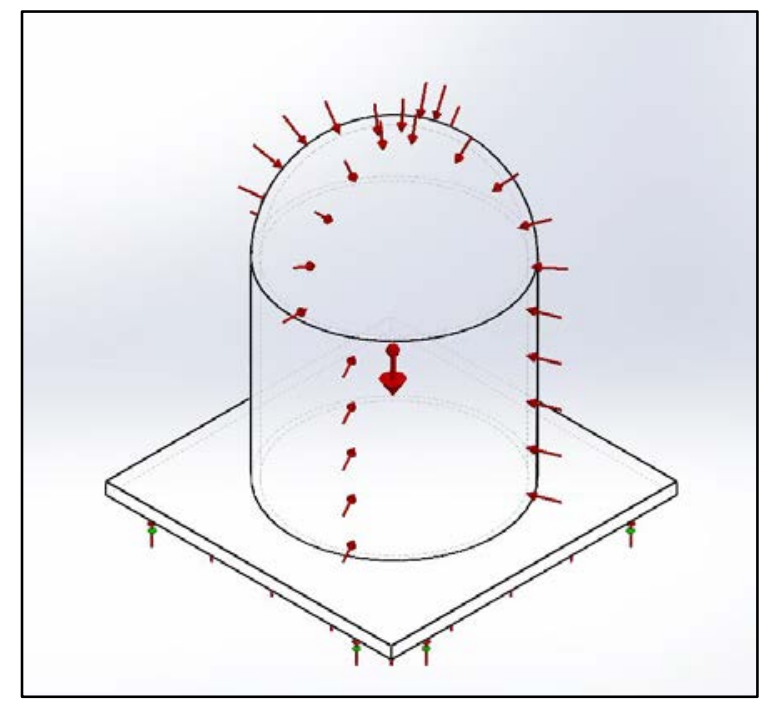

Figure 38. Final Design Loading

The materials selection would also be identical to the preliminary design by using Garolite as the base and medium impact acrylic as the container 


\section{Results}

\subsection{Functionality of the Preliminary Vacuum Chamber}

The structural design and versatility of the vacuum chamber was originally tested with an analog vacuum gage. This was to make sure the preliminary design could reach a 99\% vacuum before investing in a high accuracy digital vacuum gage. The initial testing of the vacuum chamber with analog gage resulted in some major problems. The vacuum gage's lowest reading was only $9 \mathrm{KPa}$ or approximately 10\% of atmospheric pressure as seen below.

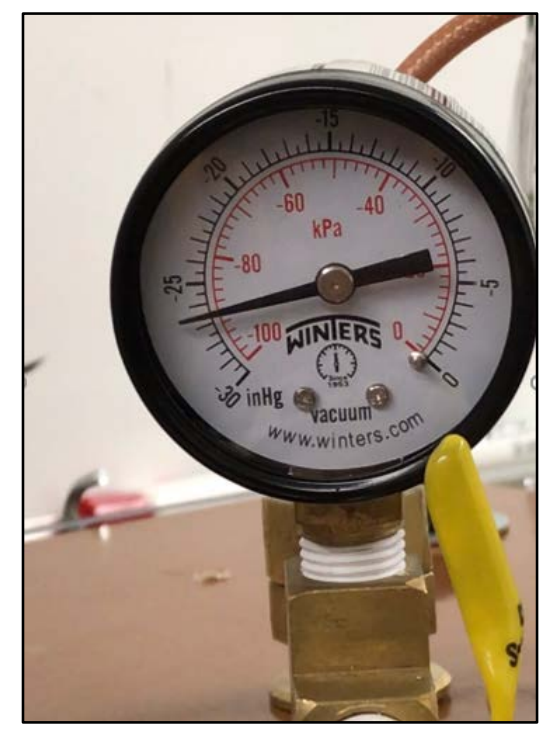

Figure 39. 9 Kilopascals on Analog Vacuum Gage

After checking for leaks in the threaded connections it was discovered that the plasma plug has a loose seal and was replaced with a threaded plug wrapped in Teflon tape. Once the largest leak was found and sealed, the vacuum chamber was tested again and reached a maximal vacuum gage reading as seen in the following figure. 


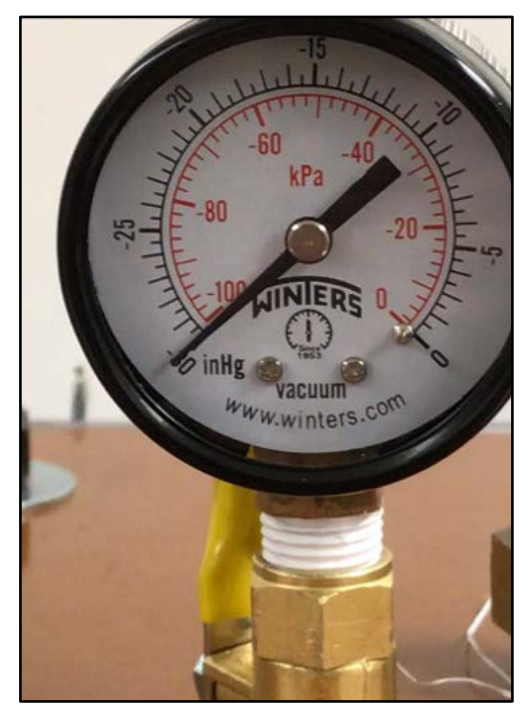

Figure 40. 99\% Vacuum on Analog Vacuum Gage

Now the analog vacuum gage was replaced with a digital vacuum gage to get more accurate readings. The digital vacuum gage selected measured in microns. Microns refers to pressure units of mmHg which is the measure of height of mercury manometer where 1 micron is $\mathbf{1 0}^{\mathbf{- 6}}$ meters. 1 micron converts to 1 milli-Torr or 0.001 Torr. 1 micron is also $0.133 \mathrm{~Pa}$ or 1. $933 \cdot \mathbf{1 0}^{-5}$ psi. The table below shows the percentage of a full vacuum for different units of pressure from atmospheric pressure all the way to a full vacuum.

Table 1. Vacuum

Table 5. Vacuum Percentage Pressure Scale [8] 


\begin{tabular}{|c|c|c|c|c|c|c|}
\hline $\begin{array}{c}\% \\
\text { Vacuum }\end{array}$ & $\begin{array}{c}\text { Torr } \\
\text { (mm Mercury) }\end{array}$ & Micron & $\begin{array}{l}\text { psia, } \\
\text { (Ib/in } \\
\text { abs) }\end{array}$ & $\begin{array}{l}\text { Inches } \\
\text { Mercury } \\
\text { Absolute }\end{array}$ & $\begin{array}{l}\text { Inches } \\
\text { Mercury } \\
\text { Gauge }\end{array}$ & $\begin{array}{l}k P a \\
a b s\end{array}$ \\
\hline 0.0 & 760.0 & 760,000 & 14.7 & 29.92 & 0.00 & 101.4 \\
\hline 1.3 & 750.0 & 750,000 & 14.5 & 29.5 & 0.42 & 99.9 \\
\hline 1.9 & 735.6 & 735,600 & 14.2 & 28.9 & 1.02 & 97.7 \\
\hline 7.9 & 700.0 & 700,000 & 13.5 & 27.6 & 2.32 & 93.5 \\
\hline 21.0 & 600.0 & 600,000 & 11.6 & 23.6 & 6.32 & 79.9 \\
\hline 34.0 & 500.0 & 500,000 & 9.7 & 19.7 & 10.22 & 66.7 \\
\hline 47.0 & 400.0 & 400,000 & 7.7 & 15.7 & 14.22 & 53.2 \\
\hline 50.0 & 380.0 & 380,000 & 7.3 & 15.0 & 14.92 & 50.8 \\
\hline 61.0 & 300.0 & 300,000 & 5.8 & 11.8 & 18.12 & 40 \\
\hline 74.0 & 200.0 & 200,000 & 3.9 & 7.85 & 22.07 & 26.6 \\
\hline 87.0 & 100.0 & 100,000 & 1.93 & 3.94 & 25.98 & 13.3 \\
\hline 88.0 & 90.0 & 90,000 & 1.74 & 3.54 & 26.38 & 12 \\
\hline 89.5 & 80.0 & 80,000 & 1.55 & 3.15 & 26.77 & 10.7 \\
\hline 90.8 & 70.0 & 70,000 & 1.35 & 2.76 & 27.16 & 9.3 \\
\hline 92.1 & 60.0 & 60,000 & 1.16 & 2.36 & 27.56 & 8 \\
\hline 93.0 & 51.7 & 51,700 & 1.00 & 2.03 & 27.89 & 6.9 \\
\hline 93.5 & 50.0 & 50,000 & 0.97 & 1.97 & 27.95 & 6.7 \\
\hline 94.8 & 40.0 & 40,000 & 0.77 & 1.57 & 28.35 & 5.3 \\
\hline 96.1 & 30.0 & 30,000 & 0.58 & 1.18 & 28.74 & 4 \\
\hline 96.6 & 25.4 & 25,400 & 0.49 & 1.00 & 28.92 & 3.4 \\
\hline 97.4 & 20.0 & 20,000 & 0.39 & 0.785 & 29.14 & 2.7 \\
\hline 98.7 & 10.0 & 10,000 & 0.193 & 0.394 & 29.53 & 1.3 \\
\hline 99.0 & 7.6 & 7,600 & 0.147 & 0.299 & 29.62 & 1.0 \\
\hline 99.87 & 1.0 & 1,000 & 0.01934 & 0.03937 & 29.88 & 0.13 \\
\hline 99.90 & 0.75 & 750 & 0.0145 & 0.0295 & 29.89 & 0.1 \\
\hline 99.99 & 0.10 & 100 & 0.00193 & 0.00394 & 29.916 & 0.013 \\
\hline 99.999 & 0.01 & 10 & 0.000193 & 0.000394 & 29.9196 & 0.0013 \\
\hline 100 & 0.00 & 0 & 0 & 0 & 29.92 & 0 \\
\hline
\end{tabular}

The vacuum pump was rated with having an ultimate vacuum $0.003 \mathrm{~Pa}$ or 25 microns. With connecting the vacuum gage directly to the vacuum pump to prevent any leakage, the result showed 4450 to 4500 microns with 3 significant figures.

The typical range the vacuum chamber would fluctuate between was 11,100 microns to 11,600 microns. The minimal pressure reading that was reached inside the vacuum chamber was 9600 microns. Significantly more than what the ultimate vacuum rating for the vacuum pump stated, but was appropriate considering the vacuum gage directly attached to the vacuum pump wash recorded to having reached 4500 microns.

\subsection{Comparison of the FEA Simulation and Strain Gauge Results}

The results from Solidworks had stated the maximum Von Misses stress occurred along the hoop orientation and located directly at the location of the acrylic coming into contact with the Garolite plate. The maximum recorded stress from the FEA report was 1.56 MPa. 
The strain gauge results would need to be multiplied by the Young's Modulus for medium impact acrylic to know what the developed stress was in both the hoop stress orientation and longitudinal stress orientation. The results from the strain gauge experiments had the maximum strain in hoop strain orientation to be 0.00346 measured on the micro scale and longitudinal strain orientation to have the strain recorded was 0.00081 measured on the micro scale. Both of the measurements for strain came back negative because the loading condition came from the ambient pressure pushing on the surface area of the cylinder and externally compressing it. Compared to pressure vessels where the pressure is greater internally and therefore causes the vessel to be in tension. Since the initial length is greater than the final length, is a logical conclusion that the strain would be negative with a compressive loading. The equation for strain shown below makes this observation more apparent in the understanding of the reading from the strain gauges.

$$
\epsilon=\frac{\Delta l}{l_{0}}
$$

\section{Equation 1. Strain}

By Hooke's Law, we can calculate the stress induced in the vacuum chamber by knowing the Young's modulus of the material in question and the strain produced and recorded by the strain gauges. The following formula is Hooke’s Law.

$$
\boldsymbol{\sigma}=\boldsymbol{E} \cdot \boldsymbol{\epsilon}
$$

\section{Equation 2. Hooke's Law}

The stress developed in the hoop orientation was $1.61 \mathrm{MPa}$ and for the longitudinal orientation, the stress was $0.989 \mathrm{MPa}$. 
Using the formula for calculating the hoop stress of a pressure vessel and inserting the dimensions of the vacuum chamber, the following stress was calculated.

$$
\begin{aligned}
\sigma_{\theta \text { cylinder }} & =P \cdot \frac{r}{t}=(14.7 p s i) \cdot\left(\frac{4 \text { inches }}{0.25 \text { inches }}\right)=235.2 \text { psi } \\
& =1.62 \mathrm{MPa}
\end{aligned}
$$

The longitudinal stress can also be calculated by using the condition from the figure below:

$$
\begin{aligned}
\sigma_{L}= & \frac{P \cdot \pi \cdot r^{2}}{\pi\left(R^{2}-r^{2}\right)}=\frac{14.7 p s i \cdot 4 \mathrm{in}^{2}}{4.25 \mathrm{in}^{2}-4 \mathrm{in}^{2}}=114.03 \mathrm{psi} \\
& =0.786 \mathrm{MPa}
\end{aligned}
$$

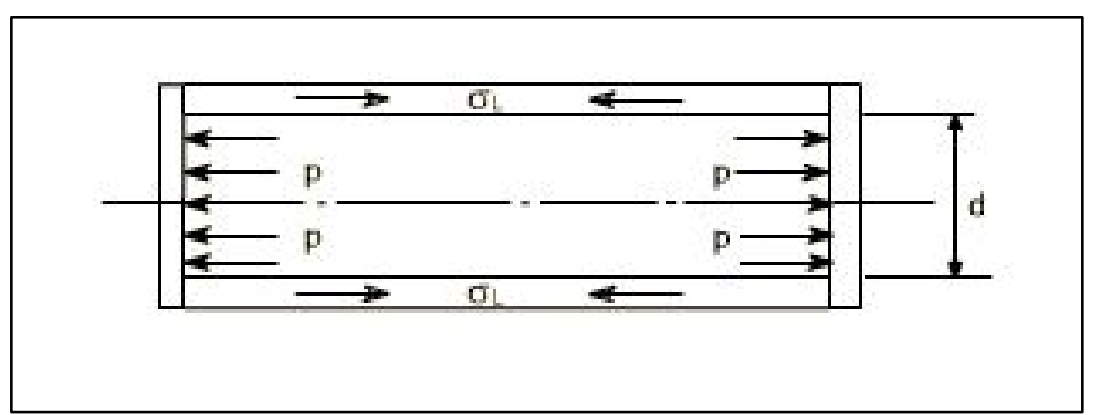

Figure 1. Axial Stress Developed in a Pressure Vessel [1]

[33]

The last calculation was to find the stress for a spherical pressure vessel and since the final design for Option 1 was chosen for the FEA simulation, then it would be necessary to examine the stress at the dome. The following equation calculates that stress.

$$
\begin{aligned}
\sigma_{\theta \text { sphere }} & =P \cdot \frac{r}{2 t}=(14.7 \mathrm{psi}) \cdot\left(\frac{4 \text { inches }}{2 \cdot 0.25 \text { inches }}\right) \\
& =117.6 \mathrm{psi}=0.81 \mathrm{MPa}
\end{aligned}
$$

Equation 3. Calculation for Spherical Hoop Stress 
This compared with the original design shows that the spherical dome design would reduce the maximum stress induced by a factor of 2 .

The results showed that the hoop orientation is more stressful and is obvious when observing the formulas for hoop stress and longitudinal stress since there is no combined loading and the only loading conditions are ambient pressure and the force of gravity.

\subsection{Plasma Igniter Application at Low Pressure and Vacuum Conditions}

With a vacuum pulled inside the chamber, the plasma igniter was able to generate a plasma corona. This led to a series of trials where the plasma igniter would be turned on and then a vacuum was pulled and the results of the diameter of the plasma corona were recorded. The next two figures show what the minimum and maximum plasma coronas are at atmospheric pressure and at a $98.8 \%$ vacuum respectively.

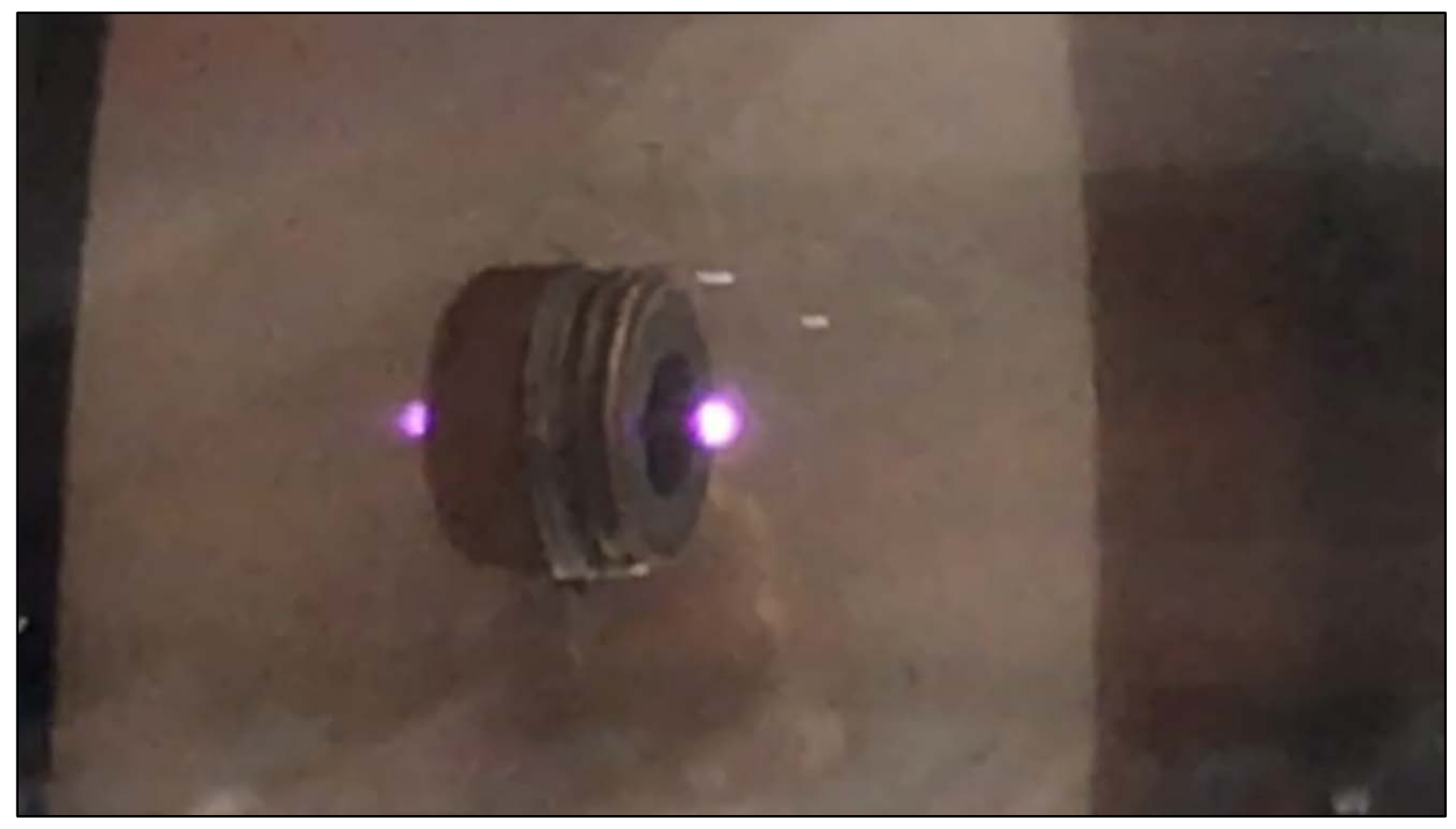

Figure 2. Minimum Plasma Corona 


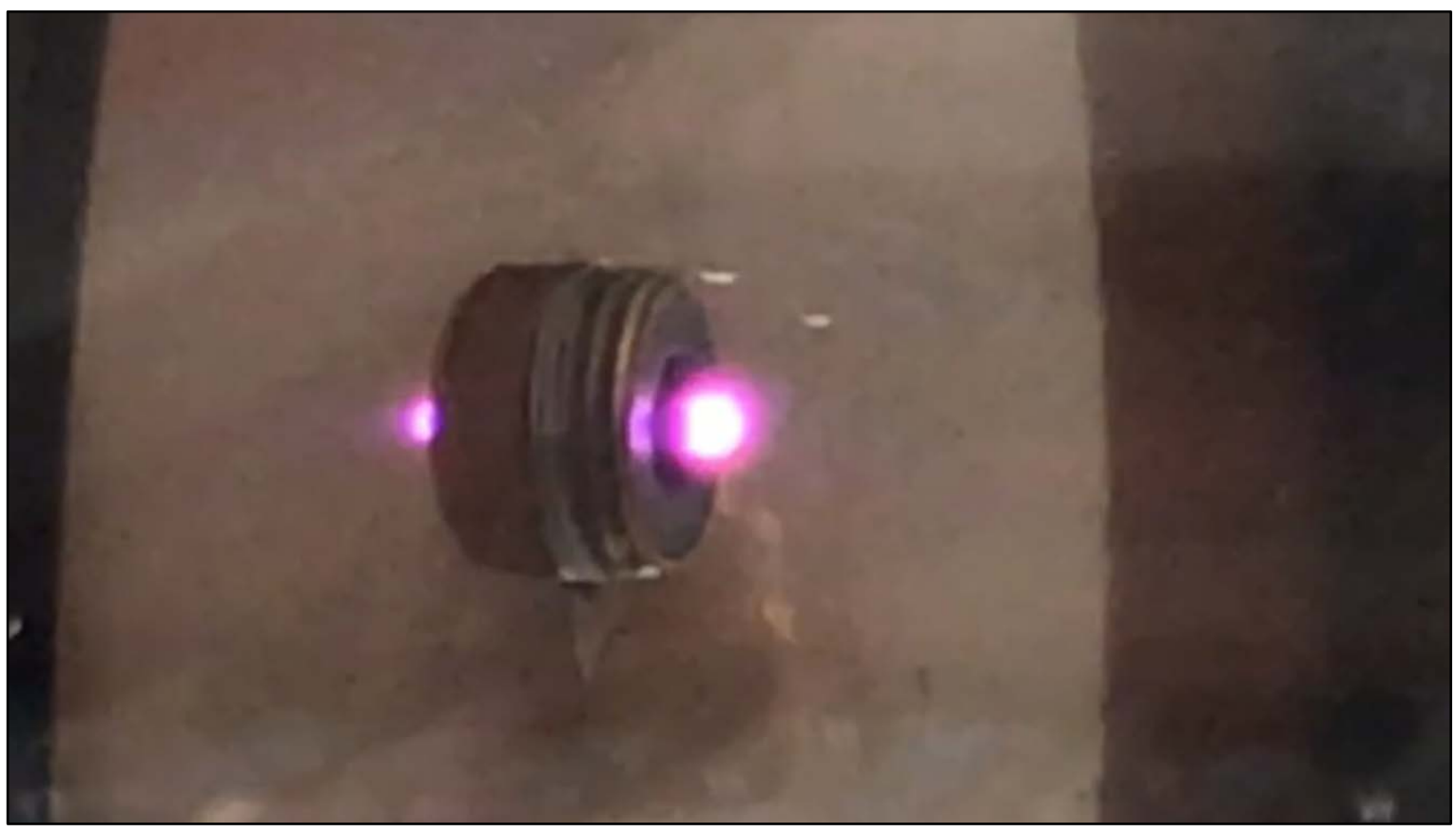

Figure 3. Maximum Plasma Corona

These two figures show that the experimental hypothesis was correct in the assumption that as pressure decreases, the diameter of the plasma corona will expand. Although the plasma reacted as expected, it had not reached the volume that was anticipated. It was theorized prior to running the experiment was that the plasma corona would grow to a diameter on the scale of centimeters and not remain on the order of magnitude for millimeters. While it did not reach that scale, it did grow by starting a $1.6 \mathrm{~mm}$ in diameter and growing to $2.1 \mathrm{~mm}$ in diameter for a $261 \%$ growth in volume at 11,500 microns of pressure. It should be noted that the power that was being supplied to the plasma igniter plug was measured along with the reflected power as well. For 100 watts of power being supplied, upwards of 22 watts were reflected through the signal generator. If this could be reduced so that more power is supplied to the plasma plug, the corona would grow even more. Another reason the growth of the plasma corona is limited is due to the fact that as the corona grew, it had become closer to the edge of the plasma plug and had 
grounded itself. To solve this problem another experiment was conducted involving two parallel aluminum plates.

\subsection{Parallel Plates and Plasma Arc Applications}

These experiments were conducted with parallel aluminum plates that had resulted in plasma arcing from plate to plate. These experiments had 20,000 volts being supplied from the high voltage power supply. By using another power supply, it could reach upwards of 40,000 volts which could be used in future experiments. The original parallel plate setup was so that the plates had a gap of around 8 inches as seen in the figure below.

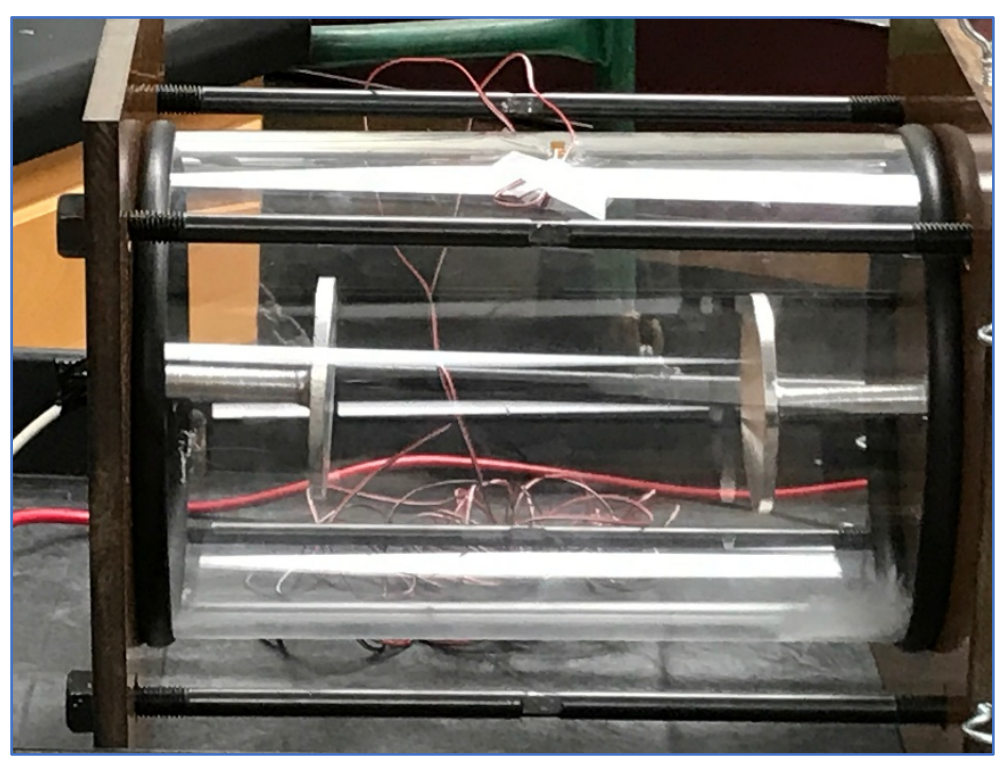

Figure 4. Parallel Plate Setup

After the first trial, it was clear from the small plasma arc jumping the gap that the plates needed to be closer so that the plasma had a path of least resistance that allows the plasma to grow and make arcs between the plates easier. The second trial had the parallel plates 6 inches away from each other. In future experiments, the rods supporting the plates could be extended so when completely threaded into the Garolite, the gap between parallel plates would be up to 2 inches away. The trials conducted had plates with threads that only allowed the minimum gap 
between plates to be 6 inches. Another observation was that the rough surface of the parallel plate could be the reason for the radical changes in path of least resistance for the plasma arcs hence the rapidly change plasma arcs during the experiment.

This shows the experiment was successful enough to have the vacuum chamber operate effectively with high voltage and plasma was able to arc from one aluminum plate to the other plate. From here, recommendations will be made to investigate how to further this application of plasma igniter technology and the potential for the manipulation of the plasma using magnetic fields. 


\section{Conclusions and Recommendations}

\subsection{Conclusions}

The findings from the results has led to conclusions about the design of the vacuum chamber, the improvements to the design, and experiments conducted inside the vacuum chamber. The first conclusion to be made from the results would be the validity of the vacuum chamber and the completed design. The functionality of the vacuum chamber was tested and completed showing that it could reach a $98.8 \%$ perfect vacuum at a level of 9600 microns. From there, the capability of the vacuum chamber was also tested to see that the preliminary design met the other original criteria such as having a factor of safety greater than 5 and staying within the budget and capable of generating plasma with the plasma igniter plug at pressures below atmospheric conditions.

The minimal pressure reached inside the vacuum chamber was 9600 microns and consistently stayed in the range of 11,100 to 11,600 microns. When comparing the direct connection between the vacuum gauge and vacuum pump, the pressure measure was 4450 to 4500 microns. This was acceptable overall as it was $99.4 \%$ of an absolute vacuum. When calculating the ratio of ultimate vacuum rating of the vacuum pump to the pressure when the vacuum gage was directly attached to the vacuum pump came out to being 25 microns to 4500 microns or 1:180. This was compared with the minimal vacuum gage reading to minimal pressure inside the vacuum chamber and came out to 4500 microns to 9600 microns or 15:32. This was considered acceptable as previously stated for being $98.8 \%$ of a perfect vacuum.

After the vacuum chamber results concluded the preliminary design for the vacuum chamber was operational, the next focus was on the plasma igniter plug and the experiments conducted inside the vacuum chamber. The plasma igniter was tested by turning on the power supply and signal generator then pulling a vacuum while recording the growth of the plasma corona over 
time. The minimum diameter for the plasma corona was 1.6 millimeters and maximum diameter was 2.1 millimeters. The difference between the minimum volume and maximum volume of the plasma corona with the assumptions that is was spherical, was a growth of $261 \%$ in a vacuum at 11,500 microns. It was believed that it would have continued to grow if the was more power being supplied, if the pressure had reached value less than 11,500 microns, or if it had not grounded itself to the plasma plug ground.

This issue was resolved by conducting another experiment with two aluminum parallel plates, attached at the bottom of the vacuum chamber and another attached to the top of the vacuum chamber. By pulling a vacuum, it allowed the plasma to arc from plate to plate by reducing the resistance to travel distances creating the path of least resistance for the plasma. The plates were originally tested where the plates were separated by 8 inches. They were later threaded into the chamber even further to reduce the distance to approximately 6 inches between the plates. This allowed the plasma to arc with less voltage and allowed it to rapidly arc to multiple locations on each plate. Ideally the plates could get within 2 inches of each other and generate multiple stabilized arcs of plasma.

With the FEA report generated from the simulation on Solidworks, it was important to validate the simulation results with data collected from strain gauges to know that the generated conditions in the simulation were accurate to real world conditions. The maximum recorded stress from the FEA report was 1.56 MPa.

The stress developed in the hoop orientation was 1.62 MPa and for the longitudinal orientation, the stress was $0.786 \mathrm{MPa}$.

The comparison of the final design's hoop stress was $0.81 \mathrm{MPa}$ versus the preliminary design's hoop stress that was 1.62 MPa. The difference was a factor of 2 which occurred from 
the stress equations for a pressure vessel that is cylindrical like the preliminary design and spherical like the final design.

\subsection{Recommendations}

The instructions for furthering the research would consist of adding data acquisition sensors and hardware, using different gases to flush the vacuum chamber and test the plasma igniter, and using external and internal magnets to focus on the manipulation of the plasma coronas and plasma arcs inside the chamber.

The first set of recommendations are for the addition of data acquisition sensors and equipment. A vacuum gage is already equipped on the current model, but some other beneficial sensors would be a pressure gage alongside the vacuum gage. This could lead to pressurized experimentation inside the vacuum chamber, but would need to simulate another FEA simulation in Solidworks prior to experimentation to guarantee the safety of personnel operating the unit since failure would most likely result in projectiles that could prove to be dangerous and even life threatening.

Another sensor that would be beneficial would be to add a thermocouple to measure the temperature inside the vacuum chamber for experiments with other gases inside or pressurized experiments. Another recommendation would be to seek Type $\mathrm{J}$ and Type $\mathrm{K}$ thermocouples from Omega engineering to add as sensors to the vacuum chamber.

It is also recommended to add a port to the bottom side of the Garolite plate. This port could be used for a viewport to record images and videos in the UV and IR spectrums to observe the nature of the plasma corona and plasma arcs. The viewport would benefit the most from being made of Sapphire for clarity and strength, but is an expensive addition to the chamber that would be outside the current budget. 
With these sensors and data acquisition equipment, it would make sense to have a system that could be operated from a remote location for safety and convenience purposes. Another reason for controlling from a remote region would be the ability to record and run experiments with high voltage conditions. With a properly established data acquisition system, the control of the experiments could be done through the use of Simulink and MATLAB.

The second set of recommendations are to conduct experiments with different gases filled in the chamber and seeing how the plasma reacts. By flushing the chamber with different gases instead of pulling a vacuum, there might be some observations on how the plasma changes in different environments. Some examples of gases that might be interesting to conduct experiments with would be gases such as Neon, Argon, and Nitrogen to name a few. To have a system replaced with these gases, a vacuum would be pulled to purge the chamber of air. Then a second valve would fill the vacuum with a gas of choice and then conduct the experiments. In case safety with certain gases are a concern, by using the data acquisition control previously mentioned, the test could be performed from an external location for safety and easily control the experiment.

The final set of recommendations are to conduct experiments with external and internal magnetic fields in reference to the vacuum chamber and try to manipulate the plasma corona and arcs generated. Since plasma is ionized gas, then the electron field that is contained in the plasma can become impacted from magnetic fields. These magnetic field could be generated outside the vacuum chamber or inside the vacuum chamber. The externally generated magnetic fields used to manipulate the plasma would most likely be in the form of permanent magnets such as neodymium magnets. These could be attach by some linear slide rail on the side of the steel 
support rods and reach anywhere along the outside surface of the acrylic in an attempted to move the plasma corona or plasma arcs between the parallel aluminum plates.

The other experiment that could be conducted in an attempt to use magnetic fields to manipulate the plasma generated inside the vacuum chamber would be to create an electromagnet connected to the plasma igniter plug and pulse a magnetic field through the electromagnet. The execution of this experiment would be require similar additions as the externally condition, but yield better results since the magnetic field could be stronger directly next to the plasma itself. The implantation would be start by wrapping magnetic wire in a coil around the plasma igniter. The magnetic wire would be connected to a controllable power supply that would have current flow through the magnetic wire and produce an induced magnetic field. By generating electromagnetic pluses at the tip of the plasma igniter plug, then it might be possible to have the plasma corona leave the plasma igniter tip and travel down the length of the vacuum chamber. If this is possible, there are a host of applications that can stem from this capability with medical, pharmaceutical, and nanoscale manufacturing being some of the sectors that would be impacted from this technology. 


\section{$\underline{\text { References }}$}

[1] J. Smith, Plamsa, DC, 2017. 


\section{Appendix A Preliminary Solidworks FEA Report}

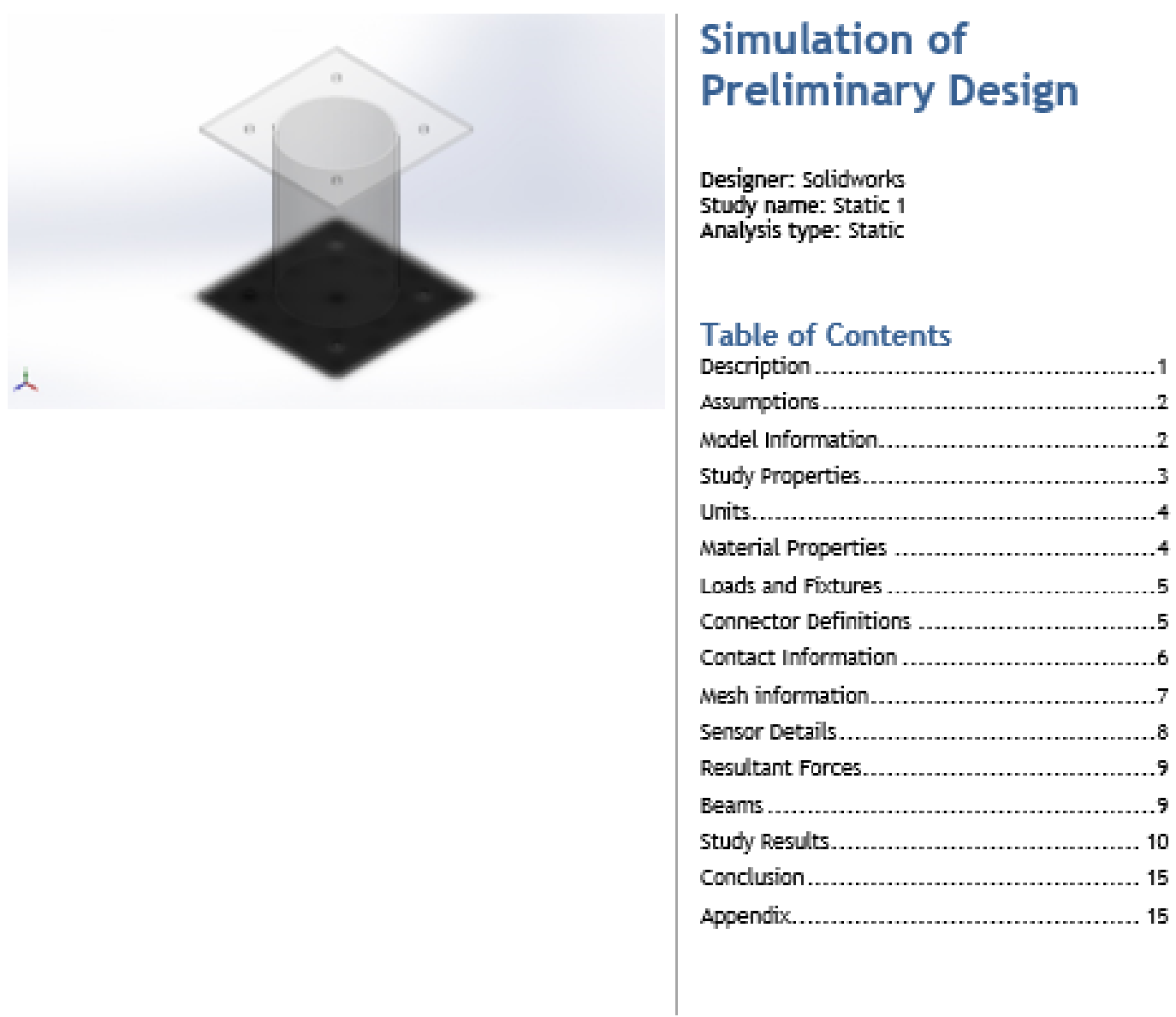


Model Information

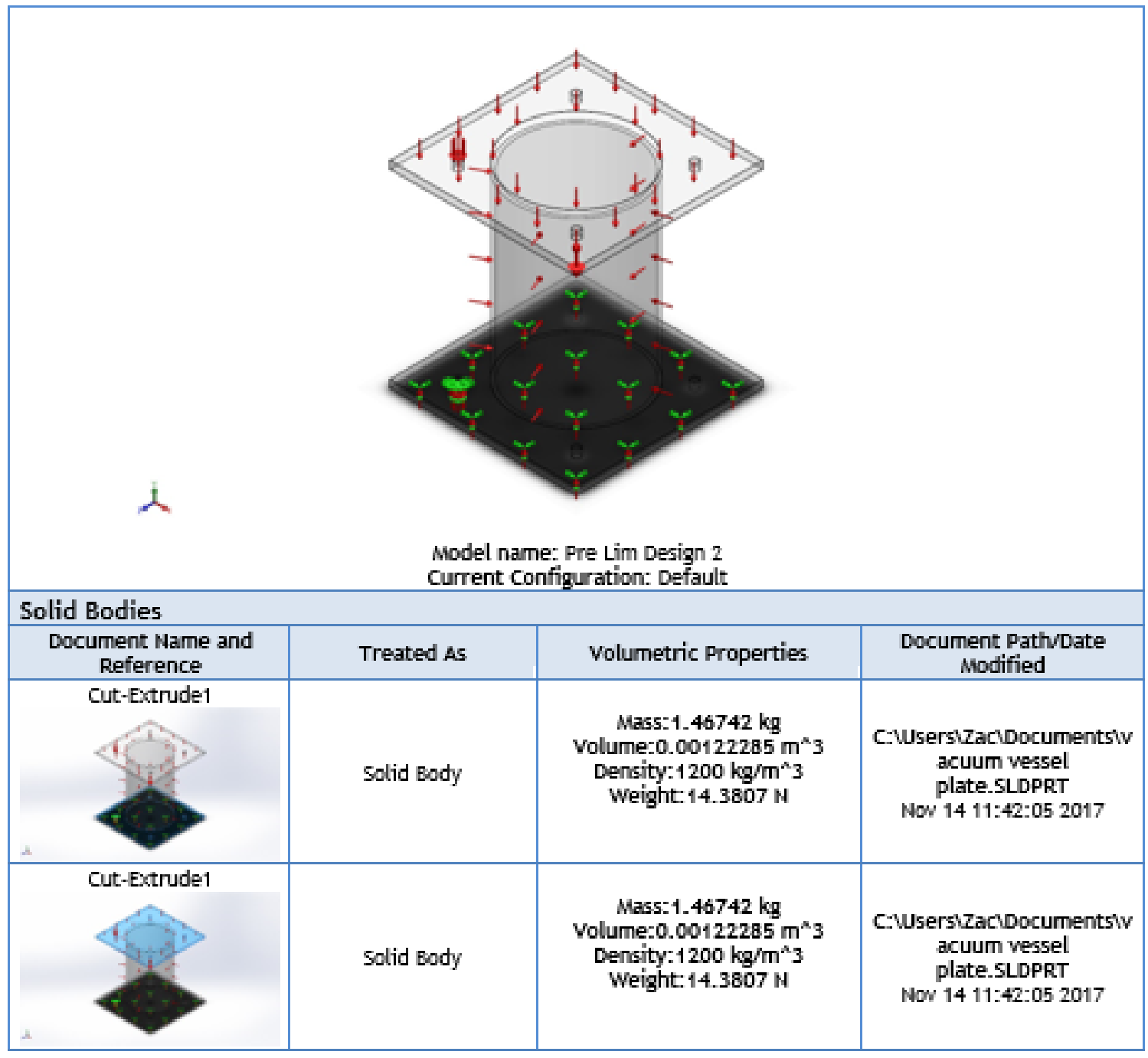




\begin{tabular}{|c|c|c|c|}
\hline Boss-Extrude1 & & & \\
\hline & Solid Body & $\begin{array}{l}\text { Mass:1.43633 kg } \\
\text { Volume:0.00119694 m³ } \\
\text { Density:1200 kg/m³ } \\
\text { Weight:14.0761 N }\end{array}$ & $\begin{array}{l}\text { C:NusersiZacidocumentsiv } \\
\text { acuum vessel.SLDPRT } \\
\text { Now } 14 \text { 11:42:07 2017 }\end{array}$ \\
\hline & & & \\
\hline
\end{tabular}

\section{Study Properties}

\begin{tabular}{|l|l|}
\hline Study name & Static 1 \\
\hline Analysis type & Static \\
\hline Mesh type & Solid Mesh \\
\hline Thermal Effect: & On \\
\hline Thermal option & Include temperature loads \\
\hline Zero strain temperature & 298 Kelvin \\
\hline Include fluid pressure effects from SOLIDWORKS & Off \\
\hline Flow Simulation & EFERlus \\
\hline Inplane Effect: & Off \\
\hline Soft Spring: & Off \\
\hline Inertial Relief: & Off \\
\hline Incompatible bonding options & Automatic \\
\hline Large displacement & Off \\
\hline Compute free body forces & On \\
\hline Friction & Off \\
\hline Use Adaptive Method: & Off \\
\hline Result folder & SoLIDWORKS document (C:NUsersizaciDocuments) \\
\hline
\end{tabular}


Units

\begin{tabular}{|l|l|}
\hline Unit system: & SI (MKS) \\
\hline Length/Displacement & $\mathrm{mm}$ \\
\hline Temperature & Kelvin \\
\hline Angular velocity & $\mathrm{Rad} / \mathrm{sec}$ \\
\hline Pressure/Stress & $\mathrm{N} / \mathrm{m}^{\wedge} 2$ \\
\hline
\end{tabular}

Material Properties

\begin{tabular}{|c|c|c|c|}
\hline \multirow[t]{2}{*}{ Model Reference } & \multicolumn{2}{|c|}{ Properties } & \multirow{2}{*}{\begin{tabular}{l}
\multicolumn{1}{c}{ Components } \\
Solidkody 1 (Cut- \\
Bstouded)(vacuum vessel \\
plate-1), \\
Solidkodx 1 (Cut- \\
Bctodded) (vacuum vessel \\
plate-2)
\end{tabular}} \\
\hline & $\begin{array}{r}\text { Name: } \\
\text { Model type: } \\
\text { Default failure } \\
\text { criterion: } \\
\text { Yield strength: } \\
\text { Tensile strength: } \\
\text { Compressive } \\
\text { strength: } \\
\text { Elastic modulus: } \\
\text { Poisson's ratio: } \\
\text { Mass density: } \\
\text { Shear modulus: } \\
\text { Thermal expansion } \\
\text { coefficient: }\end{array}$ & $\begin{array}{l}\text { Garolite } \\
\text { Linear Elastic Isotropic } \\
\text { Unknown } \\
4.5 \mathrm{e}+007 \mathrm{~N} / \mathrm{m}^{2} 2 \\
8.96318 \mathrm{e}+007 \mathrm{~N} / \mathrm{m}^{\prime} 2 \\
2.34422 \mathrm{e}+008 \mathrm{~N} / \mathrm{m}^{\prime} 2 \\
\\
3 \mathrm{e}+009 \mathrm{~N} / \mathrm{m}^{\wedge} 2 \\
0.35 \\
1200 \mathrm{~kg} / \mathrm{m}^{\wedge} 3 \\
8.9 \mathrm{e}+008 \mathrm{~N} / \mathrm{m}^{\prime} 2 \\
5.2 \mathrm{e} \cdot 005 / \mathrm{Kelvin}\end{array}$ & \\
\hline \multicolumn{4}{|l|}{ Curve Data:W/A } \\
\hline$\alpha$ & $\begin{array}{r}\text { Name: } \\
\text { Model type: } \\
\text { Default failure } \\
\text { criterion: } \\
\text { Yield strength: } \\
\text { Tensile strength: } \\
\text { Elastic modulus: } \\
\text { Poisson's ratio: } \\
\text { Mass density: } \\
\text { Shear modulus: } \\
\text { Thermal expansion } \\
\text { coefficient: }\end{array}$ & $\begin{array}{l}\text { Manual Acrylic } \\
\text { Linear Elastic Isotropic } \\
\text { Unknown } \\
4.13685 \mathrm{e}+007 \mathrm{~N} / \mathrm{m}^{2} 2 \\
7.58423 \mathrm{e}+007 \mathrm{~N} / \mathrm{m}^{2} 2 \\
3.2 \mathrm{e}+009 \mathrm{~N} / \mathrm{m}^{2} 2 \\
0.35 \\
1200 \mathrm{~kg} / \mathrm{m}^{\wedge} 3 \\
8.9 \mathrm{e}+008 \mathrm{~N} / \mathrm{m}^{\prime} 2 \\
5.2 \mathrm{e}-005 / \text { Kelvin }\end{array}$ & $\begin{array}{l}\text { SolidBodx } 1 \text { (Boss- } \\
\text { Ectouded) (vacuum vessel-1) }\end{array}$ \\
\hline
\end{tabular}


Loads and Fixtures

\begin{tabular}{|c|c|c|c|c|}
\hline Fixture name & Fixture Image & \multicolumn{2}{c|}{ Fixture Details } \\
\hline & \multicolumn{3}{|c|}{$\begin{array}{c}\text { Entities: } 1 \text { face(s) } \\
\text { Type: Fixed Geometry }\end{array}$} \\
Fixed-2 & & & \\
& & & \\
\hline
\end{tabular}

\begin{tabular}{|c|c|c|c|}
\hline Load name & Load Image & \multicolumn{2}{|c|}{ Load Details } \\
\hline Gravity-1 & + & $\begin{array}{l}\text { Reference: } \\
\text { Values: } \\
\text { Units: }\end{array}$ & $\begin{array}{l}\text { Top Plane } \\
0 \quad 0-9.81 \\
\text { Sl }\end{array}$ \\
\hline Pressure-3 & $\alpha$ & $\begin{array}{r}\text { Entities: } \\
\text { Type: } \\
\text { value: } \\
\text { Units: } \\
\text { Phase Angle: } \\
\text { Units: }\end{array}$ & $\begin{array}{l}4 \text { face(s), } 1 \text { plane(s) } \\
\text { Narmal to selected face } \\
14.5038 \\
\text { psi } \\
0 \\
\text { des }\end{array}$ \\
\hline
\end{tabular}

\title{
Connector Definitions
}

\author{
No Data
}




\section{Contact Information}

\begin{tabular}{|c|c|c|}
\hline Contact & Contact Image & Contact Properties \\
\hline & & Type: Bonded \\
Global Contact & & \\
& & \\
\hline
\end{tabular}


Mesh information

\begin{tabular}{|l|l|}
\hline Mesh type & Solid Mesh \\
\hline Mesher Used: & Standard mesh \\
\hline Automatic Transition: & Off \\
\hline Include Mesh Auto Loops: & Off \\
\hline Jacobian points & 4 Points \\
\hline Element Size & 0.706796 in \\
\hline Tolerance & 0.0353398 in \\
\hline Mesh Quality & High \\
\hline Rerreshfailed parts with incompatible mesh & Off \\
\hline
\end{tabular}

Mesh information - Details

\begin{tabular}{|l|l|}
\hline Total Nodes & 17370 \\
\hline Total Elements & 8835 \\
\hline Maximum Aspect Ratio & 11.546 \\
\hline \% of elements with Aspect Ratio < 3 & 65.2 \\
\hline \% of elements with Aspect Ratio > 10 & 0.0679 \\
\hline \% of distorted elements(Jacobian) & 0 \\
\hline Time to complete mesh(bh:ma:s5): & $00: 00: 01$ \\
\hline Computer name: & \\
\hline
\end{tabular}




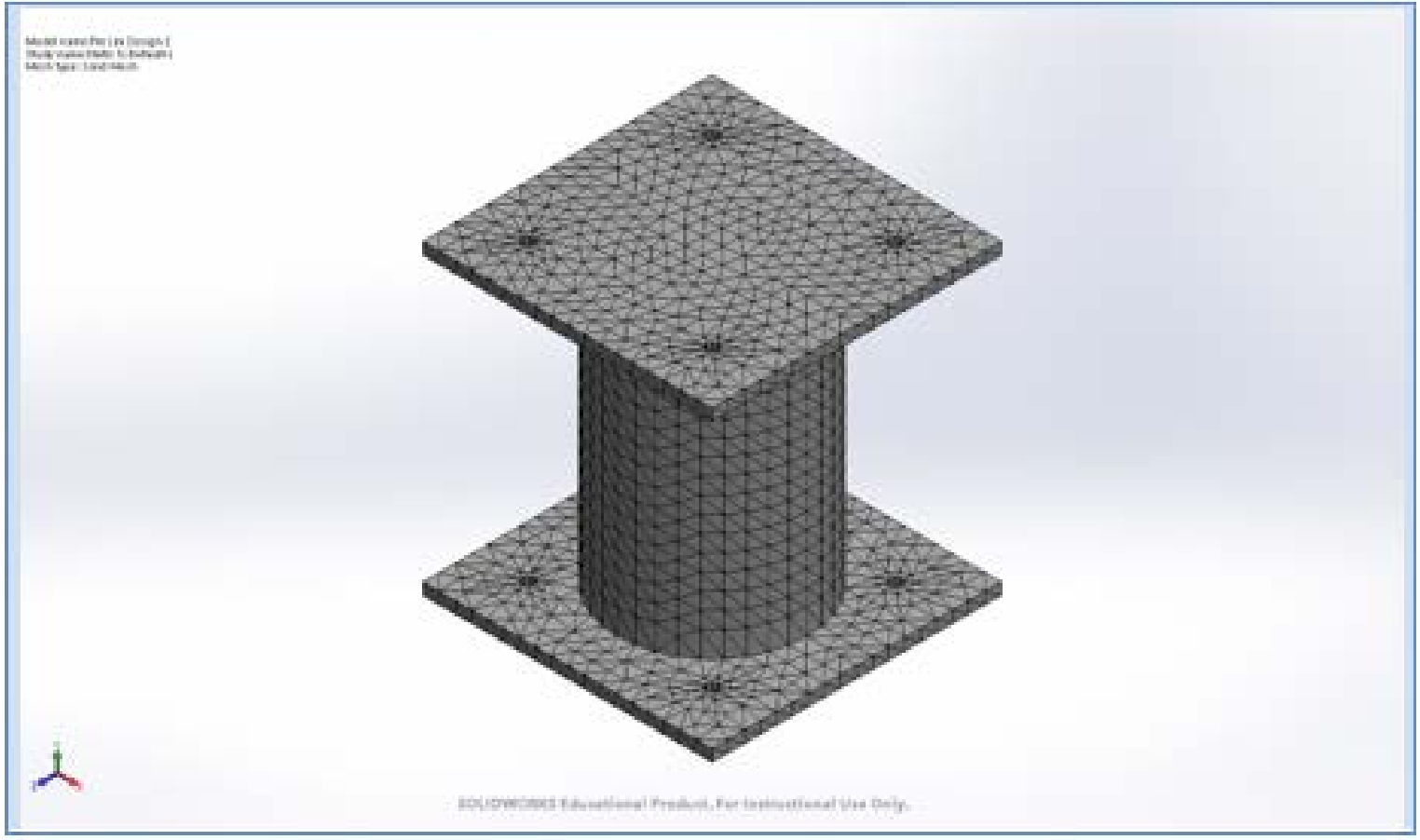

Sensor Details

\begin{tabular}{|c|c|c|}
\hline Sensor name & Location & Sensor Details \\
\hline Stress1 & 2 & $\begin{array}{l}\text { Value : } \\
\text { Entities : } \\
\text { Result : Stress } \\
\text { Component : VoN: von Mises Stress } \\
\text { Criterion :Model Max } \\
\text { Step Criterion : Across all steps } \\
\text { Step No::1 } \\
\text { Alert Value: NA }\end{array}$ \\
\hline
\end{tabular}




\section{Resultant Forces}

\section{Reaction forces}

\begin{tabular}{|l|l|l|l|l|l|}
\hline Selection set & Units & Sum X & Sum Y & Sum Z & Resultant \\
\hline Entire Model & N & -0.278328 & 36.5987 & -0.61153 & 37.0048 \\
\hline
\end{tabular}

\section{Reaction Moments}

\begin{tabular}{|l|l|l|l|l|l|}
\hline Selection set & Units & Sum X & Sum Y & Sum Z & Resultant \\
\hline Entire Model & $N_{6} \infty 0$ & 0 & 0 & 0 & 0 \\
\hline
\end{tabular}

Beams

No Data 


\section{Study Results}

\begin{tabular}{|l|l|l|l|}
\hline Name & Type & Min & Max \\
\hline Stress1 & VON: von Nises Stress & $\begin{array}{l}35.0149 \mathrm{~N} / \mathrm{m}^{\wedge} 2 \\
\text { Node: } 147\end{array}$ & $\begin{array}{l}1.12066 \mathrm{e}+007 \mathrm{~N} / \mathrm{m}^{\wedge} 2 \\
\text { Node: } 5714\end{array}$ \\
\hline & & & \\
\hline
\end{tabular}

\begin{tabular}{|l|l|l|l|}
\hline Name & Type & Min & Max \\
\hline Displacement1 & URE5: Resultant Displacement & $\begin{array}{l}0 \mathrm{~mm} \\
\text { Node: } 73\end{array}$ & $\begin{array}{l}3.92587 \mathrm{~mm} \\
\text { Node: } 5775\end{array}$ \\
\hline
\end{tabular}




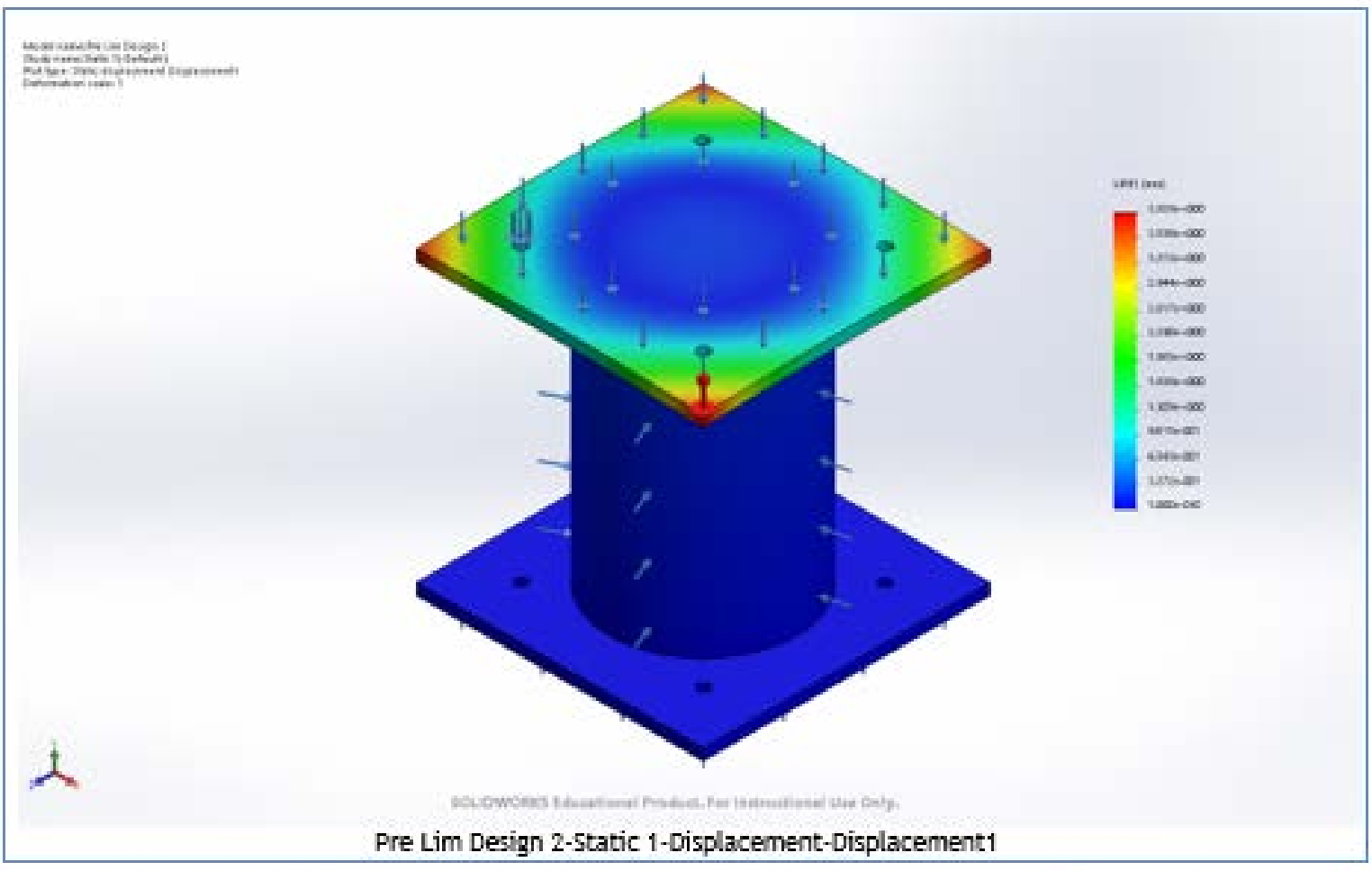

\begin{tabular}{|l|l|l|l|}
\hline Name & Type & Min & Max \\
\hline Strain1 & ESTRN: Equivalent Strain & $\begin{array}{l}1.75514 \mathrm{e}-008 \\
\text { Element: 50 }\end{array}$ & $\begin{array}{l}0.00239914 \\
\text { Element: 5255 }\end{array}$ \\
\hline
\end{tabular}




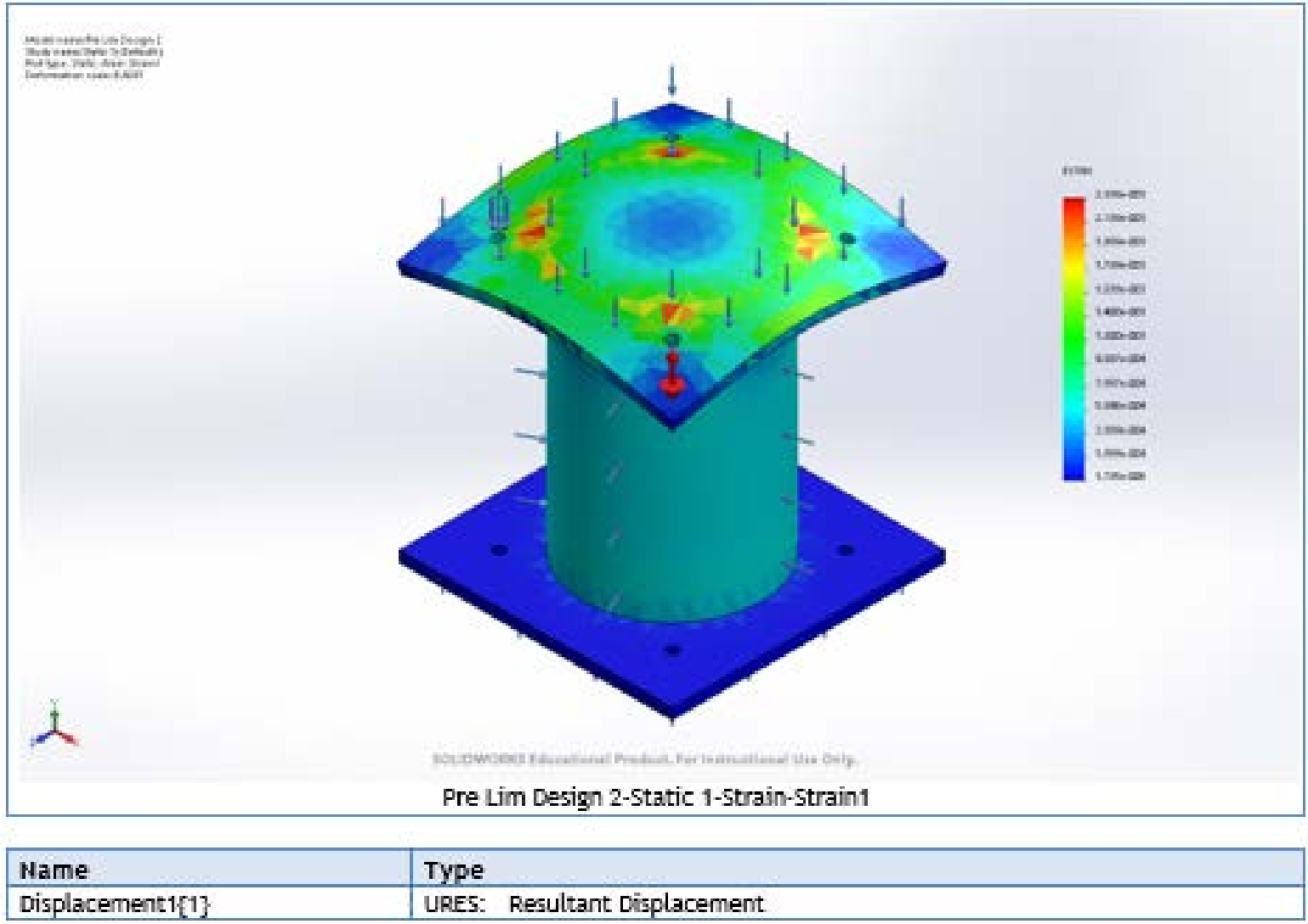




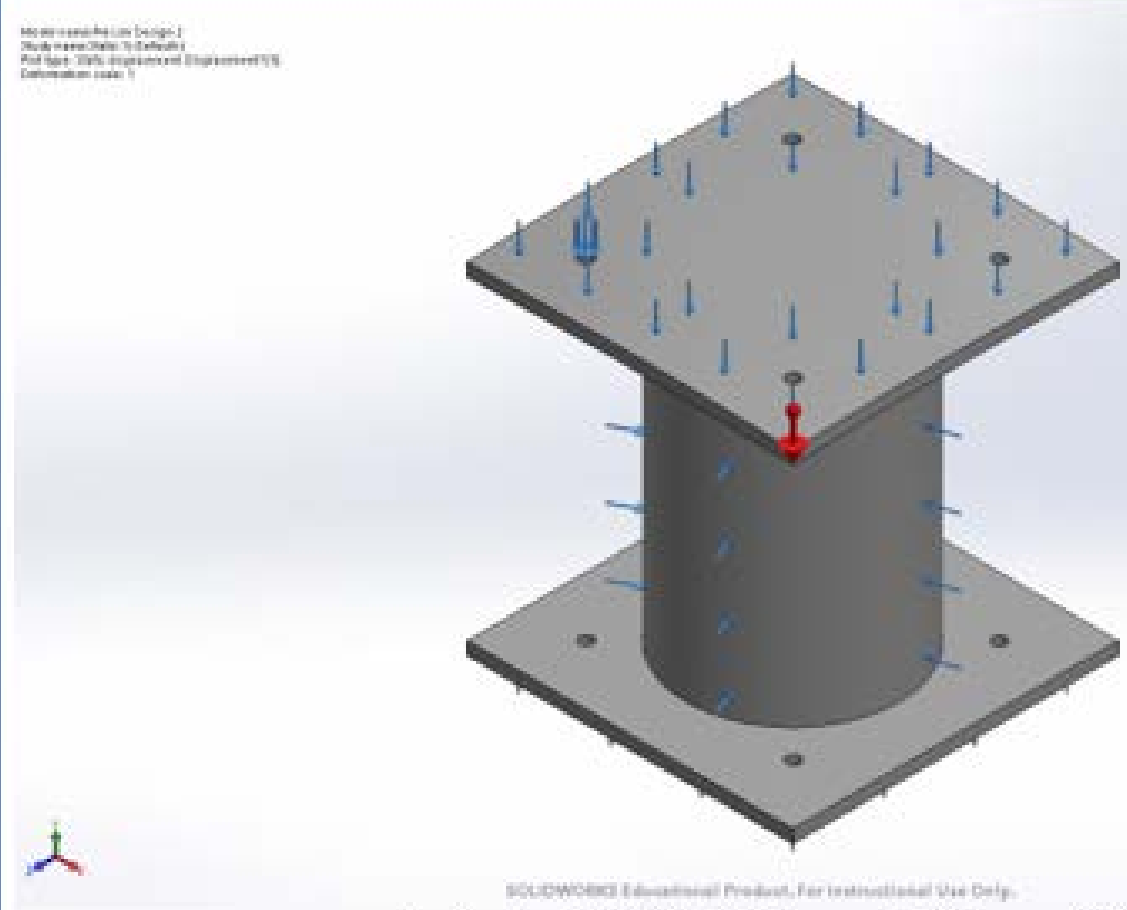

Pre Lim Design 2-Static 1-Displacement-Displacement1 $\{1\}$

\begin{tabular}{|l|l|l|l|}
\hline Name & Type & Min & Max \\
\hline Factor of Safety1 & Automatic & $\begin{array}{l}3.63169 \\
\text { Node: 5656 }\end{array}$ & $\begin{array}{l}1.28517 e+006 \\
\text { Node: 147 }\end{array}$ \\
\hline
\end{tabular}




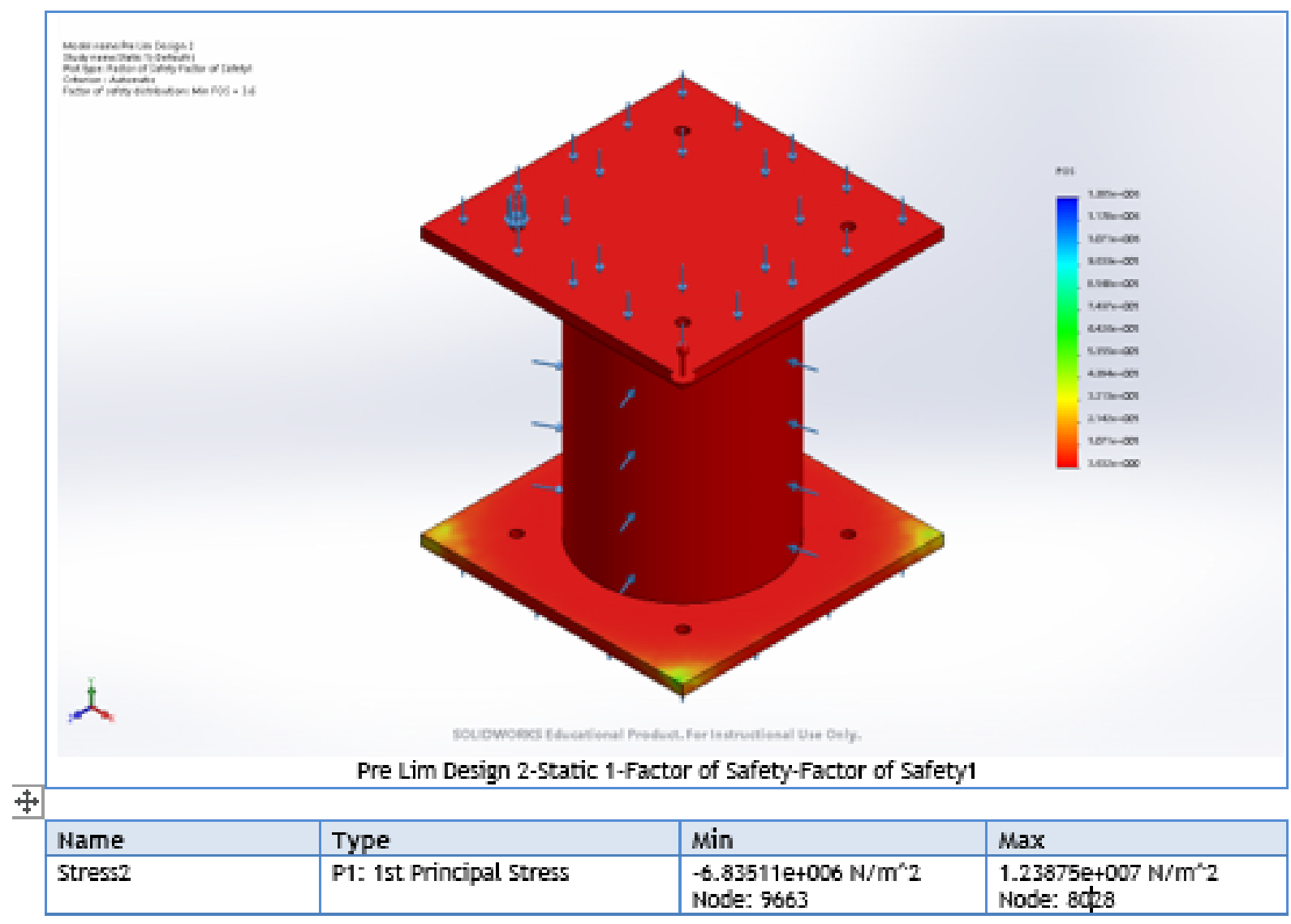




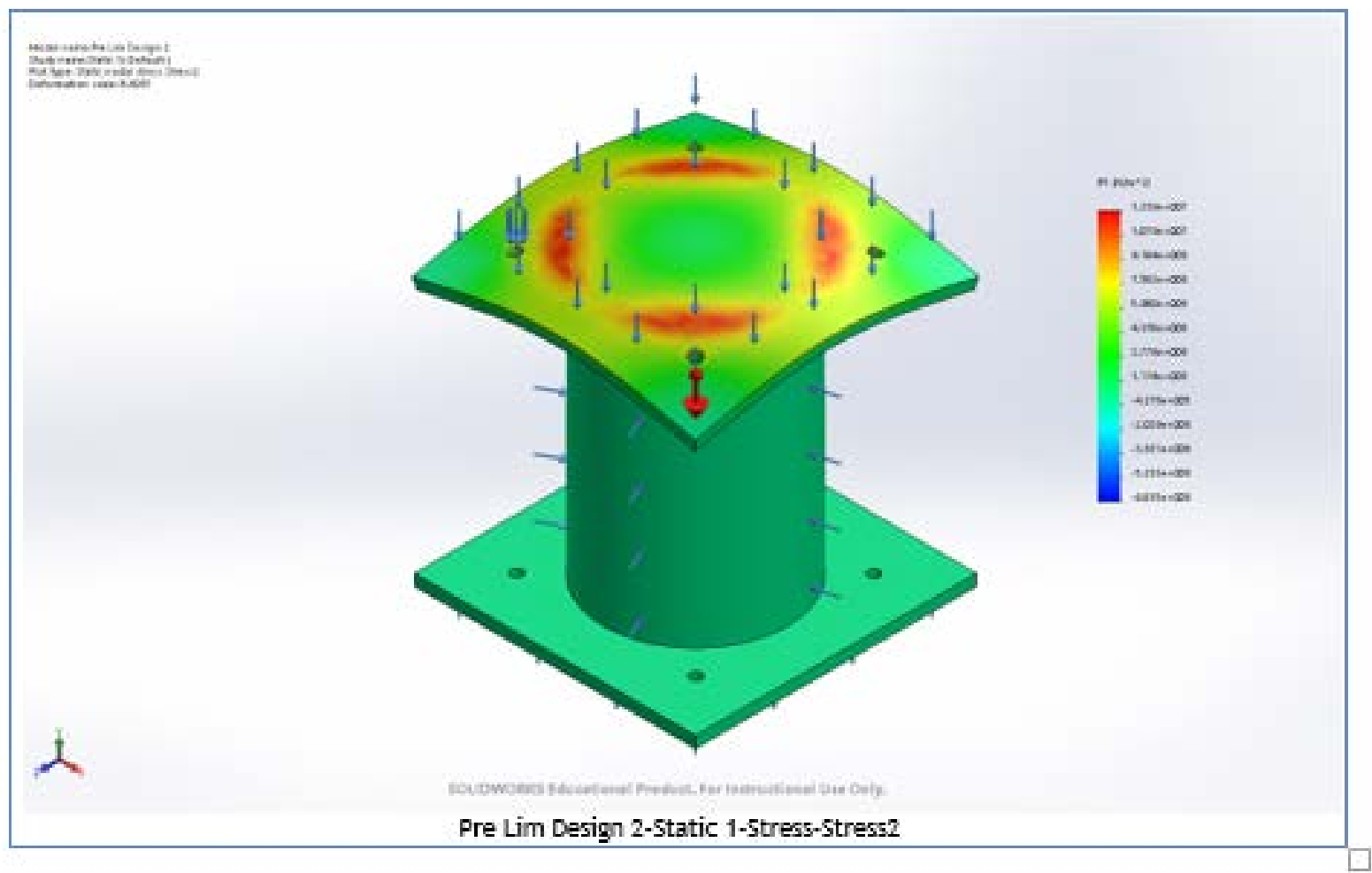




\section{Appendix B Final Solidworks FEA Report}

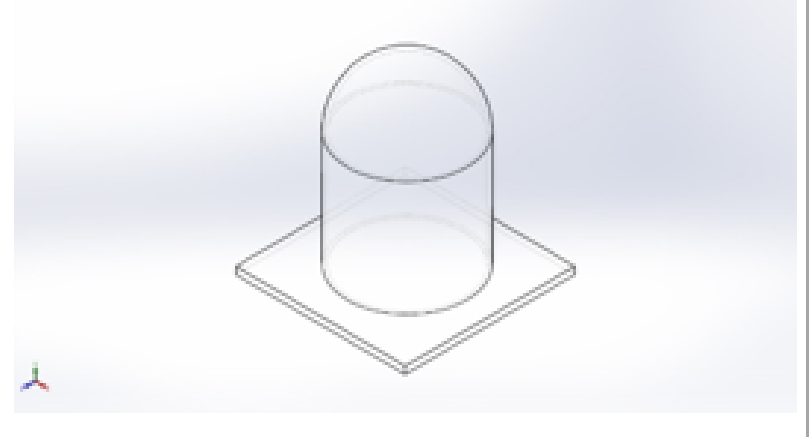

\section{Simulation of Final \\ Design}

Designer: Solidworks

Study name: Static 1

Analysis type: Static

Table of Contents

Description ..............................................1

Assumptions............................................ 2

Model Information .....................................2

Study Properties..........................................

Units .....................................................

Material Properties ........................................4

Loads and Fixtures ..................................... 5

Connector Definitions .................................... 5

Contact Information ....................................

Mesh information........................................7

Sensor Details................................................

Resultant Forces .......................................9

Beams ..................................................

Study Results ..................................... 10

Conclusion.......................................... 13

Appendix ......................................... 13 


\section{Model Information}

\begin{tabular}{|c|c|c|c|}
\hline & \\
\hline Solid Bodies & Treated As & volumetric Properties & $\begin{array}{c}\text { Document Path/Date } \\
\text { Modified }\end{array}$ \\
\hline Document Name and \\
Reference
\end{tabular}


Study Properties

\begin{tabular}{|l|l|}
\hline Study name & Static 1 \\
\hline Analysis type & Static \\
\hline Mesh type & Solid Mesh \\
\hline Thermal Effect: & On \\
\hline Thermal option & Include temperature loads \\
\hline Zero strain temperature & 298 Kelvin \\
\hline Include fluid pressure effects from SOLIDWORKS & Off \\
\hline Flow Simulation & \\
\hline Solver type & EEESPlus \\
\hline Ioplane Effect: & Off \\
\hline Soft Spring: & Off \\
\hline Inertial Relief: & Off \\
\hline Incompatible bonding options & Automatic \\
\hline Large displacement & Off \\
\hline Compute free body forces & On \\
\hline Friction & Off \\
\hline Use Adaptive Method: & Off \\
\hline Result folder & SOLIDWORKS document (C:lUsersiZaciDesktop) \\
\hline
\end{tabular}

Units

\begin{tabular}{|l|l|}
\hline Unit system: & SI (N.S5) \\
\hline Length/Displacement & $\mathrm{mm}$ \\
\hline Temperature & Kelvin \\
\hline Angular velocity & $\mathrm{Rad} / \mathrm{sec}$ \\
\hline Pressure/Stress & $\mathrm{N} / \mathrm{min}^{\wedge}$ \\
\hline
\end{tabular}


Material Properties

\begin{tabular}{|c|c|c|c|}
\hline Model Reference & Prode & erties & Comnonents \\
\hline & $\begin{array}{r}\text { Name: } \\
\text { Model type: } \\
\text { Default failure } \\
\text { criterion: } \\
\text { Yield strength: } \\
\text { Tensile strength: } \\
\text { Elastic modulus: } \\
\text { Poisson's ratio: } \\
\text { Mass density: } \\
\text { Shear modulus: } \\
\text { Thermal expansion } \\
\text { coefficient: }\end{array}$ & 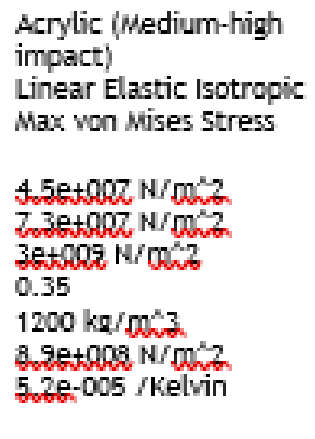 & 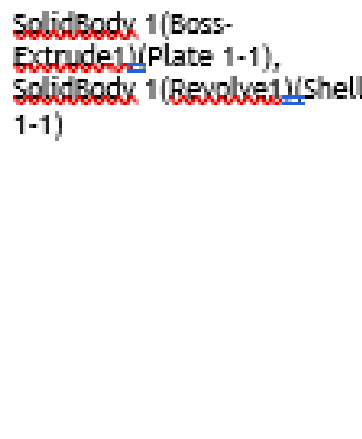 \\
\hline
\end{tabular}


Loads and Fixtures

\begin{tabular}{|c|c|c|c|c|c|}
\hline Fixture name & \multicolumn{2}{|c|}{ Fixture Image } & \multicolumn{3}{|c|}{ Fixture Details } \\
\hline Fixed-1 & & & \multicolumn{3}{|c|}{$\begin{array}{l}\text { Entities: } 1 \text { face(s) } \\
\text { Type: Fixed Geometry }\end{array}$} \\
\hline \multicolumn{6}{|c|}{ Resultant Forces } \\
\hline \multicolumn{2}{|c|}{ Components } & $\mathrm{x}$ & $Y$ & $z$ & Resultant \\
\hline \multicolumn{2}{|c|}{ Reaction force(N) } & -0.0126209 & -5600.31 & -0.00297954 & 5600.31 \\
\hline \multicolumn{2}{|c|}{ Reaction Minment $\left(\alpha_{-\infty}\right)$} & 0 & 0 & 0 & 0 \\
\hline
\end{tabular}

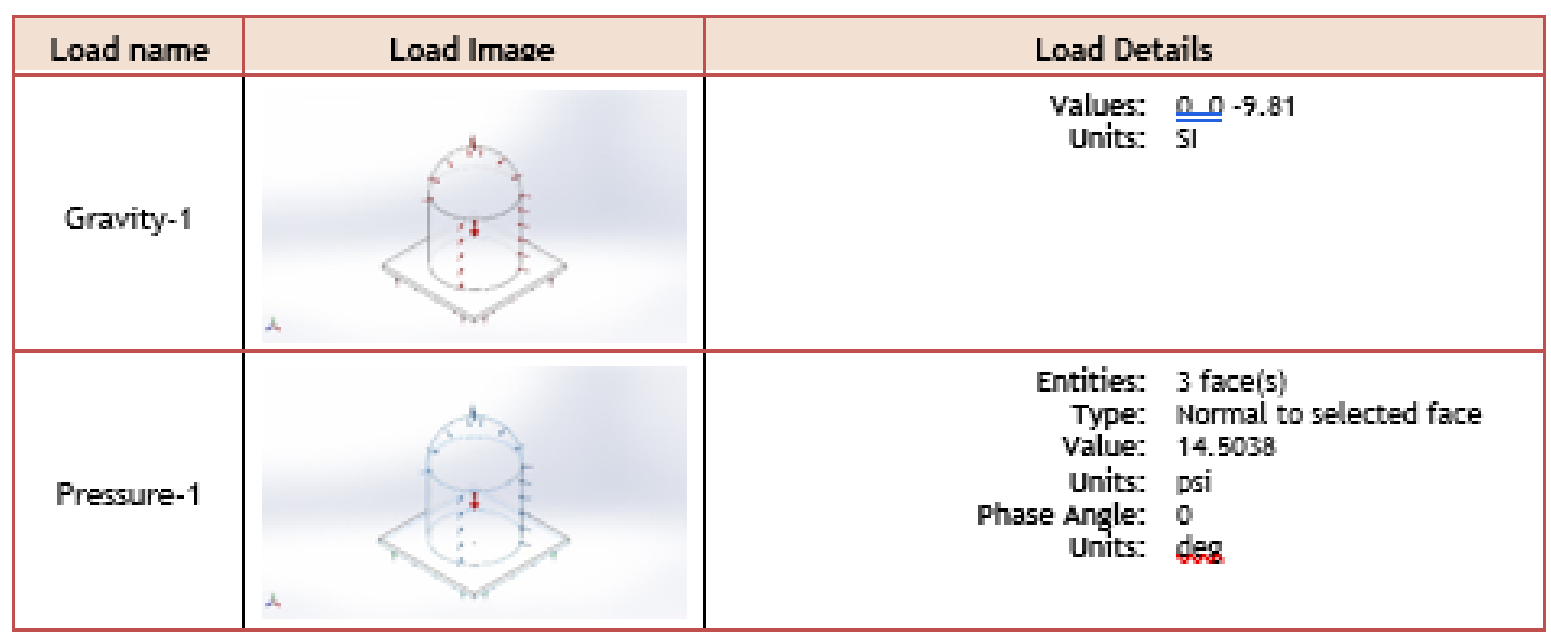

\section{Connector Definitions} No Data 


\section{Contact Information}

\begin{tabular}{|c|c|c|}
\hline Contact & Contact Image & Contact Properties \\
\hline & & $\begin{array}{c}\text { Type: Bonded } \\
\text { Components: } 1 \text { component(s) } \\
\text { Options: Compatible } \\
\text { mesh }\end{array}$ \\
\hline & 1 & \\
\hline
\end{tabular}


Mesh information

\begin{tabular}{|l|l|}
\hline Mesh type & Solid Mesh \\
\hline Uesher Used: & Standard mesh \\
\hline Automatic Transition: & Off \\
\hline Include Mesh Auto Loops: & Off \\
\hline Jacobian points & 4 Points \\
\hline Element Size & $0.0156344 \mathrm{~m}$ \\
\hline Tolerance & $0.000781722 \mathrm{~m}$ \\
\hline Mesh Quality & High \\
\hline Reoresh failed parts with incompatible mesh & Off \\
\hline
\end{tabular}

Mesh information - Details

\begin{tabular}{|l|l|}
\hline Total Nodes & 15726 \\
\hline Total Elements & 8006 \\
\hline Maximum Aspect Ratio & 9.9399 \\
\hline \% of elements with Aspect Ratio < 3 & 80.4 \\
\hline \% of elements with Aspect Ratio > 10 & 0 \\
\hline \% of distorted elements(Jacobian) & 0 \\
\hline Time to complete mesh(bh:mo:ss): & $00: 00: 01$ \\
\hline Computer name: & \\
\hline
\end{tabular}



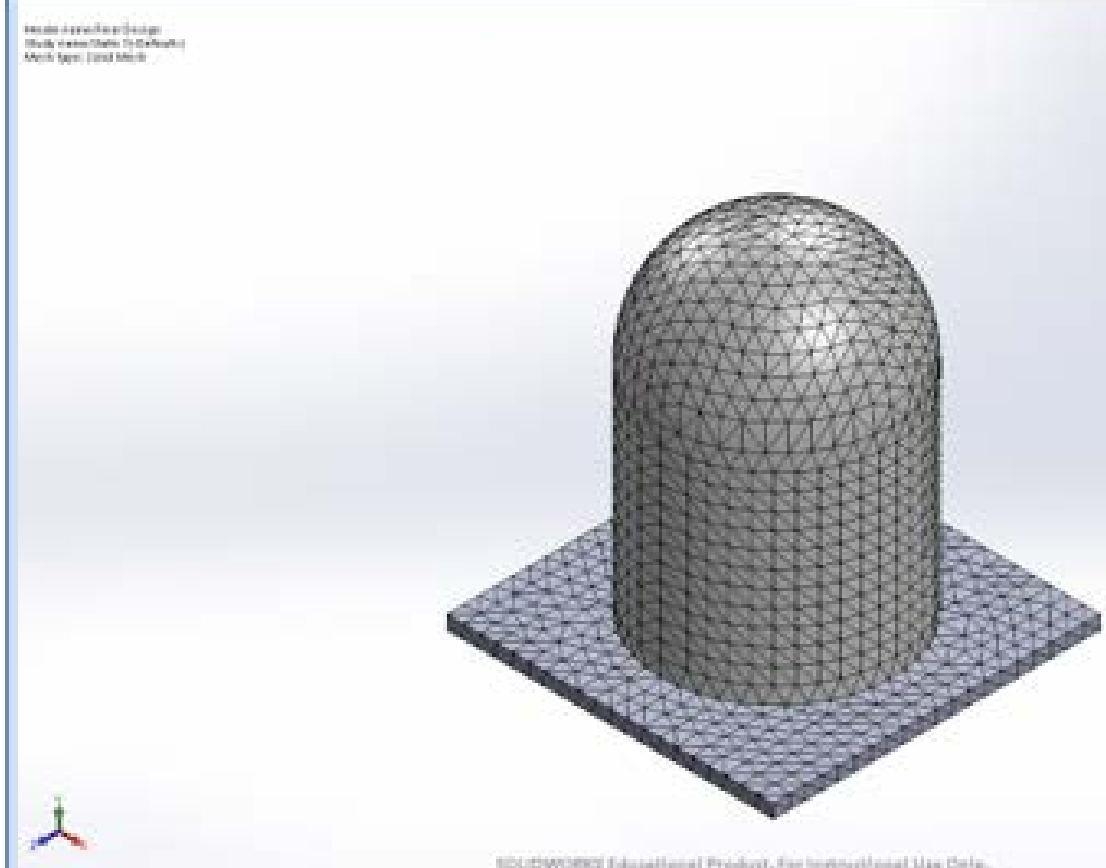

\section{Sensor Details}

\begin{tabular}{|c|c|c|}
\hline Sensor name & Location & Sensor Details \\
\hline Stress1 & $\alpha$ & 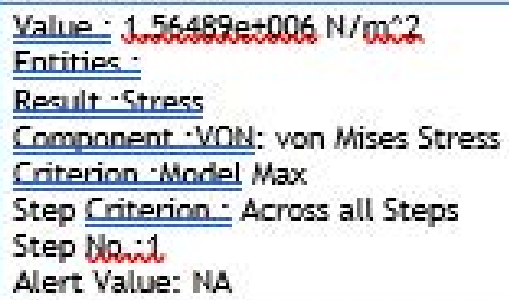 \\
\hline
\end{tabular}




\section{Resultant Forces}

Reaction forces

\begin{tabular}{|c|c|c|c|c|c|}
\hline Selection set & Units & Sum $X$ & Sum Y & Sum Z & Resultant \\
\hline Entire Model & $\mathrm{N}$ & -0.0126209 & -5600.31 & -0.00297994 & 5600.31 \\
\hline \multicolumn{6}{|c|}{ Reaction Moments } \\
\hline Selection set & Units & $\operatorname{Sum} X$ & Sum $Y$ & Sum Z & Resultant \\
\hline Entire Model & $N, \infty$ & 0 & 0 & 0 & 0 \\
\hline
\end{tabular}

Beams

No Data 


\section{Study Results}

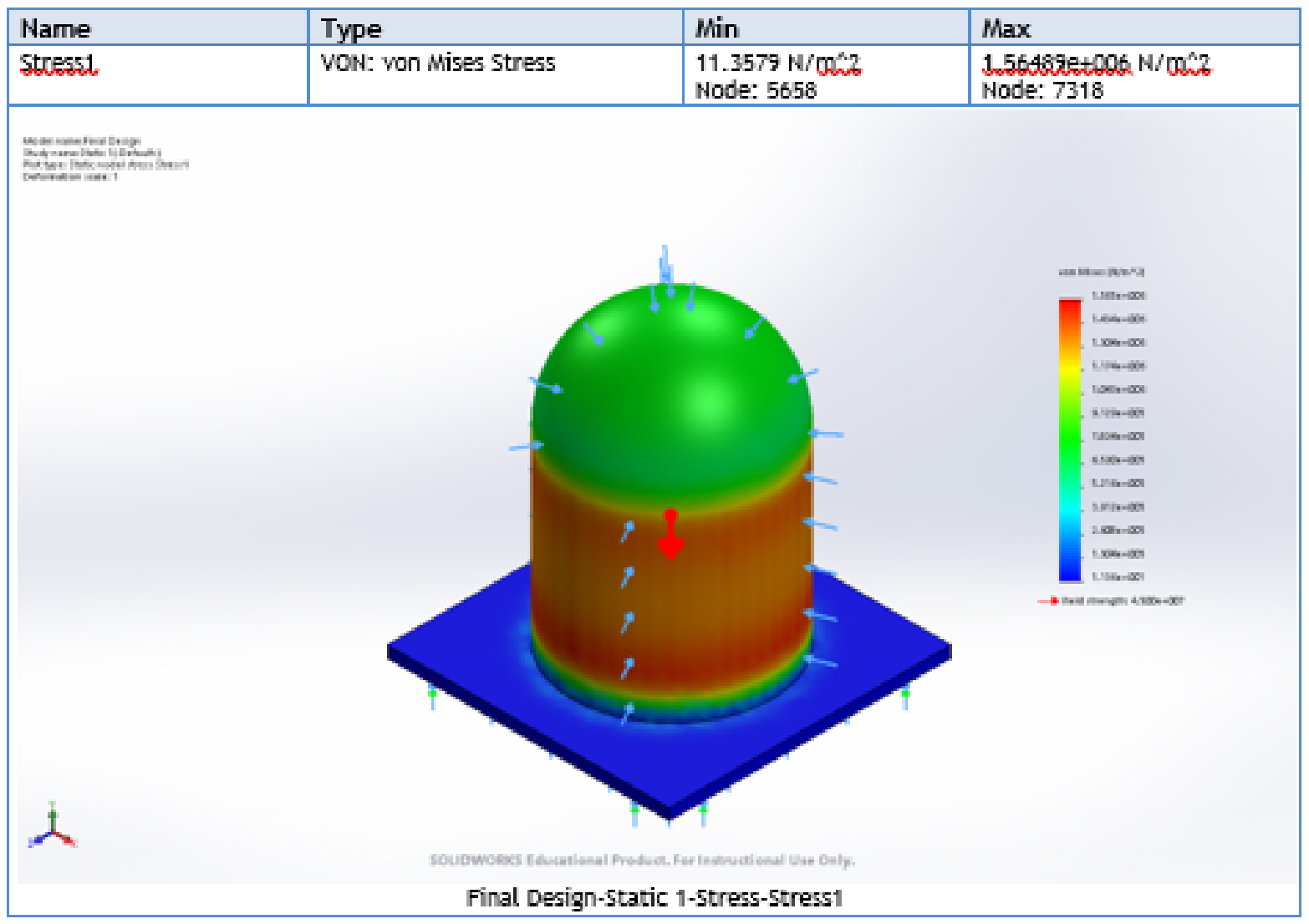

\begin{tabular}{|l|l|l|l|}
\hline Name & Type & Min & Max \\
\hline Displacemeat1 & URES: Resultant Displacement & $\begin{array}{l}0 \mathrm{~mm} \\
\text { Node: } 342\end{array}$ & $\begin{array}{l}0.0530754 \mathrm{~mm} \\
\text { Node: } 7562\end{array}$ \\
\hline
\end{tabular}




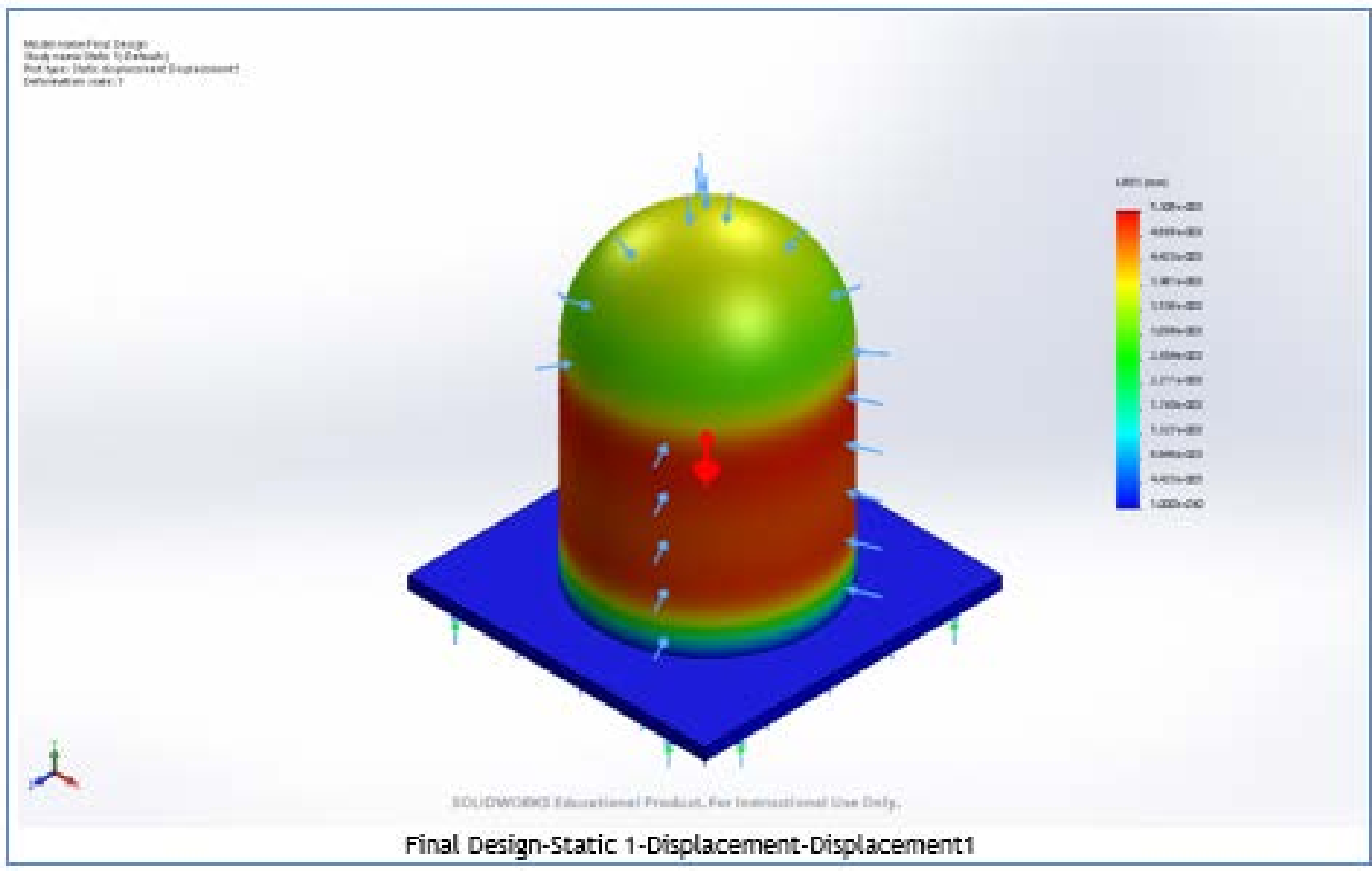

\begin{tabular}{|l|l|l|l|}
\hline Name & Type & Min & Max \\
\hline Stcaind & ESTad; Equivalent Strain & $\begin{array}{l}6.865216-009 \\
\text { Element: } 1947\end{array}$ & $\begin{array}{l}0.000461074 \\
\text { Element: 6063 }\end{array}$ \\
\hline
\end{tabular}




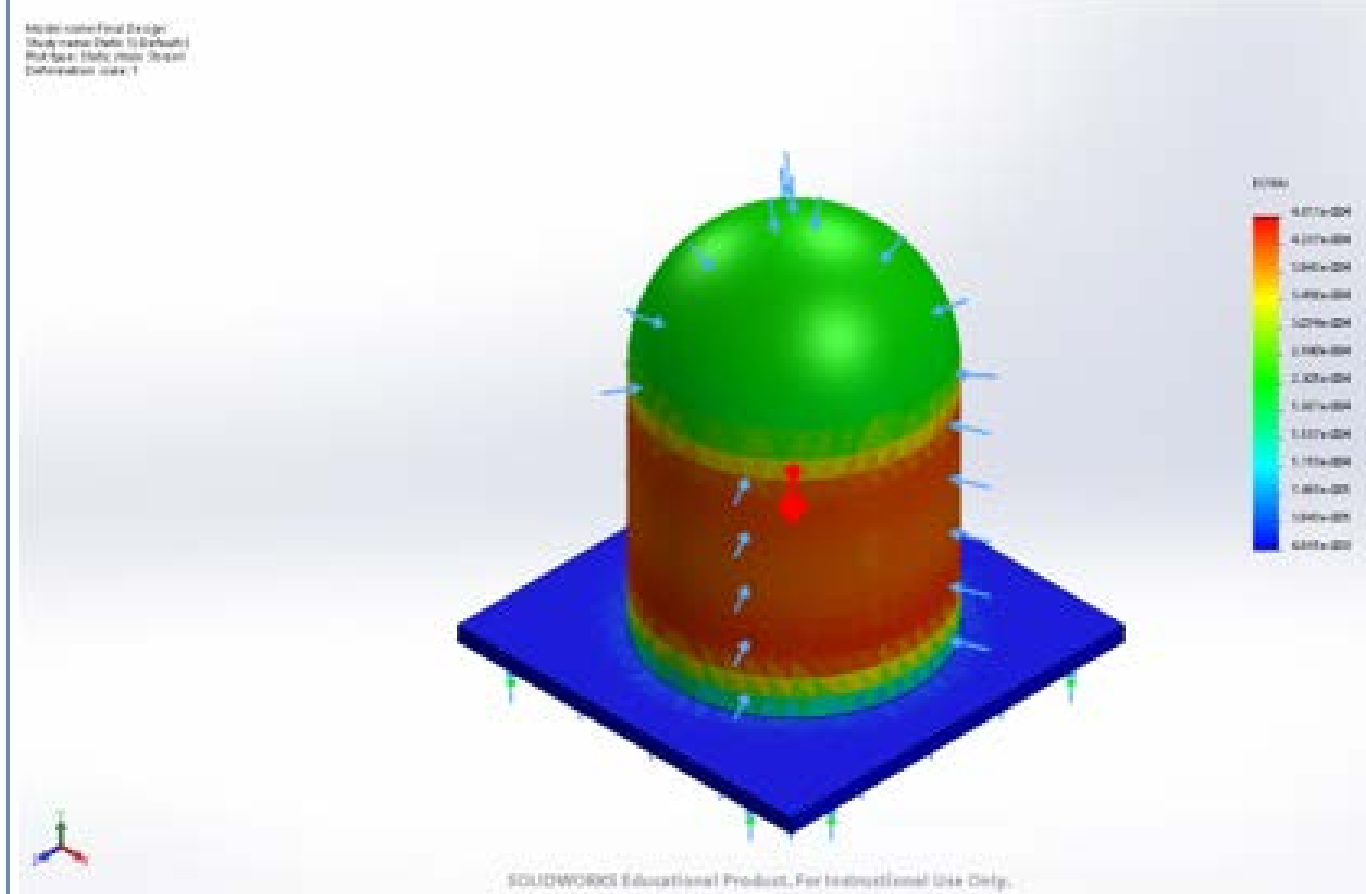

Final Design-Static 1-5train-Strain1

\begin{tabular}{|l|l|}
\hline Name & Type \\
\hline Displacemeot $\{1\}$ & Deformed shape \\
\hline
\end{tabular}




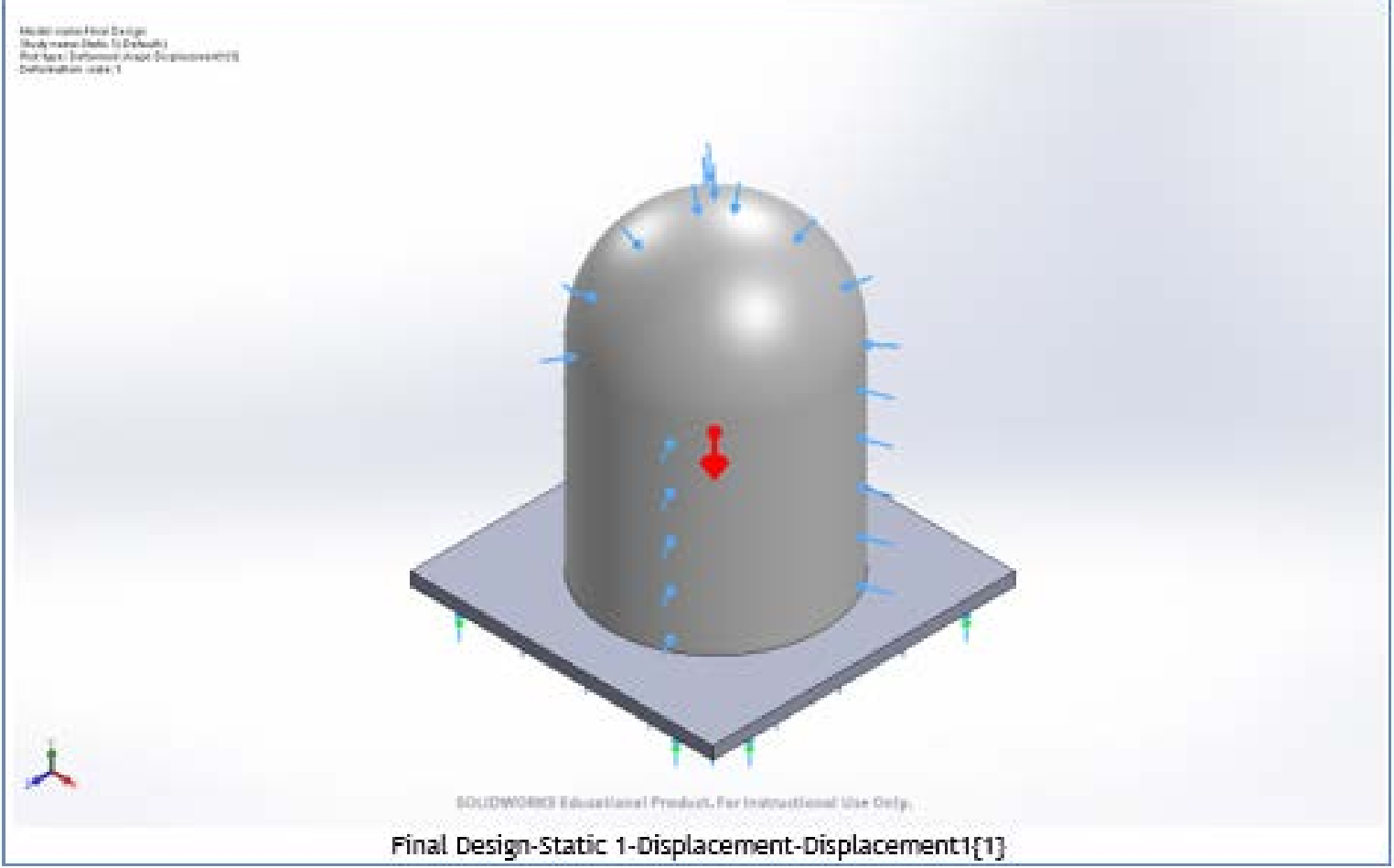




\section{Appendix C Strain Gauge Experiment Data}

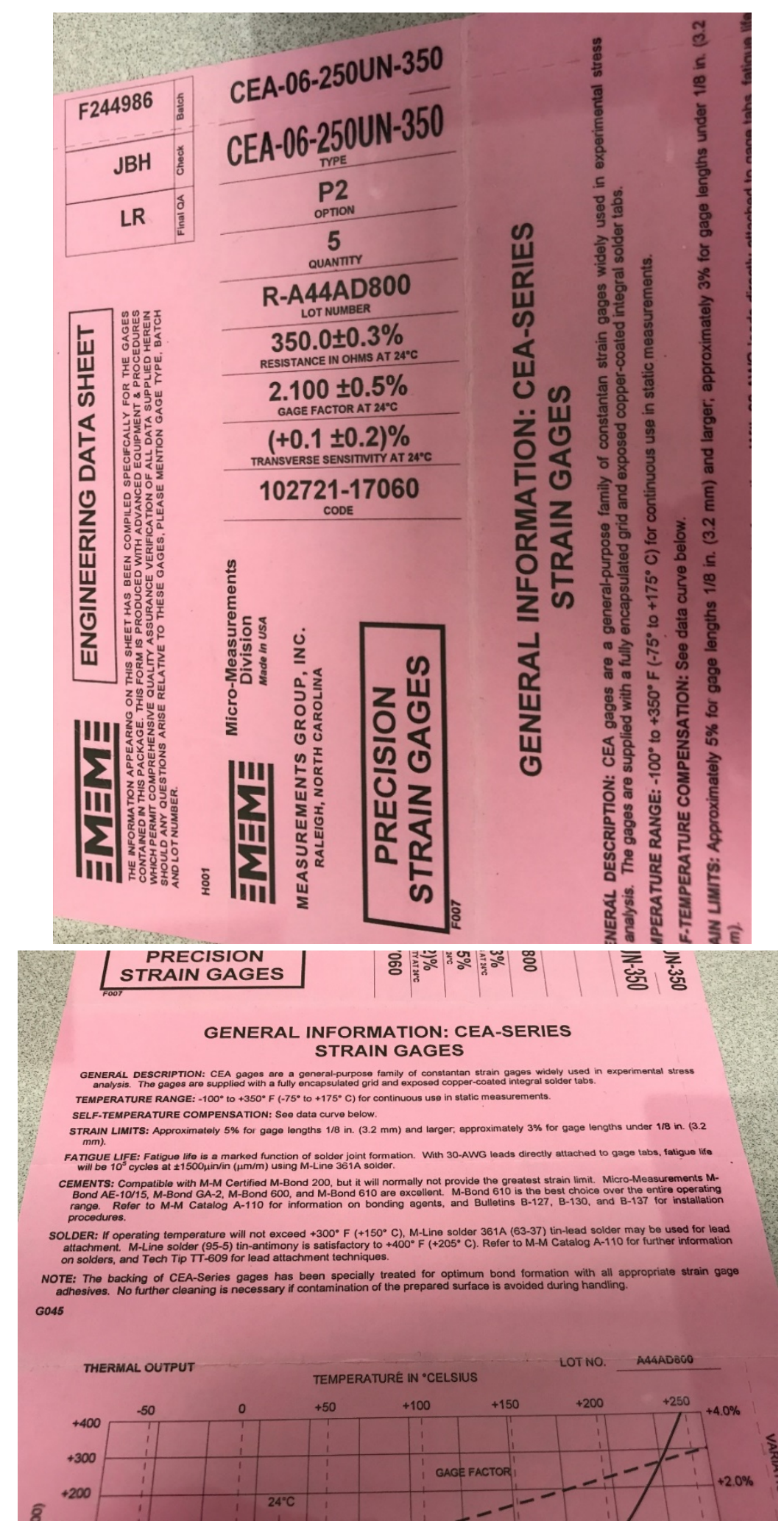




\section{MATERIALS PROPERTIES}

\begin{tabular}{|c|c|c|c|c|c|}
\hline \multirow{2}{*}{ Material } & \multicolumn{2}{|c|}{$\begin{array}{l}\text { Modulus of } \\
\text { Elasticity, } E\end{array}$} & \multirow{2}{*}{$\begin{array}{l}\text { Poisson's } \\
\text { Ratio, v }\end{array}$} & \multicolumn{2}{|c|}{$\begin{array}{c}\text { Thermal Coefficient } \\
\text { of Expansion, } \alpha\end{array}$} \\
\hline & psi $\times 10^{-6 *}$ & $G P a$ & & $\mathbf{P P M} /{ }^{\circ} \mathbf{F}$ & $P P M / C$ \\
\hline ABS Plastic-Unfilled & $0.2-0.4$ & $1.4-2.8$ & - & $33-72$ & $60-130$ \\
\hline Acrylic-Cast & $0.35-0.45$ & $2.4-3.1$ & - & $27-50$ & $50-90$ \\
\hline Alumina - Fired & 40 & 275 & - & 3.0 & 5.4 \\
\hline Aluminum - Alloy 2024-T4 & 10.6 & 73 & 0.32 & 12.9 & 23.2 \\
\hline Aluminum - Alloy 7075-T6 & 10.4 & 72 & 0.32 & 12.9 & 23.2 \\
\hline Beryllium & $40-44$ & $275-305$ & $0.024-0.05$ & 6.4 & 11.5 \\
\hline Beryllium-Copper " 25 " & 19 & 131 & $0.28-0.30$ & 9.3 & 16.7 \\
\hline $\begin{array}{l}\text { Boron-Epoxy Composite - } \\
\text { Orthotropic (Representative) }\end{array}$ & $\begin{array}{l}E_{1}-40 \\
E_{2}-4\end{array}$ & $\begin{array}{l}275 \\
27.5 \\
\end{array}$ & $\begin{array}{l}0.25\left(v_{12}\right) \\
0.025\left(v_{21}\right)\end{array}$ & $\begin{array}{c}5 \\
16 \\
\end{array}$ & $\begin{array}{c}9 \\
28 \\
\end{array}$ \\
\hline Brass $-30-70$ & 16 & 110 & 0.33 & 11.1 & 20 \\
\hline Bronze - Phosphor (10\%) & 16 & 110 & 0.31 & 10.2 & 18.4 \\
\hline Concrete & $3-6$ & $20-40$ & $0.1-0.3$ & 5.5 & 10 \\
\hline Copper & 17.8 & 123 & 0.33 & 9.2 & 16.5 \\
\hline Epoxies - Unfilled & $0.3-0.45$ & $2-3$ & - & $17-33$ & $30-60$ \\
\hline $\begin{array}{l}\text { Fiberglass-Epoxy - Orthotropic } \\
\text { (Representative) }\end{array}$ & $\begin{array}{c}E_{1}-8 \\
E_{2}-2.7\end{array}$ & $\begin{array}{l}55 \\
19 \\
\end{array}$ & $\begin{array}{l}0.25\left(v_{12}\right) \\
0.085\left(v_{21}\right)\end{array}$ & \multicolumn{2}{|c|}{$\begin{array}{l}\text { Variable with composition } \\
\text { and manufacture }\end{array}$} \\
\hline Glass - Soda-Lime & 10 & 70 & 0.21 & 5.1 & 9.2 \\
\hline Graphite & $0.3-2.4$ & $2-17$ & - & 3.0 & 5.4 \\
\hline Hastelloy C-276 & $24.5-29.8$ & $169-205$ & 0.3 & 6.3 & 11.3 \\
\hline Inconel - Wrought & 31 & 214 & - & 7.0 & 13.0 \\
\hline Inconel-X & 31 & 214 & 0.26 & $6.7-7.8$ & $12-14$ \\
\hline Invar - Annealed condition & 21 & 145 & - & $0.7-0.8$ & $1.3-1.4$ \\
\hline
\end{tabular}

Tee $\left(0-90^{\circ}\right)$ Rosette - Gage elements must be aligned with principal axes.

$$
\begin{aligned}
& \epsilon_{p}=\epsilon_{1} \\
& \epsilon_{q}=\epsilon_{2} \\
& \sigma_{p}=\frac{E}{1-\nu^{2}}\left(\epsilon_{1}+\nu \epsilon_{2}\right) \\
& \sigma_{q}=\frac{E}{1-\nu^{2}}\left(\epsilon_{2}+\nu \epsilon_{1}\right)
\end{aligned}
$$

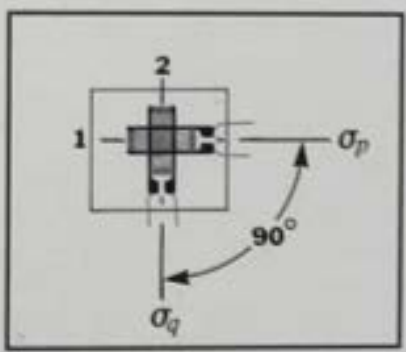

\section{Rosette Grid-Numbering Considerations}

The equations above for calculating principal strains and stresses from rosette strain measurements assume that the grid elements are numbered in a particular manner. Improper numbering of the grid elements will lead to ambiguity in the interpretation of $\phi_{p j}$; and, in the case of the rectangular rosette, can also cause errors in the calculated principal strains and stresses.

Treating the latter situation first, it is always necessary in a rectangular rosette that grid numbers 1 and 3 be assigned to the two mutually perpendicular grids. Any other numbering arrangement will produce incorrect principal strains and stresses.

Ambiguities in the interpretation of $\phi_{m}$ for both rectangular and delta rosettes can be eliminated by numbering the grid elements as follows:

In a rectangular rosette, Grid 2 must be $45^{\circ}$ away from Grid 1; and Grid 3 must be $90^{\circ}$ away, in the same direction. Similarly, in a delta rosette. Grids 2 and 3 must be $60^{\circ}$ and $120^{\circ}$ away, respectively, in the same direction from Grid 1. By definition, $\phi_{p, q}$ is the angle from the axis of Grid 1 to the nearest principal axis. When $\phi_{\text {neq }}$ is positive, the direction is the same as that of the grid numbering; and, when negative, the opposite. See Measurements Group Tech Note TN-515, Strain Gage Rosettes, for further details. 


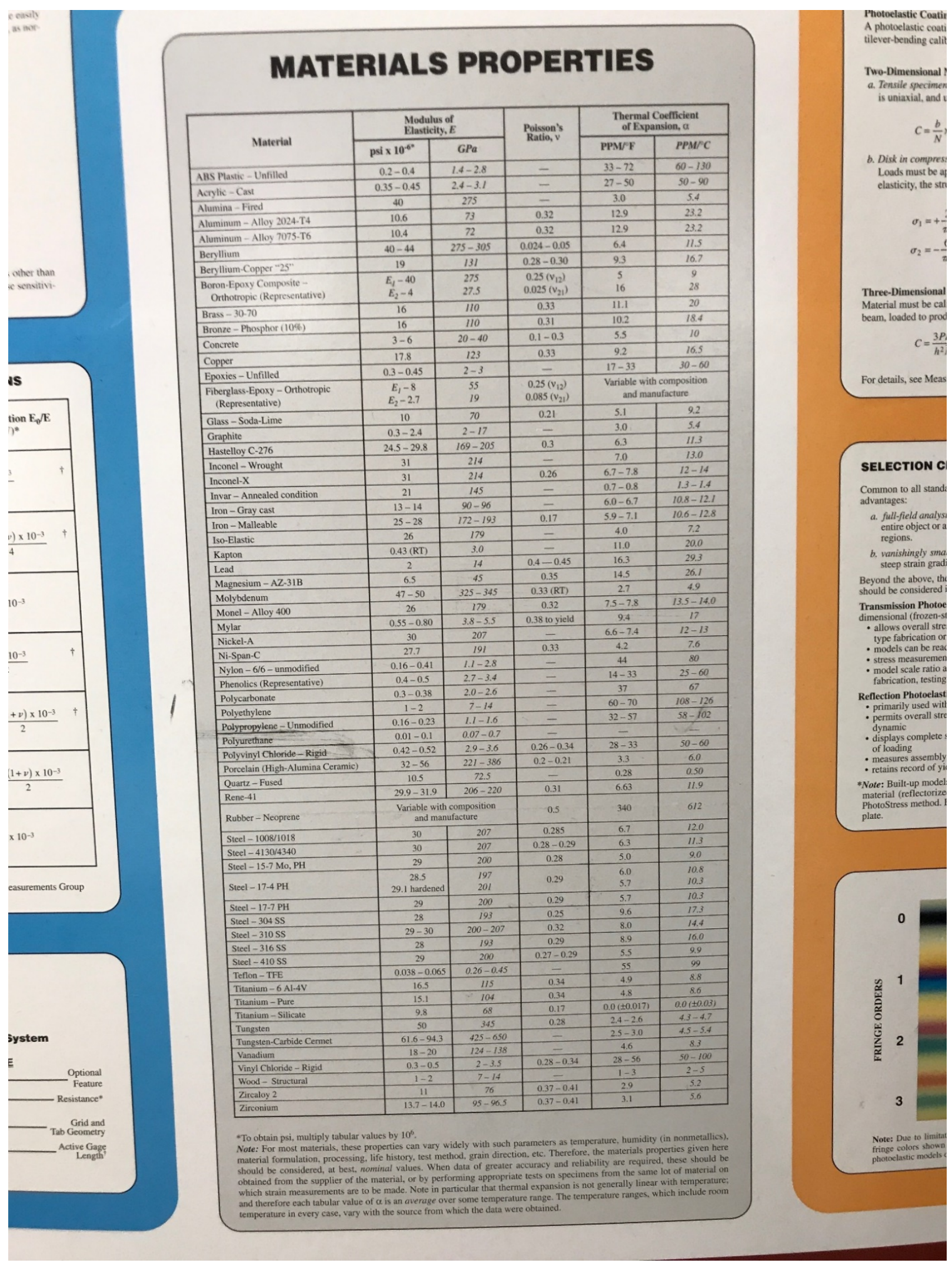




\section{$\underline{\text { Appendix D Parallel Plates Experiment Data }}$}

